Estimated Water Flows in 2005: United States

C. A. Smith, R. D. Belles, A. J. Simon

March 24, 2011 
This document was prepared as an account of work sponsored by an agency of the United States government. Neither the United States government nor Lawrence Livermore National Security, LLC, nor any of their employees makes any warranty, expressed or implied, or assumes any legal liability or responsibility for the accuracy, completeness, or usefulness of any information, apparatus, product, or process disclosed, or represents that its use would not infringe privately owned rights. Reference herein to any specific commercial product, process, or service by trade name, trademark, manufacturer, or otherwise does not necessarily constitute or imply its endorsement, recommendation, or favoring by the United States government or Lawrence Livermore National Security, LLC. The views and opinions of authors expressed herein do not necessarily state or reflect those of the United States government or Lawrence Livermore National Security, LLC, and shall not be used for advertising or product endorsement purposes.

This work performed under the auspices of the U.S. Department of Energy by Lawrence Livermore National Laboratory under Contract DE-AC52-07NA27344. 


\title{
Estimated Water Flows in 2005 United States
}

\author{
C.A. Smith, A.J. Simon, R.D. Belles
}

March 2011

Abstract
Introduction
Flow Charts
$\quad$ Individual State Water Flow Charts
$\quad$ Puerto Rico Water Flow Chart
$\quad$ Virgin Islands Water Flow Chart




\title{
Estimated Water Flows in 2005: United States
}

\author{
Clara A. Smith, A.J. Simon, Rich Belles \\ Lawrence Livermore National Laboratory
}

\begin{abstract}
Flow charts depicting water use in the United States have been constructed from publicly available data and estimates of water use patterns. Approximately 410,500 million gallons per day of water are managed throughout the United States for use in farming, power production, residential, commercial, and industrial applications. Water is obtained from four major resource classes: fresh surface-water, saline (ocean) surface-water, fresh groundwater and saline (brackish) groundwater. Water that is not consumed or evaporated during its use is returned to surface bodies of water. The flow patterns are represented in a compact "visual atlas" of 52 state-level (all 50 states in addition to Puerto Rico and the Virgin Islands) and one national water flow chart representing a comprehensive systems view of national water resources, use, and disposition.
\end{abstract}

\section{Introduction}

Lawrence Livermore National Lab (LLNL) has published flow charts (also referred to as "Sankey Diagrams") of important national commodities since the early 1970s. The most widely recognized of these charts is the U.S. energy flow chart (http://flowcharts.IInl.gov). LLNL has also published charts depicting carbon (or carbon dioxide potential) flow and water flow at the national level as well as energy, carbon, and water flows at the international, state, municipal, and organizational (i.e. United States Air Force) level. Flow charts are valuable as single-page references that contain quantitative data about resource, commodity, and byproduct flows in a graphical form that also convey structural information about the system that manages those flows.

LLNL previously produced flow charts depicting water use for the U.S. as a whole from 1995 and 2000 data. Data on water use is compiled by the U.S. Geological Survey (USGS) every five years, and is released between 3 to 4 years after the data collection year. Data for 2005 (Kenny et. al., 2009) was released in October of 2009. This is the first presentation of a comprehensive state-level package of water flow charts for the United States.

Water use data is notoriously hard to compile. Accounting policies vary between different water management districts and water use is not metered in the same way that higher-priced commodities are sold. Quantifying water use by location and sector requires substantial estimation.

Water disposition is even more difficult to quantify. While the quality of wastewater discharge is measured regularly for environmental purposes, the total quantity of wastewater is not carefully monitored, especially when that wastewater already meets environmental regulations for discharge. 
Nonetheless, this report attempts to depict the approximate relative scale of water withdrawal and consumption for various sectors of the economy.

Water is procured for economic purposes from four classes of sources: fresh surface-water, saline (ocean) surface-water, fresh groundwater and saline (brackish) groundwater. Fresh surface-water, from lakes and rivers, is used at large scale in every sector of the economy. Saline surface water, primarily ocean water, is mostly used for once-through thermoelectric cooling, although some ocean water is used for industrial cooling and a small but growing amount of ocean water is being desalinated for public consumption. Significant quantities of fresh groundwater are used in irrigation and fresh groundwater plays an important role in both public supply as well as self-supplied domestic water consumption. Brackish groundwater is the most difficult water resource to use and is therefore primarily used in the mining sector and in power production (often in geothermal power plants).

Per the most recent USGS water use report, the water economy is separated into seven use sectors: Domestic, Commercial/Industrial, Mining, Aquaculture, Livestock, Irrigation, and Thermoelectric Cooling. Public Supply, the management of quality-controlled water networks, plays an intermediate role between water resources and end use. Commercial water is not directly specified in the USGS report, however, the USGS mentions that Public Supply supports commercial and some light industrial operations. For that purpose, the commercial and industrial sectors have been combined in this analysis.

The 2009 USGS report does not describe the disposition of water that has been used by various sectors of the economy. Nonetheless, this analysis attempts to quantify the amount of water consumed by each economic sector. Of the water not consumed, the amount of water returned to surface freshwater bodies and the amount discharged to the ocean are also approximated. Those quantities are estimated as described in the Analysis section. Water can be consumed (chemically broken down or incorporated into a product) or evaporated from a sector. The majority of consumed/evaporated water eventually rejoins the global hydrologic cycle, but is not assumed to be reintroduced to the surface waters in any particular geographic location. Water that is discharged to surface bodies (lakes or streams) may be available for re-use, depending on its quality, temperature, and location. Water that is discharged to the ocean is no longer available for any purpose except those processes that use saline surface-water. 


\section{Estimated Alabama Water Flow in 2005: 10000 Million Gallons/Day}

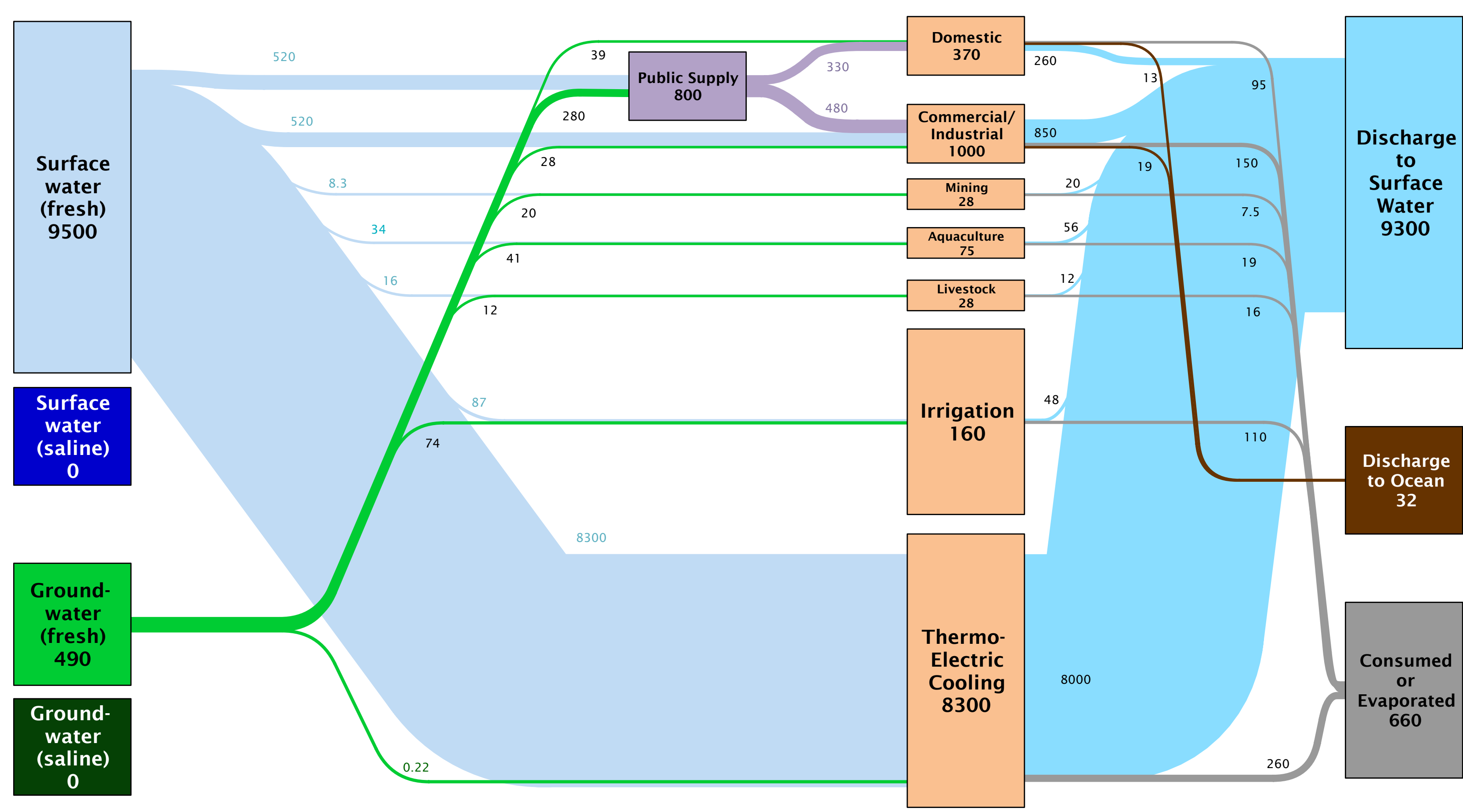

Source: LLNL 2011. Data is based on USGS Circular 1344, October 2009. If this information or a reproduction of it is used, credit must be given to the Lawrence Livermore National Laboratory and the Department of Energy, under whose auspices the work was performed. All quantities are rounded to 2 significant digits and annual flows of less than $0.05 \mathrm{MGal} / \mathrm{day}$ are not
included. Totals may not equal sum of flows due to independent rounding. Further detail on how all flows are calculated can be found at http://flowcharts.llnl.gov. LLNL-TR-475772. 


\section{Estimated Alaska Water Flow in 2005: 1100 Million Gallons/Day}

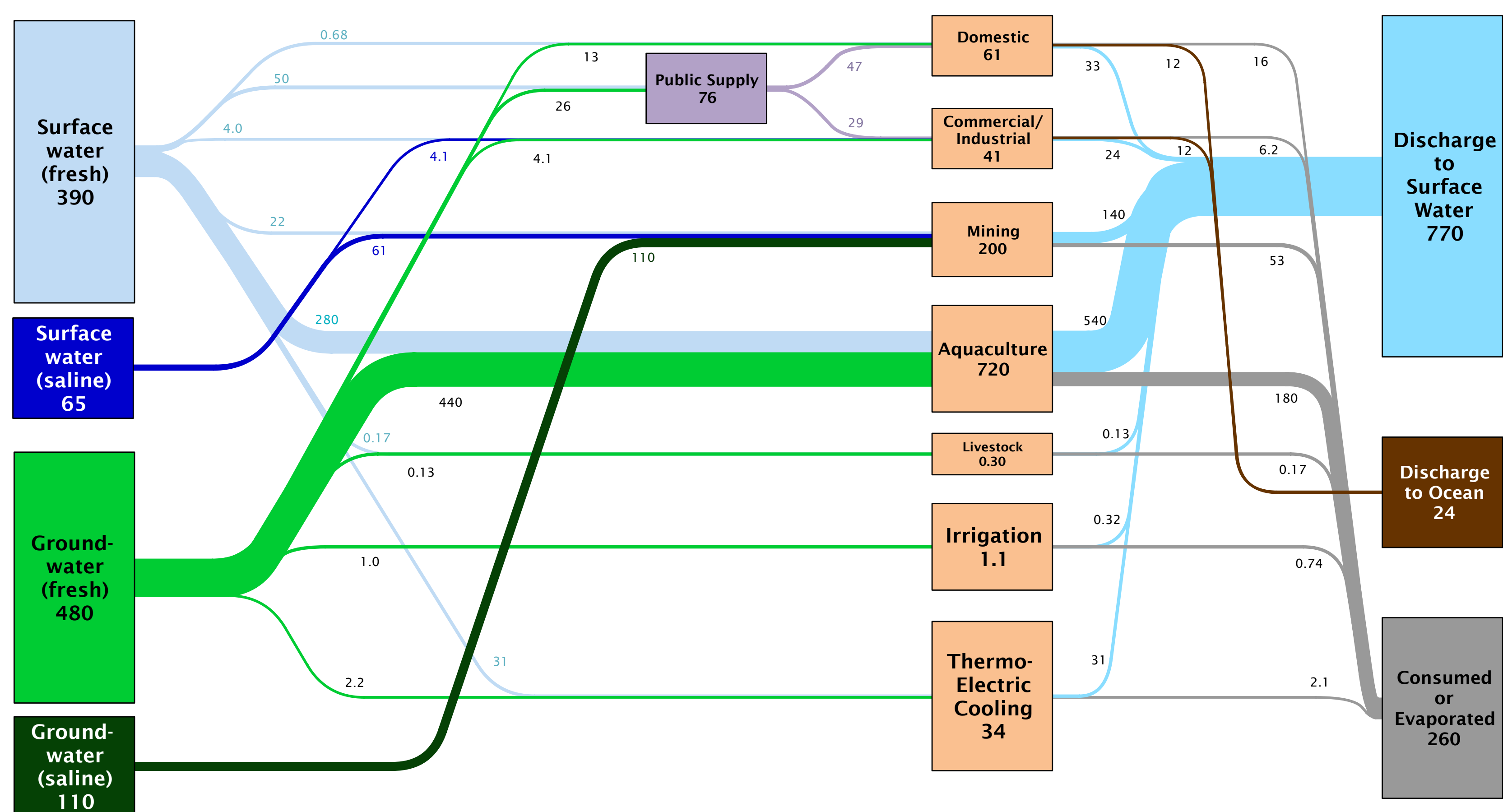

Source: LLNL 2011. Data is based on USGS Circular 1344, October 2009. If this information or a reproduction of it is used, credit must be given to the Lawrence Livermore National Laboratory and the Department of Energy, under whose auspices the work was performed. All quantities are rounded to 2 significant digits and annual flows of less than $0.05 \mathrm{MGal} / \mathrm{day}$ are not
included. Totals may not equal sum of flows due to independent rounding. Further detail on how all flows are calculated can be found at http://flowcharts.llnl.gov. LLNL-TR-475772. 


\section{Estimated Arizona Water Flow in 2005: 6200 Million Gallons/Day}

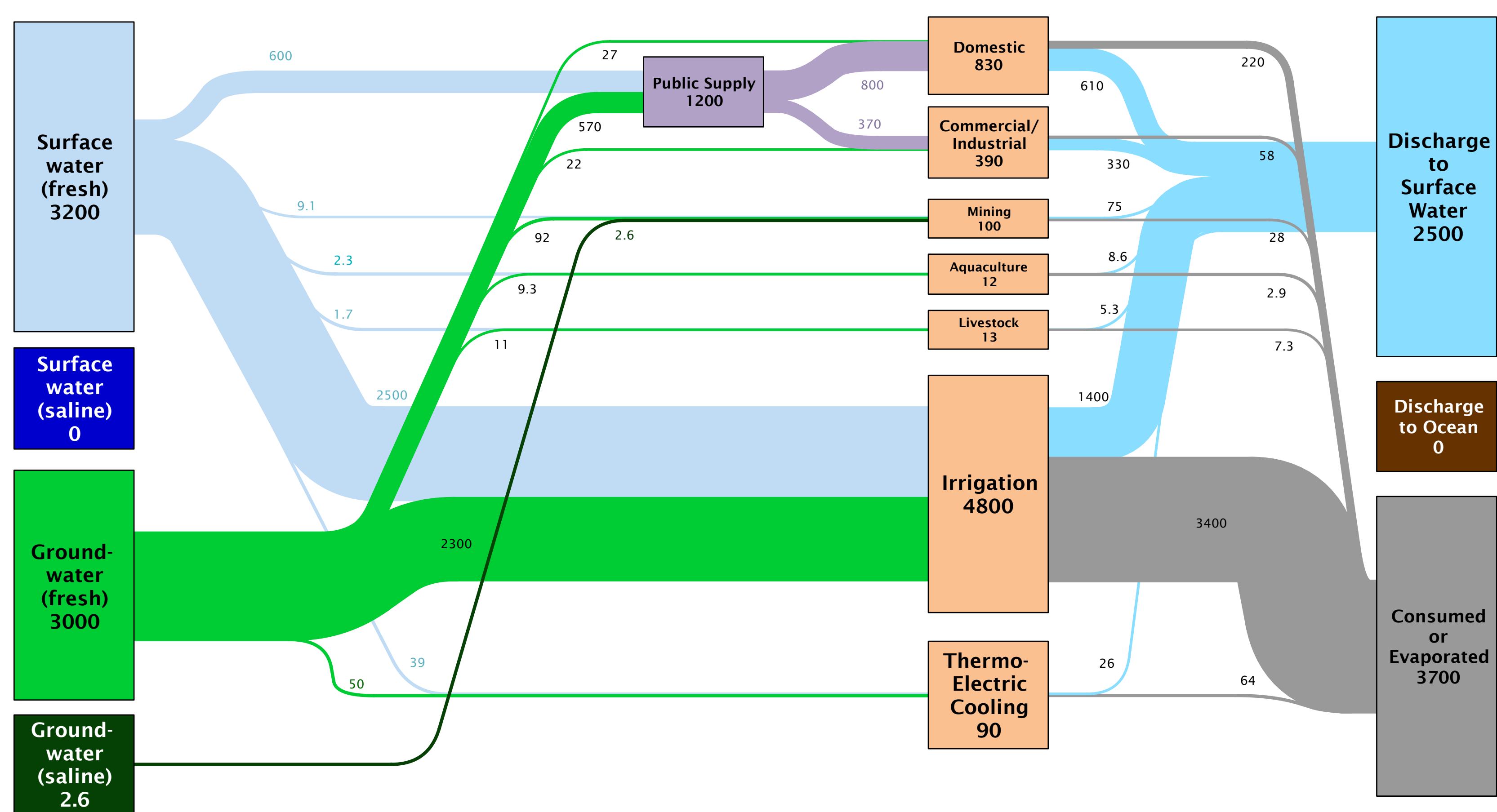

Source: LLNL 2011. Data is based on USGS Circular 1344, October 2009. If this information or a reproduction of it is used, credit must be given to the Lawrence Livermore National Laboratory and the Department of Energy, under whose auspices the work was performed. All quantities are rounded to 2 significant digits and annual flows of less than $0.05 \mathrm{MGal} / \mathrm{day}$ are not
included. Totals may not equal sum of flows due to independent rounding. Further detail on how all flows are calculated can be found at http://flowcharts.llnl.gov. LLNL-TR-475772. 


\section{Estimated Arkansas Water Flow in 2005: 11000 Million Gallons/Day}

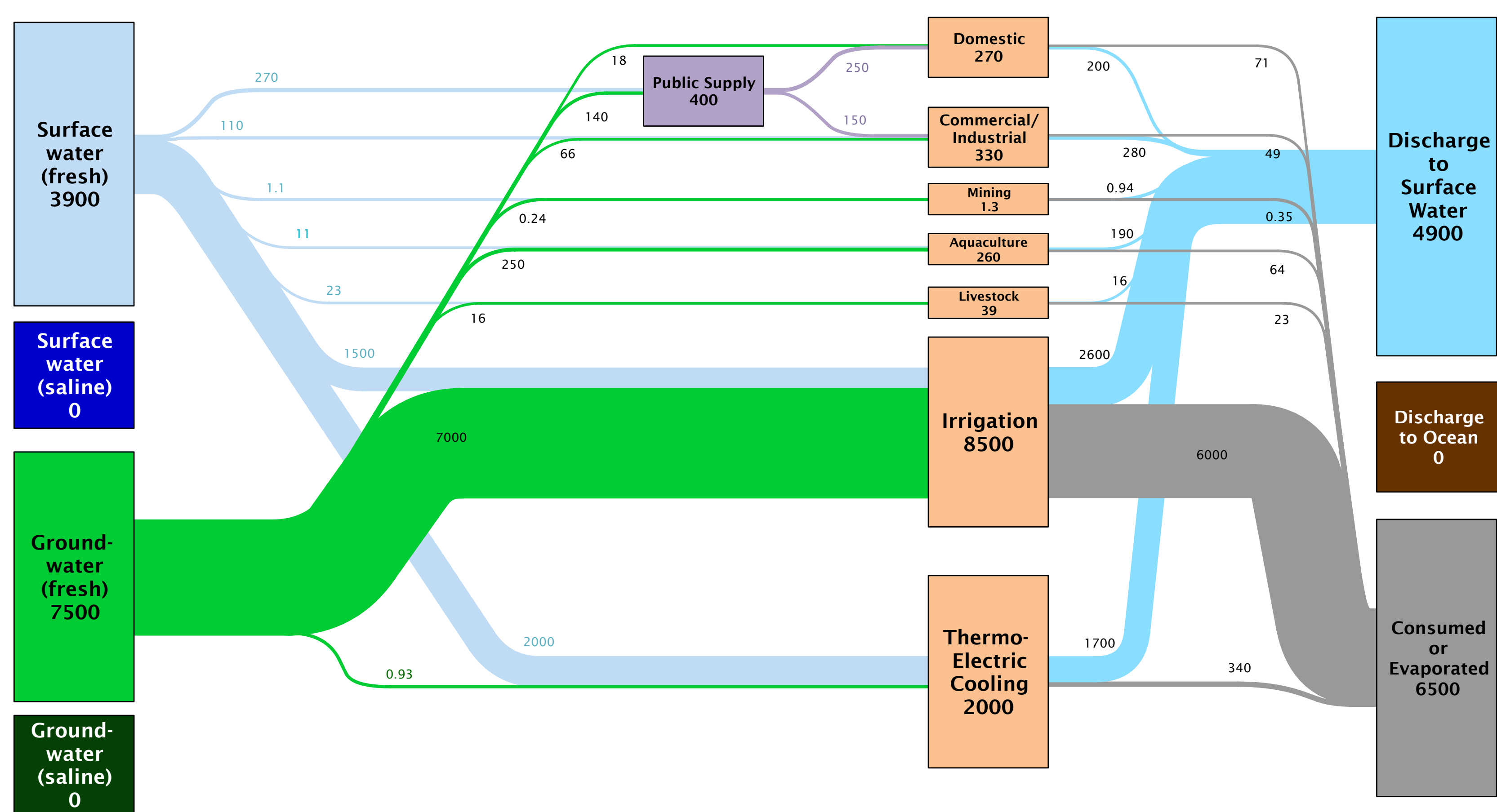

Source: LLNL 2011. Data is based on USGS Circular 1344, October 2009. If this information or a reproduction of it is used, credit must be given to the Lawrence Livermore National Laboratory and the Department of Energy, under whose auspices the work was performed. All quantities are rounded to 2 significant digits and annual flows of less than $0.05 \mathrm{MGal} / \mathrm{day}$ are not
included. Totals may not equal sum of flows due to independent rounding. Further detail on how all flows are calculated can be found at http://flowcharts.llnl.gov. LLNL-TR-475772. 


\section{Estimated California Water Flow in 2005: 46000 Million Gallons/Day}

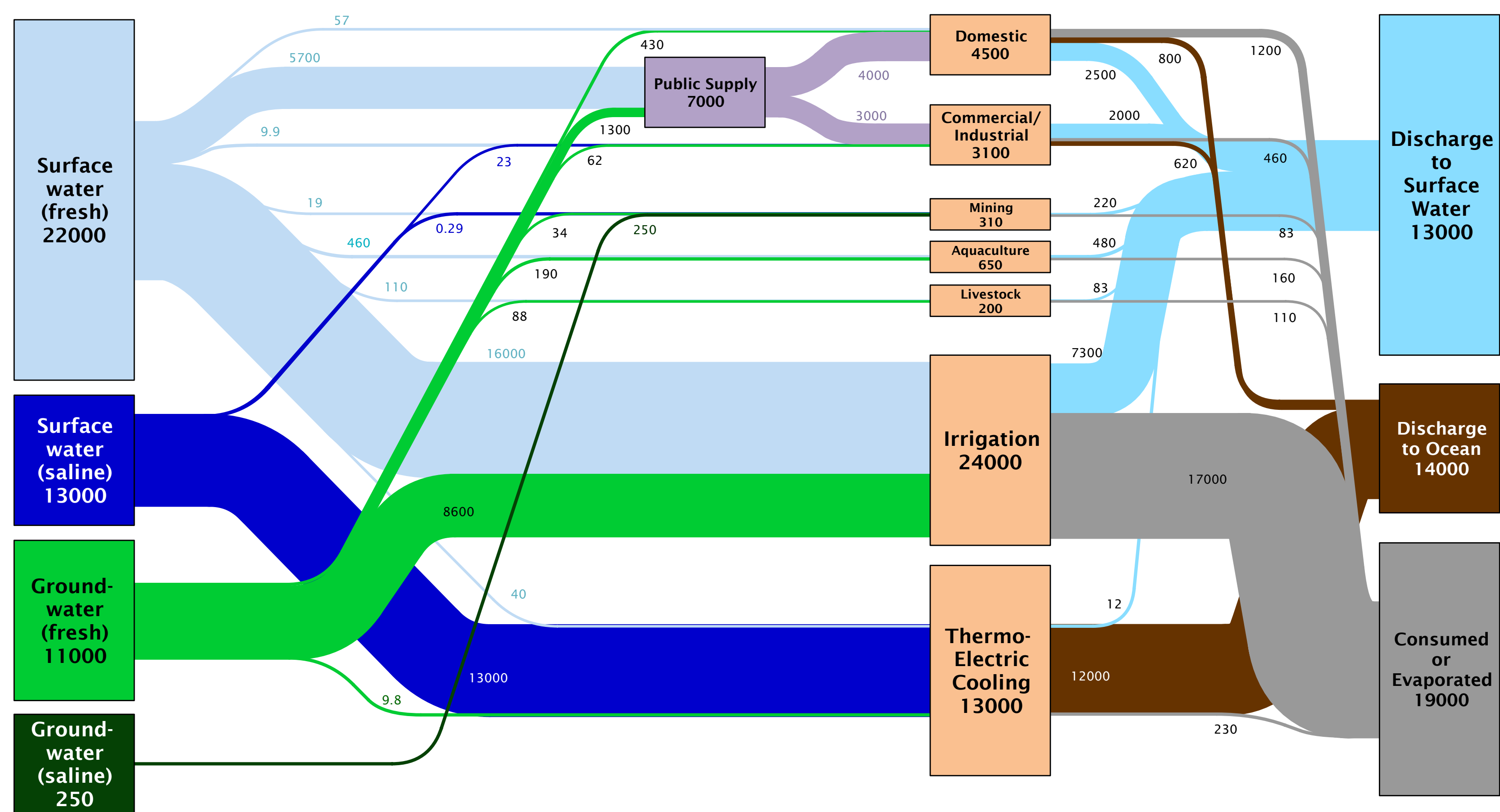

Source: LLNL 2011. Data is based on USGS Circular 1344, October 2009. If this information or a reproduction of it is used, credit must be given to the Lawrence Livermore National Laboratory and the Department of Energy, under whose auspices the work was performed. All quantities are rounded to 2 significant digits and annual flows of less than $0.05 \mathrm{MGal} / \mathrm{day}$ are not
included. Totals may not equal sum of flows due to independent rounding. Further detail on how all flows are calculated can be found at http://flowcharts.llnl.gov. LLNL-TR-475772. 


\section{Estimated Colorado Water Flow in 2005: 14000 Million Gallons/Day}

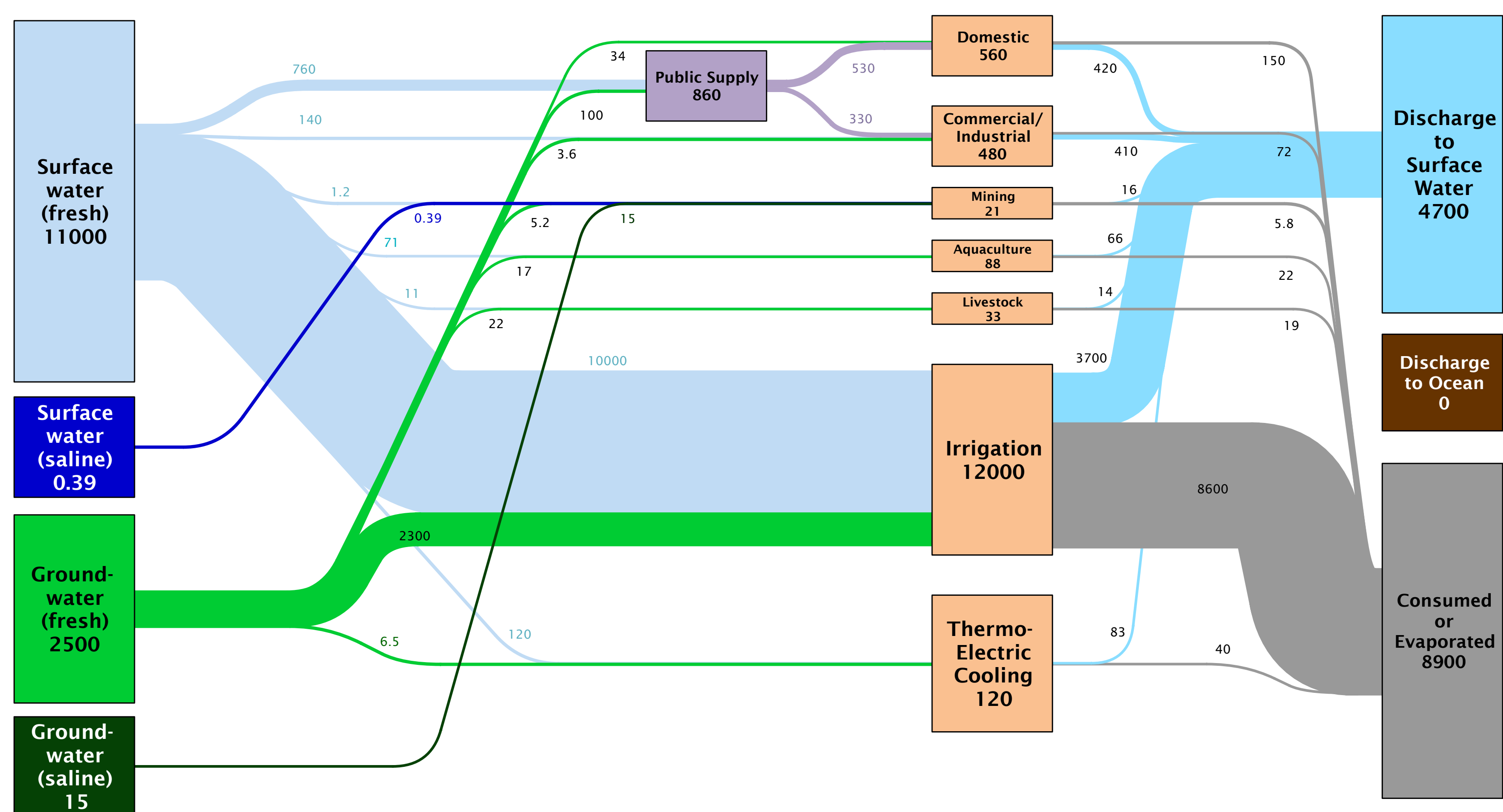

Source: LLNL 2011. Data is based on USGS Circular 1344, October 2009. If this information or a reproduction of it is used, credit must be given to the Lawrence Livermore National Laboratory and the Department of Energy, under whose auspices the work was performed. All quantities are rounded to 2 significant digits and annual flows of less than $0.05 \mathrm{MGal} / \mathrm{day}$ are not
included. Totals may not equal sum of flows due to independent rounding. Further detail on how all flows are calculated can be found at http://flowcharts.llnl.gov. LLNL-TR-475772. 


\section{Estimated Connecticut Water Flow in 2005: 3800 Million Gallons/Day}

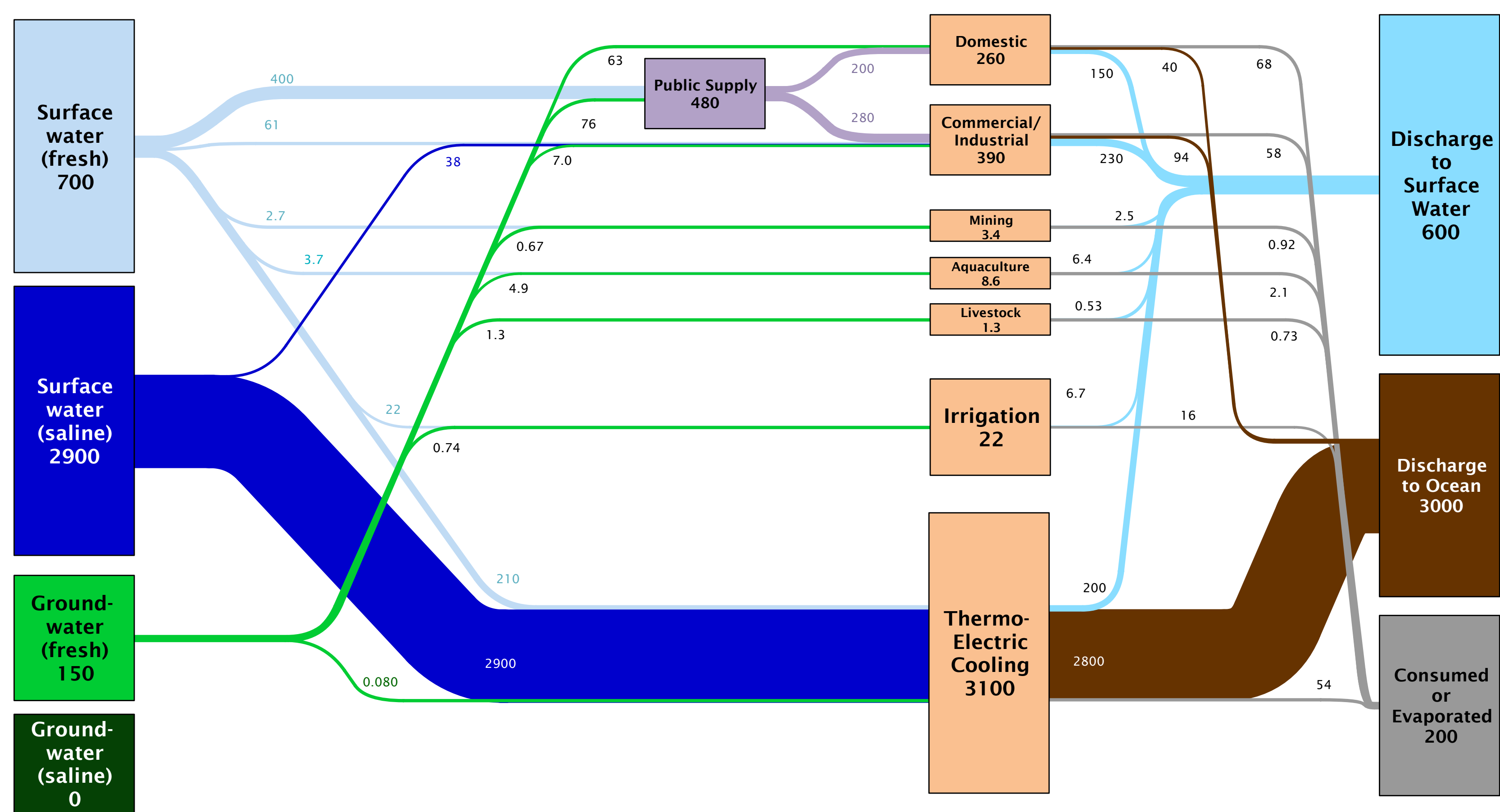

Source: LLNL 2011. Data is based on USGS Circular 1344, October 2009. If this information or a reproduction of it is used, credit must be given to the Lawrence Livermore National Laboratory and the Department of Energy, under whose auspices the work was performed. All quantities are rounded to 2 significant digits and annual flows of less than $0.05 \mathrm{MGal} / \mathrm{day}$ are not
included. Totals may not equal sum of flows due to independent rounding. Further detail on how all flows are calculated can be found at http://flowcharts.llnl.gov. LLNL-TR-475772. 


\section{Estimated Delaware Water Flow in 2005: 1000 Million Gallons/Day}

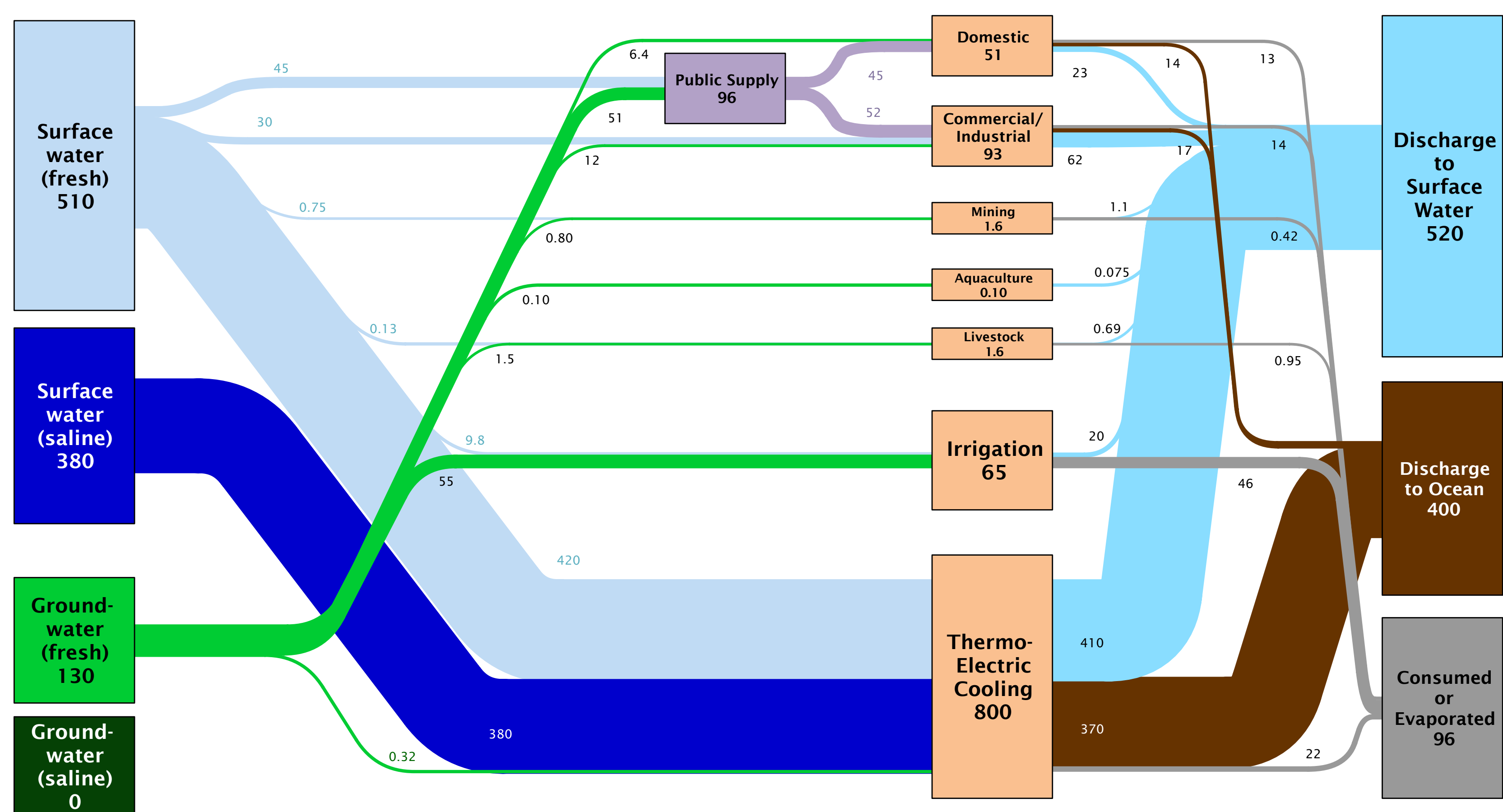

Source: LLNL 2011. Data is based on USGS Circular 1344, October 2009. If this information or a reproduction of it is used, credit must be given to the Lawrence Livermore National Laboratory and the Department of Energy, under whose auspices the work was performed. All quantities are rounded to 2 significant digits and annual flows of less than $0.05 \mathrm{MGal} /$ day are not
included. Totals may not equal sum of flows due to independent rounding. Further detail on how all flows are calculated can be found at http://flowcharts.llnl.gov. LLNL-TR-475772. 


\section{Estimated Florida Water Flow in 2005: 18000 Million Gallons/Day}

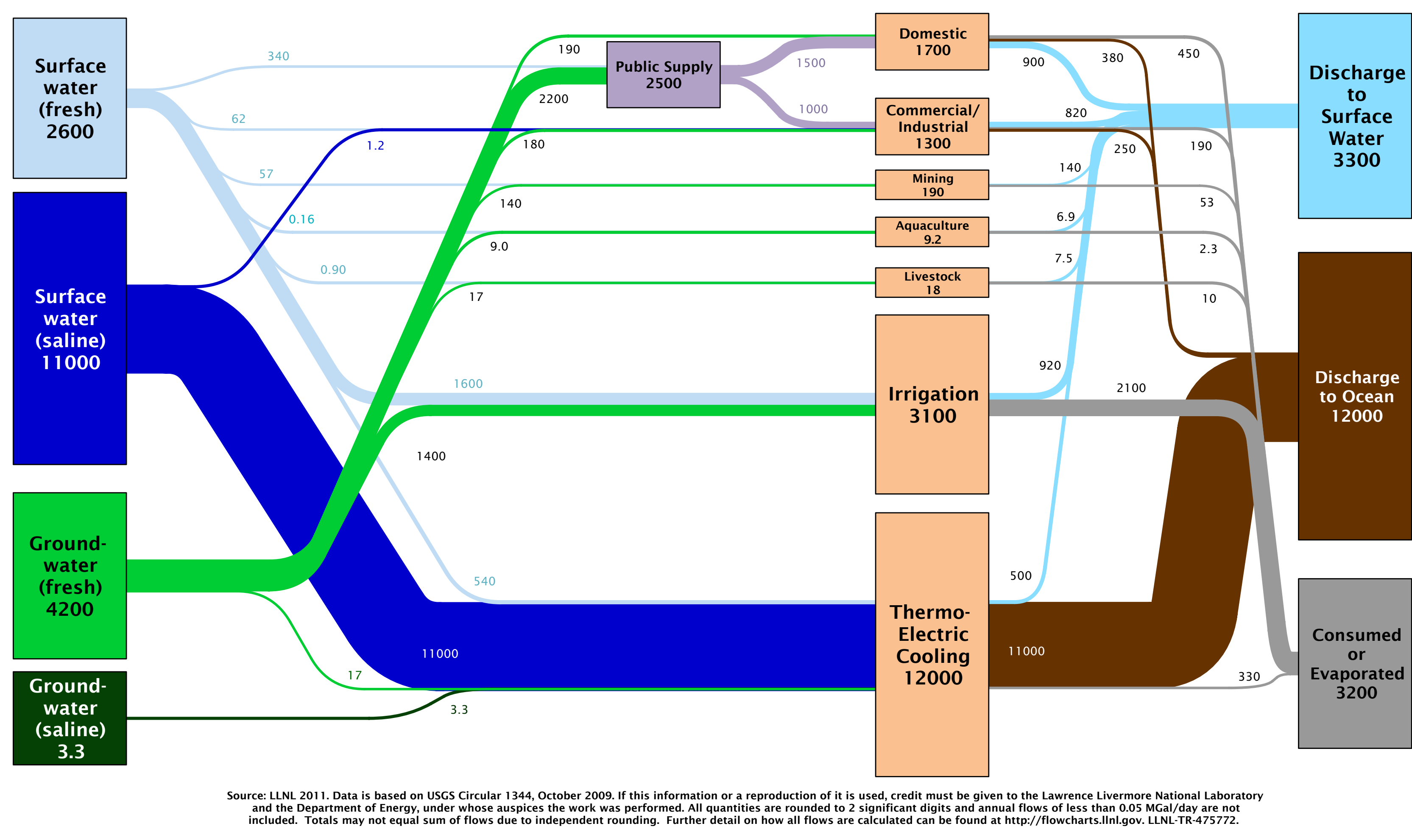




\section{Estimated Georgia Water Flow in 2005: 5400 Million Gallons/Day}

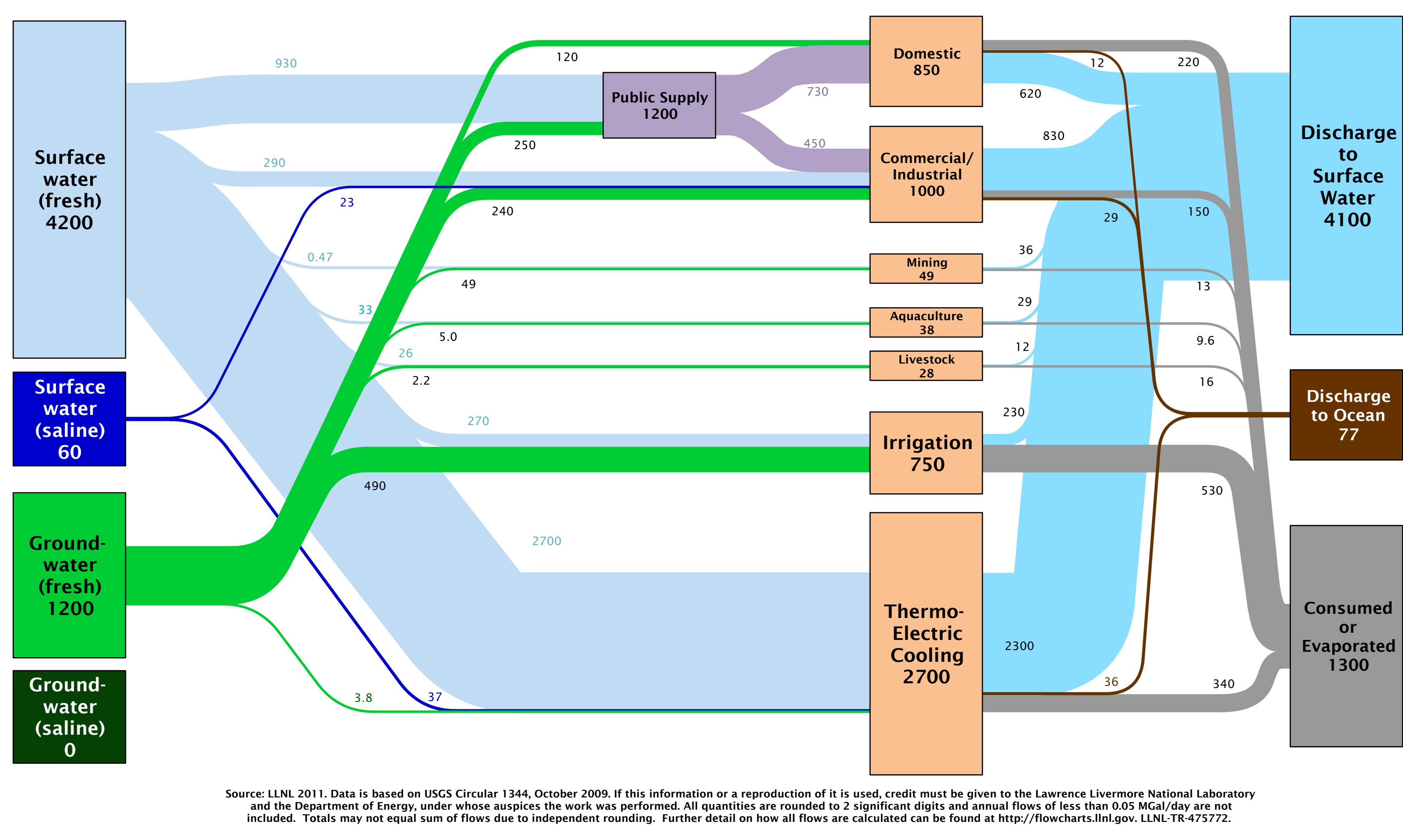




\section{Estimated Hawaii Water Flow in 2005: 1900 Million Gallons/Day}

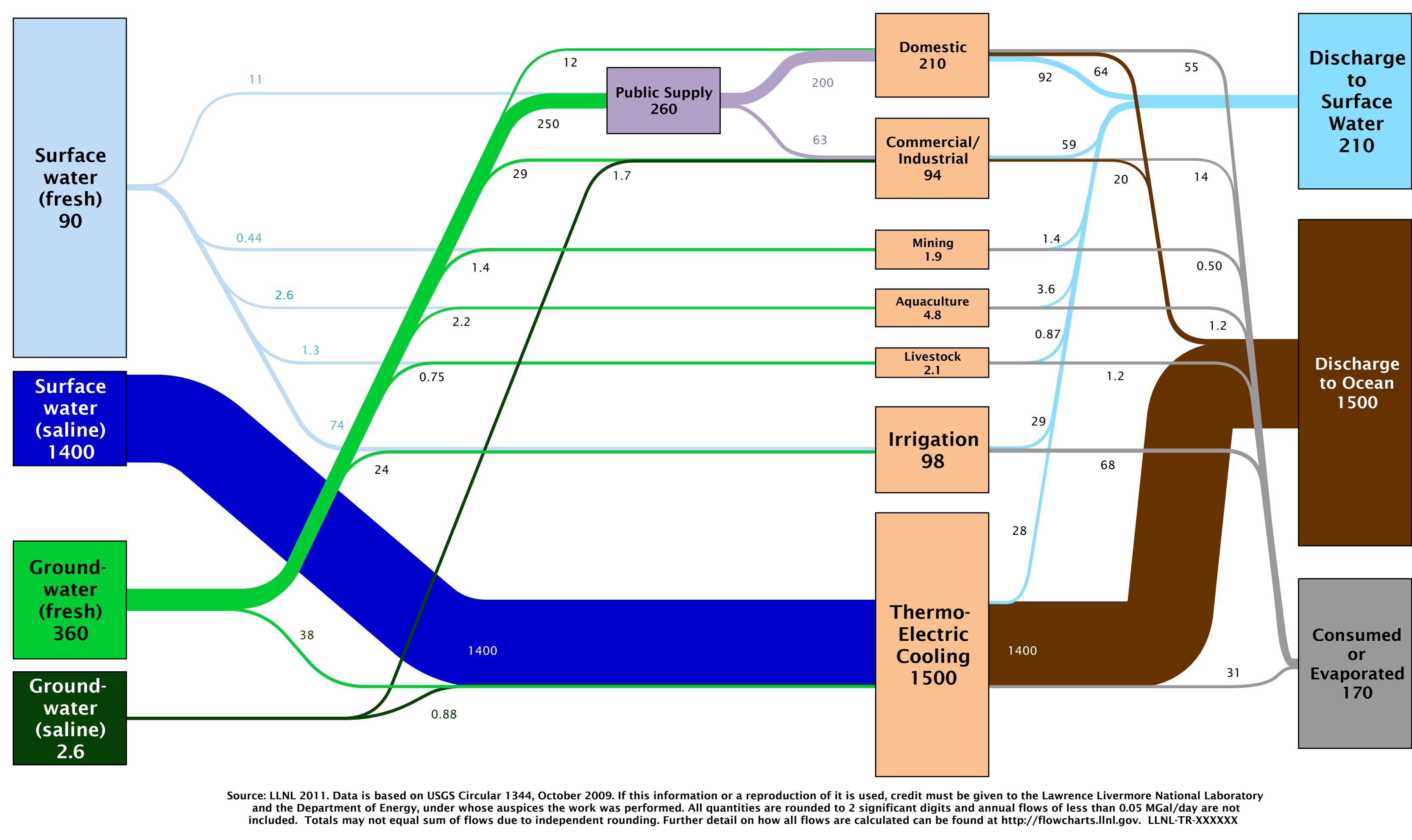




\section{Estimated Illinois Water Flow in 2005: 15000 Million Gallons/Day}

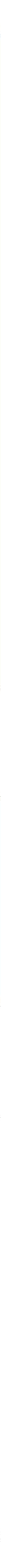

Source: LLNL 2011. Data is based on USGS Circular 1344, October 2009. If this information or a reproduction of it is used, credit must be given to the Lawrence Livermore National Laboratory and the Department of Energy, under whose auspices the work was performed. All quantities are rounded to 2 significant digits and annual flows of less than $0.05 \mathrm{MGal} / \mathrm{day}$ are not
included. Totals may not equal sum of flows due to independent rounding. Further detail on how all flows are calculated can be found at http://flowcharts.llnl.gov. LLNL-TR-475772. 


\section{Estimated Indiana Water Flow in 2005: 9300 Million Gallons/Day}

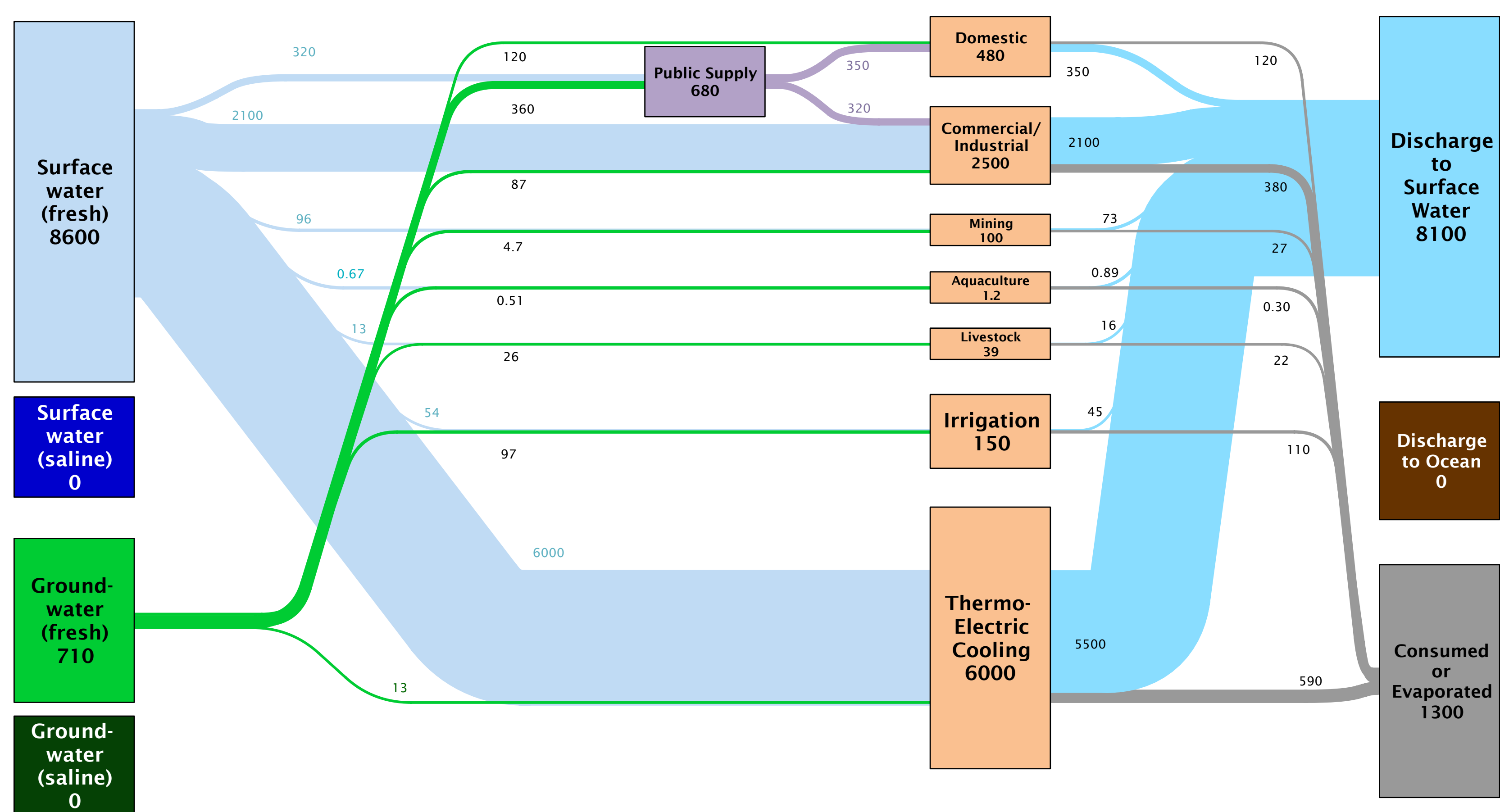

Source: LLNL 2011. Data is based on USGS Circular 1344, October 2009. If this information or a reproduction of it is used, credit must be given to the Lawrence Livermore National Laboratory and the Department of Energy, under whose auspices the work was performed. All quantities are rounded to 2 significant digits and annual flows of less than $0.05 \mathrm{MGal} /$ day are not 


\section{Estimated lowa Water Flow in 2005: 3400 Million Gallons/Day}

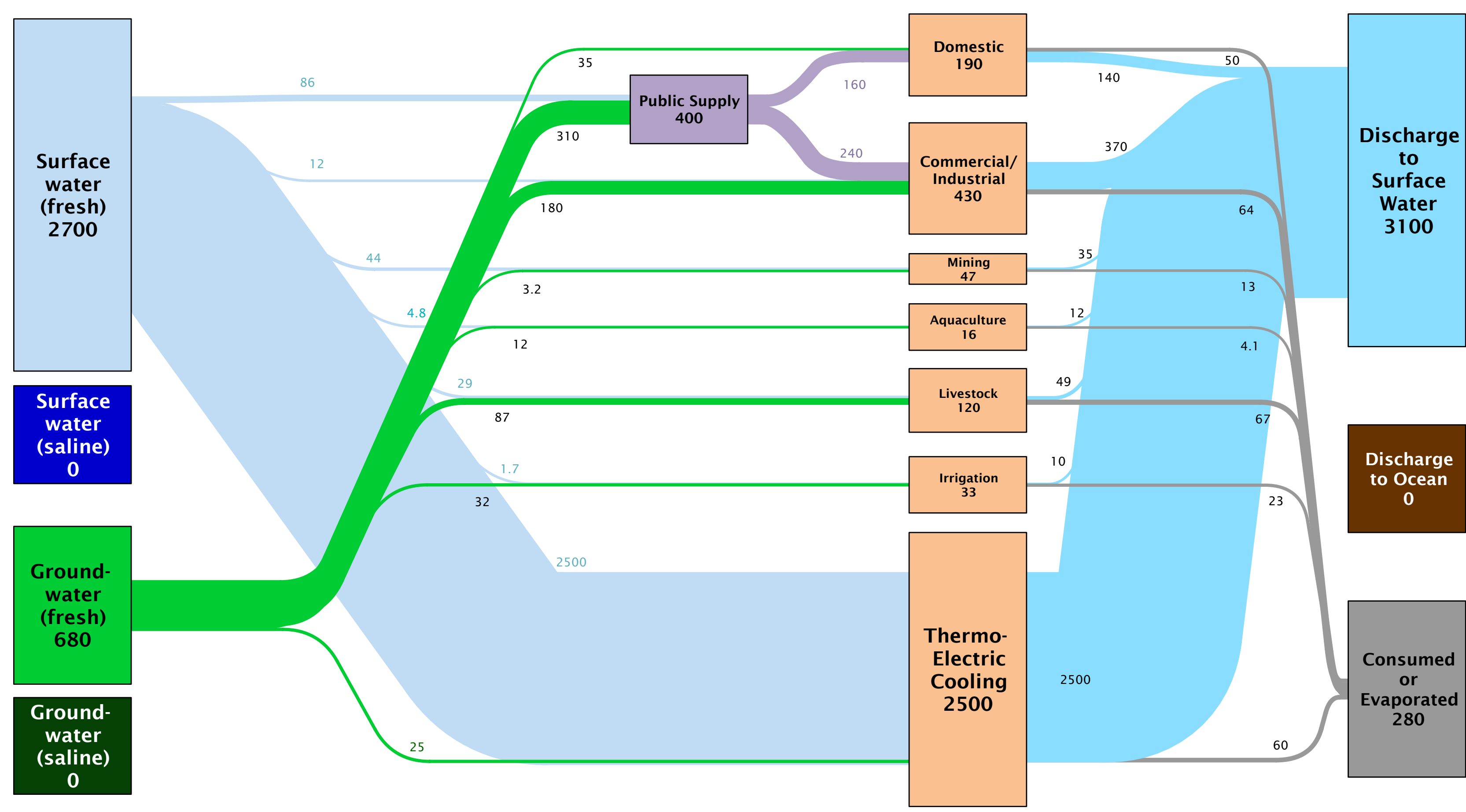

Source: LLNL 2011. Data is based on USGS Circular 1344, October 2009. If this information or a reproduction of it is used, credit must be given to the Lawrence Livermore National Laboratory and the Department of Energy, under whose auspices the work was performed. All quantities are rounded to 2 significant digits and annual flows of less than $0.05 \mathrm{MGal} / \mathrm{day}$ are not
included. Totals may not equal sum of flows due to independent rounding. Further detail on how all flows are calculated can be found at http://flowcharts.llnl.gov. LLNL-TR-475772. 


\section{Estimated Kansas Water Flow in 2005: 3800 Million Gallons/Day}

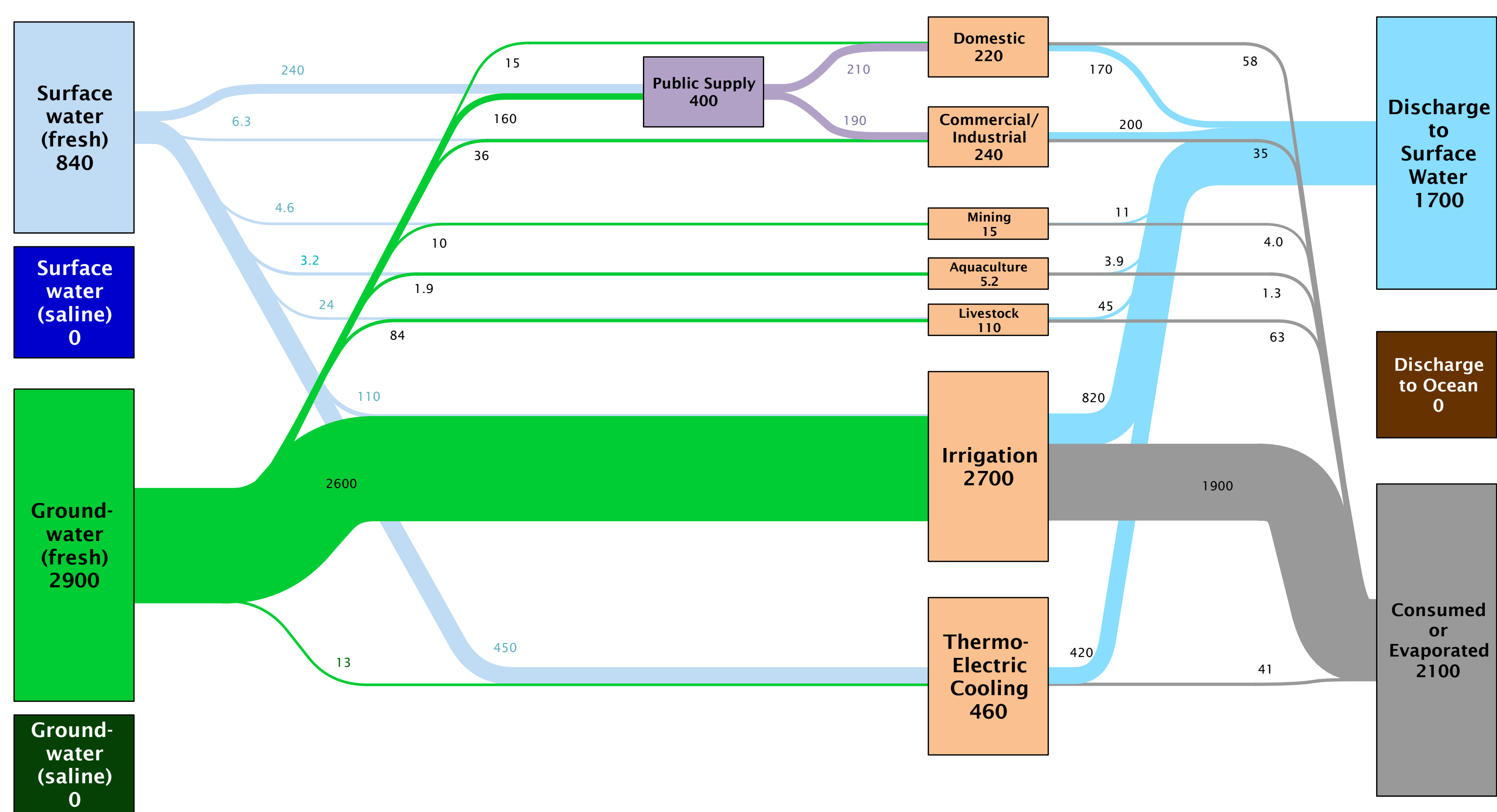

Source: LLNL 2011. Data is based on USGS Circular 1344, October 2009. If this information or a reproduction of it is used, credit must be given to the Lawrence Livermore National Laboratory and the Department of Energy, under whose auspices the work was performed. All quantities are rounded to 2 significant digits and annual flows of less than $0.05 \mathrm{MGal} /$ day are not
included. Totals may not equal sum of flows due to independent rounding. Further detail on how all flows are calculated can be found at http://flowcharts.llnl.gov. LLNL-TR-475772. 


\section{Estimated Kentucky Water Flow in 2005: 4300 Million Gallons/Day}

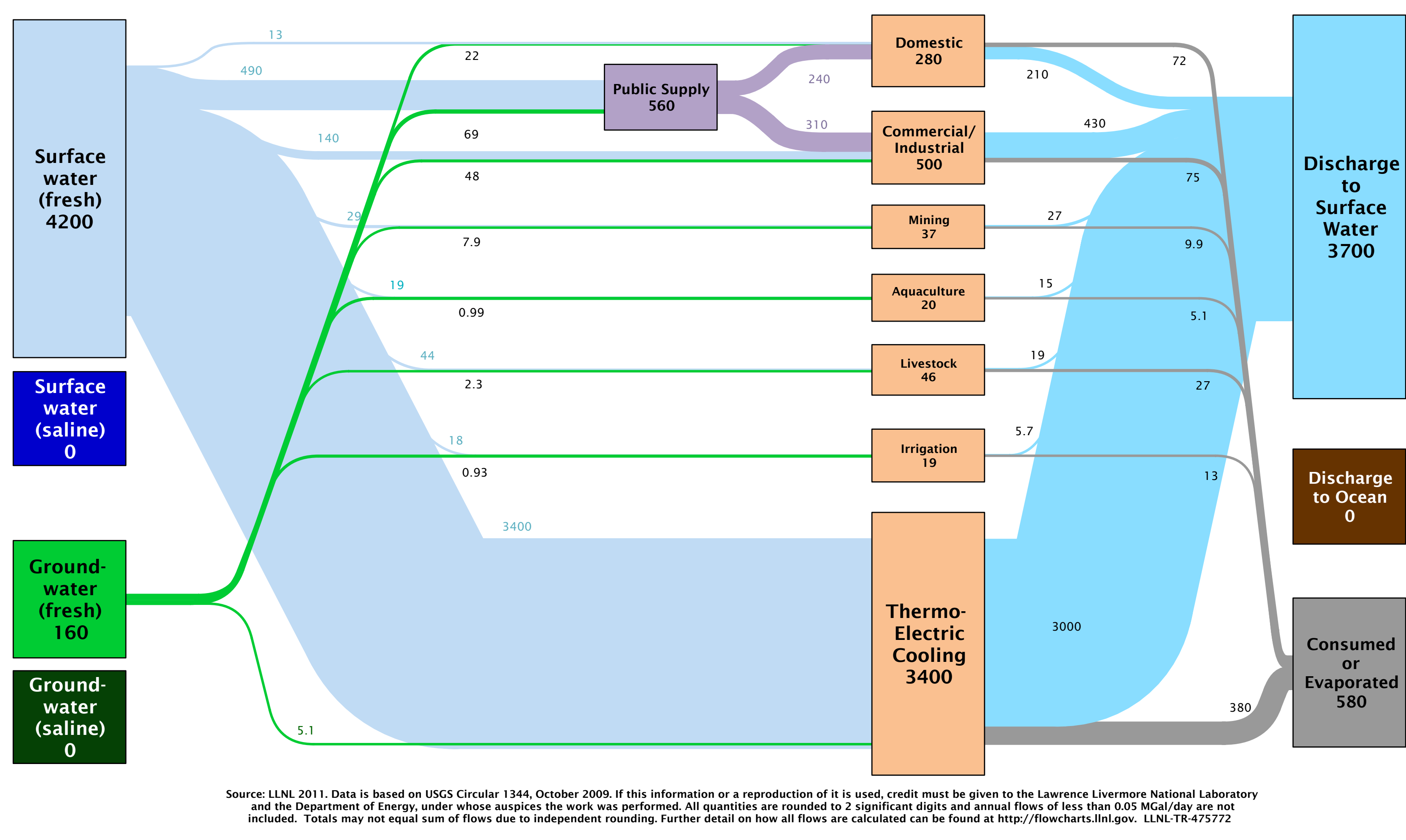




\section{Estimated Louisiana Water Flow in 2005: 12000 Million Gallons/Day}

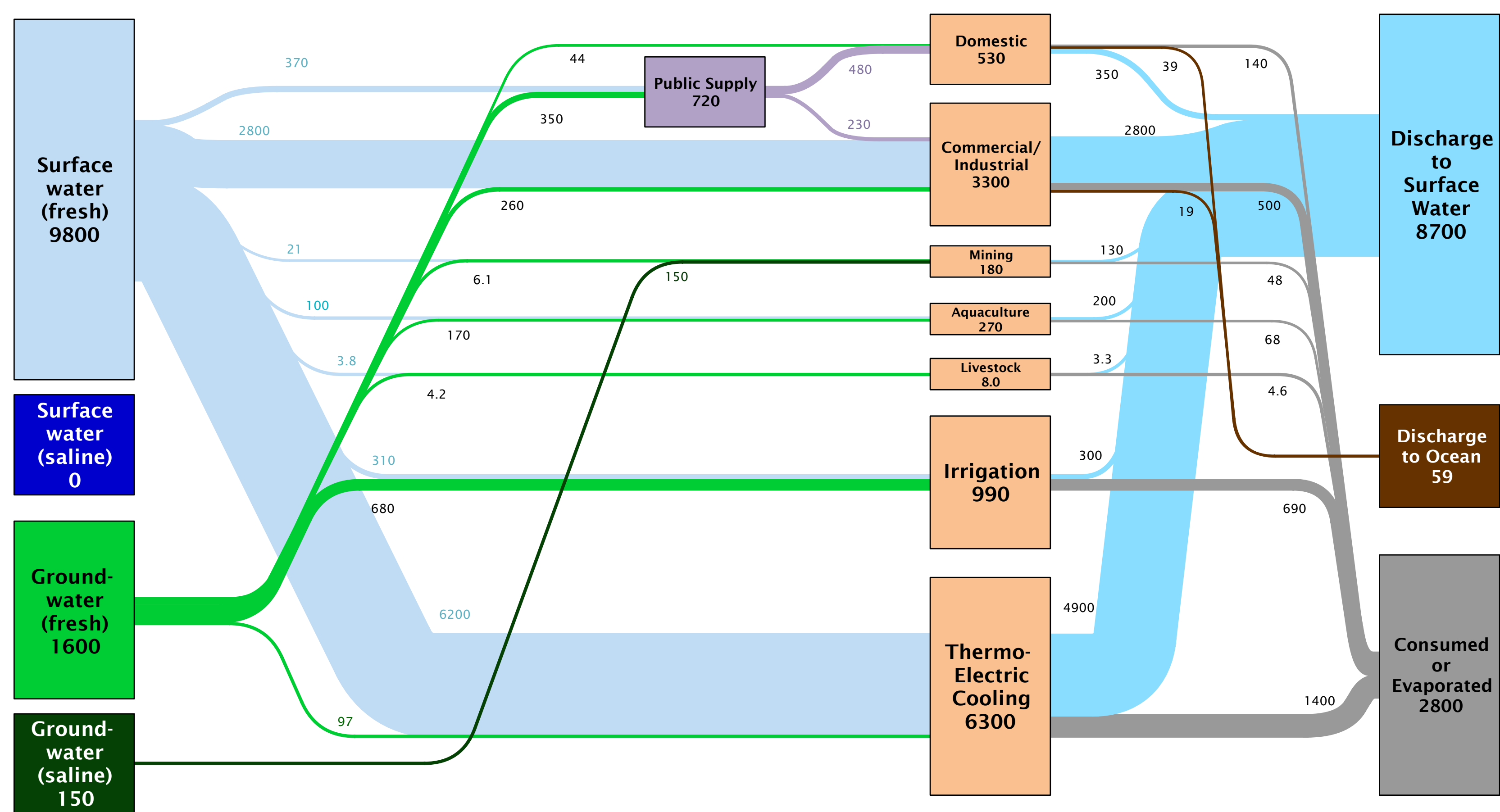

Source: LLNL 2011. Data is based on USGS Circular 1344, October 2009. If this information or a reproduction of it is used, credit must be given to the Lawrence Livermore National Laboratory and the Department of Energy, under whose auspices the work was performed. All quantities are rounded to 2 significant digits and annual flows of less than $0.05 \mathrm{MGal} / \mathrm{day}$ are not
included. Totals may not equal sum of flows due to independent rounding. Further detail on how all flows are calculated can be found at http://flowcharts.llnl.gov. LLNL-TR-475772. 


\section{Estimated Maine Water Flow in 2005: 600 Million Gallons/Day}

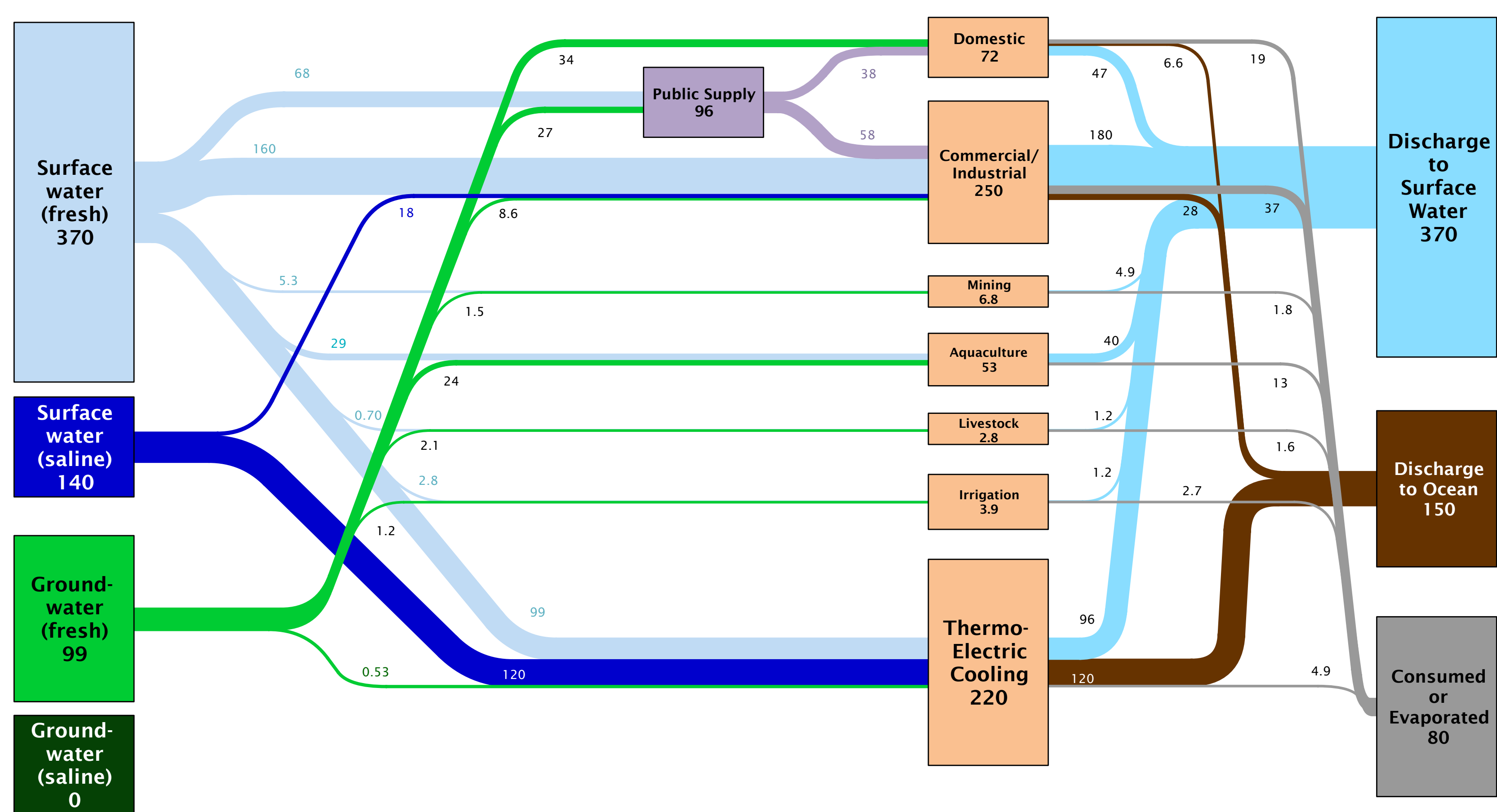

Source: LLNL 2011. Data is based on USGS Circular 1344, October 2009. If this information or a reproduction of it is used, credit must be given to the Lawrence Livermore National Laboratory and the Department of Energy, under whose auspices the work was performed. All quantities are rounded to 2 significant digits and annual flows of less than $0.05 \mathrm{MGal} / \mathrm{day}$ are not
included. Totals may not equal sum of flows due to independent rounding. Further detail on how all flows are calculated can be found at http://flowcharts.llnl.gov. LLNL-TR-475772. 


\section{Estimated Maryland Water Flow in 2005: 7500 Million Gallons/Day}

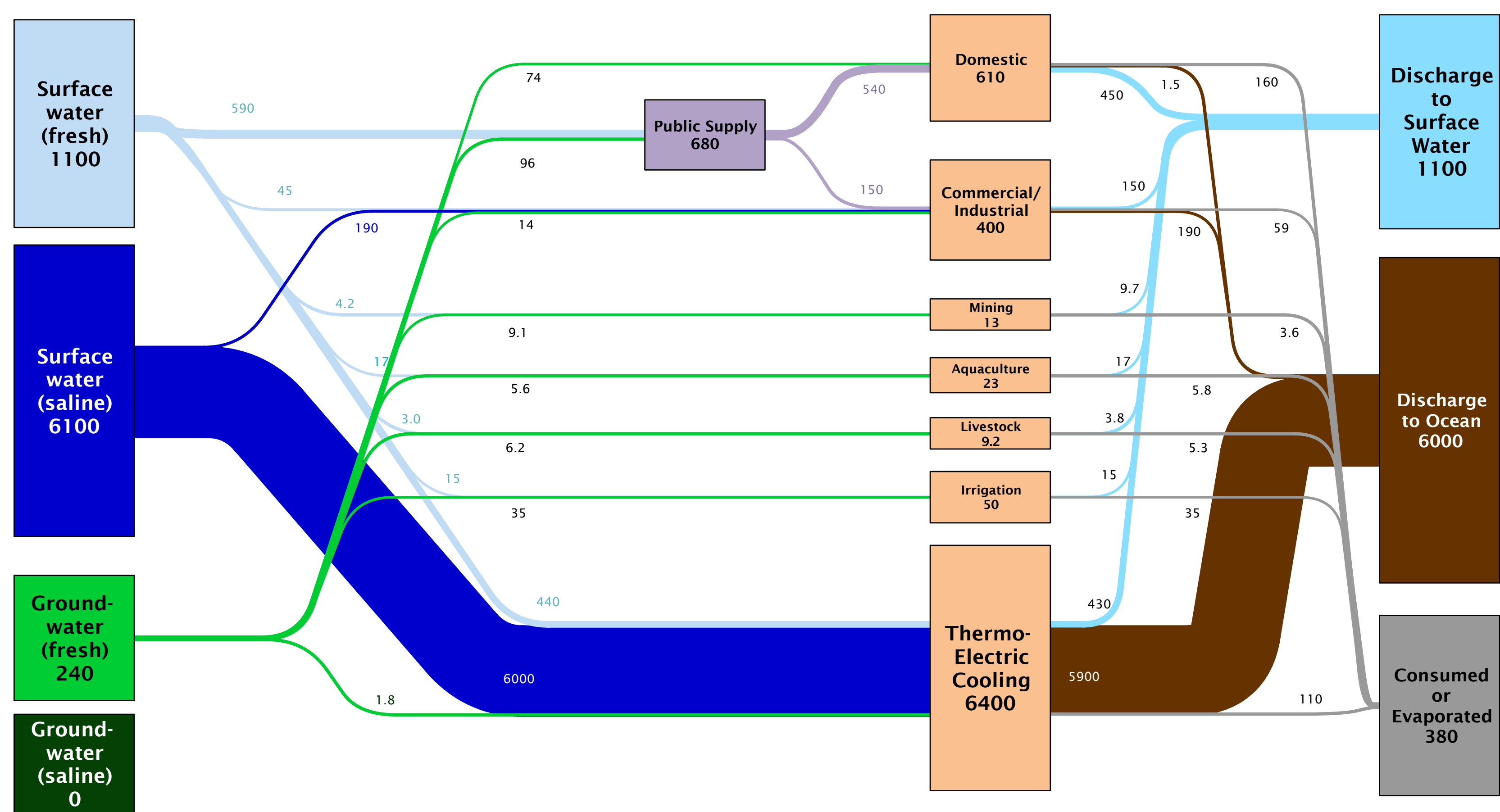

Source: LLNL 2011. Data is based on USGS Circular 1344, October 2009. If this information or a reproduction of it is used, credit must be given to the Lawrence Livermore National Laboratory and the Department of Energy, under whose auspices the work was performed. All quantities are rounded to 2 significant digits and annual flows of less than $0.05 \mathrm{MGal} / \mathrm{day}$ are not
included. Totals may not equal sum of flows due to independent rounding. Further detail on how all flows are calculated can be found at http://flowcharts.llnl.gov. LLNL-TR-475772. 


\section{Estimated Massachusetts Water Flow in 2005: 3600 Million Gallons/Day}

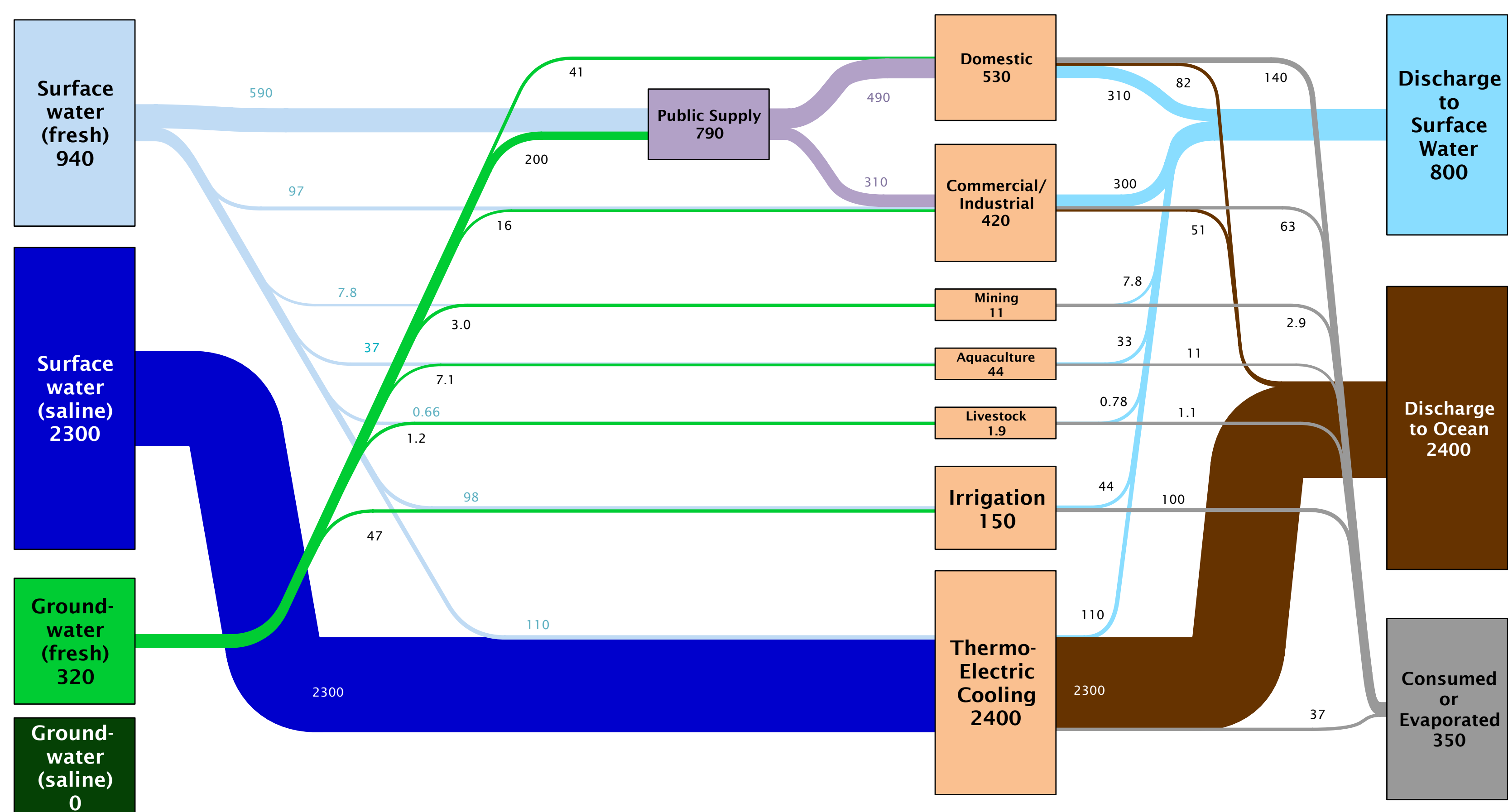

Source: LLNL 2011. Data is based on USGS Circular 1344, October 2009. If this information or a reproduction of it is used, credit must be given to the Lawrence Livermore National Laboratory and the Department of Energy, under whose auspices the work was performed. All quantities are rounded to 2 significant digits and annual flows of less than $0.05 \mathrm{MGal} /$ day are not 


\section{Estimated Michigan Water Flow in 2005: 12000 Million Gallons/Day}

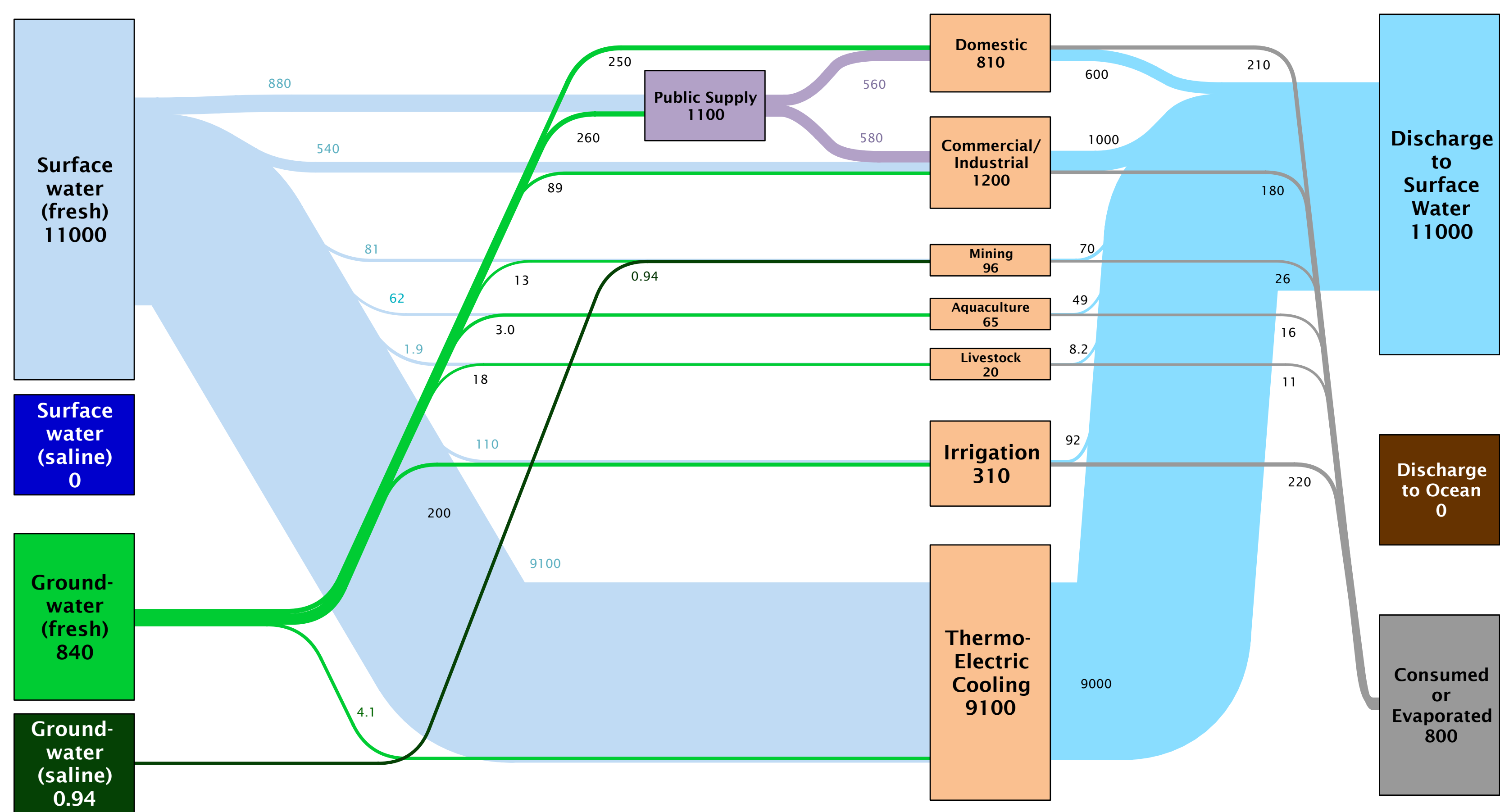

Source: LLNL 2011. Data is based on USGS Circular 1344, October 2009. If this information or a reproduction of it is used, credit must be given to the Lawrence Livermore National Laboratory and the Department of Energy, under whose auspices the work was performed. All quantities are rounded to 2 significant digits and annual flows of less than $0.05 \mathrm{MGal} / \mathrm{day}$ are not
included. Totals may not equal sum of flows due to independent rounding. Further detail on how all flows are calculated can be found at http://flowcharts.llnl.gov. LLNL-TR-475772. 


\section{Estimated Minnesota Water Flow in 2005: 4000 Million Gallons/Day}

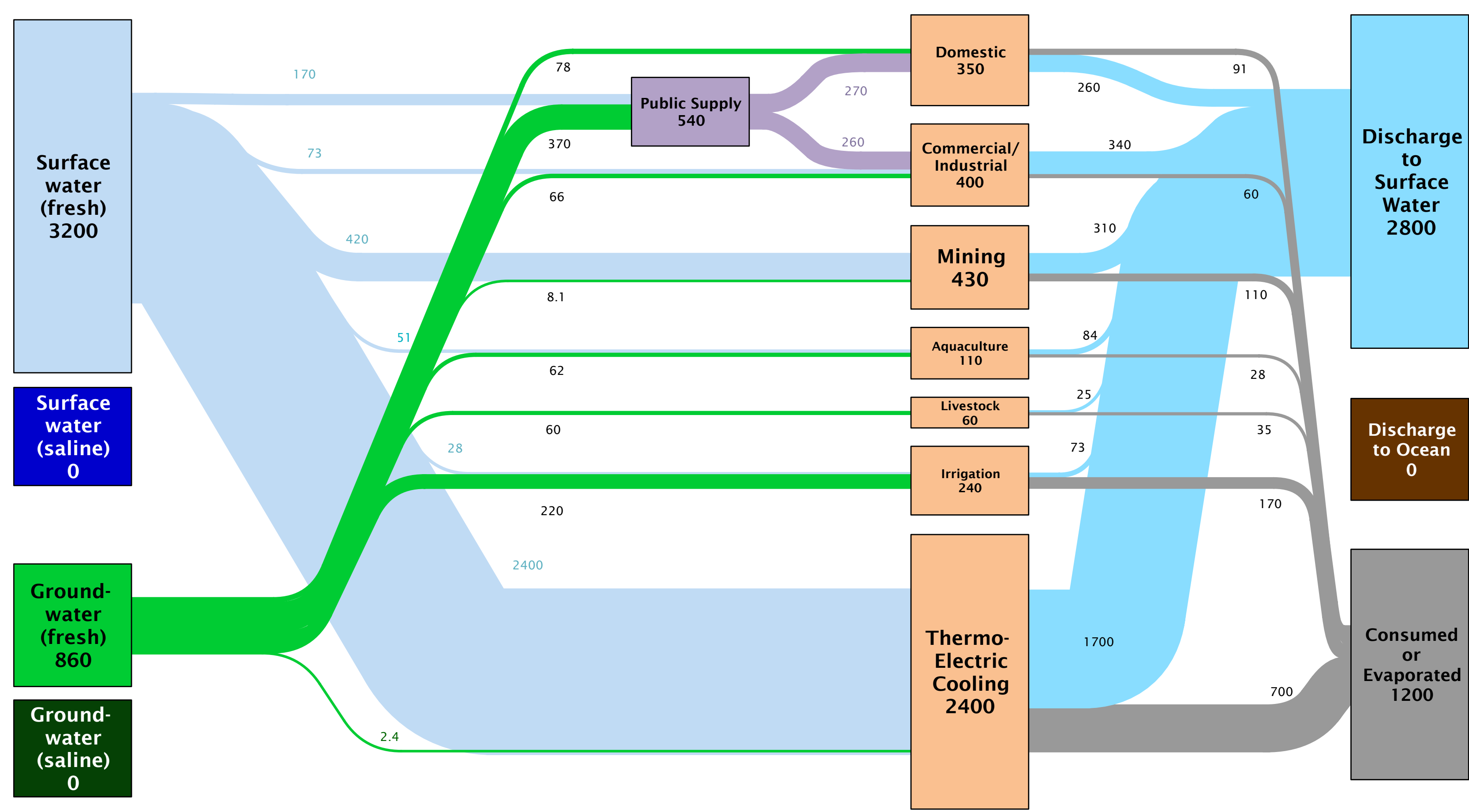

Source: LLNL 2011. Data is based on USGS Circular 1344, October 2009. If this information or a reproduction of it is used, credit must be given to the Lawrence Livermore National Laboratory and the Department of Energy, under whose auspices the work was performed. All quantities are rounded to 2 significant digits and annual flows of less than $0.05 \mathrm{MGal} / \mathrm{day}$ are not
included. Totals may not equal sum of flows due to independent rounding. Further detail on how all flows are calculated can be found at http://flowcharts.llnl.gov. LLNL-TR-475772. 


\section{Estimated Mississippi Water Flow in 2005: 2900 Million Gallons/Day}

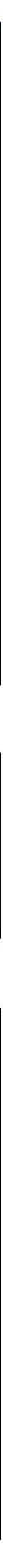

Source: LLNL 2011. Data is based on USGS Circular 1344, October 2009. If this information or a reproduction of it is used, credit must be given to the Lawrence Livermore National Laboratory and the Department of Energy, under whose auspices the work was performed. All quantities are rounded to 2 significant digits and annual flows of less than $0.05 \mathrm{MGal} /$ day are not
included. Totals may not equal sum of flows due to independent rounding. Further detail on how all flows are calculated can be found at http://flowcharts.llnl.gov. LLNL-TR-475772. 


\section{Estimated Missouri Water Flow in 2005: 8800 Million Gallons/Day}

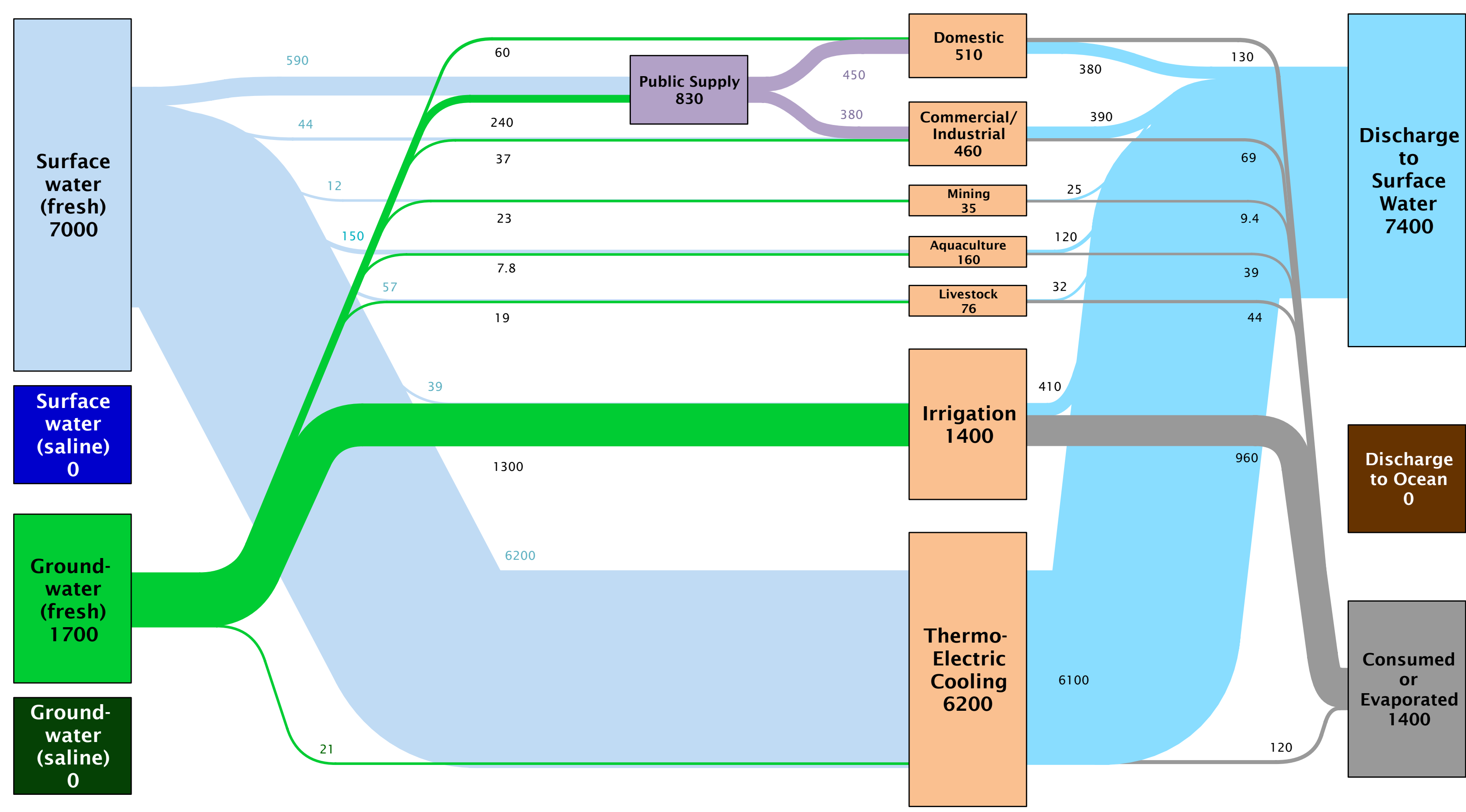

Source: LLNL 2011. Data is based on USGS Circular 1344, October 2009. If this information or a reproduction of it is used, credit must be given to the Lawrence Livermore National Laboratory and the Department of Energy, under whose auspices the work was performed. All quantities are rounded to 2 significant digits and annual flows of less than $0.05 \mathrm{MGal} / \mathrm{day}$ are not
included. Totals may not equal sum of flows due to independent rounding. Further detail on how all flows are calculated can be found at http://flowcharts.llnl.gov. LLNL-TR-475772. 


\section{Estimated Montana Water Flow in 2005: 10000 Million Gallons/Day}

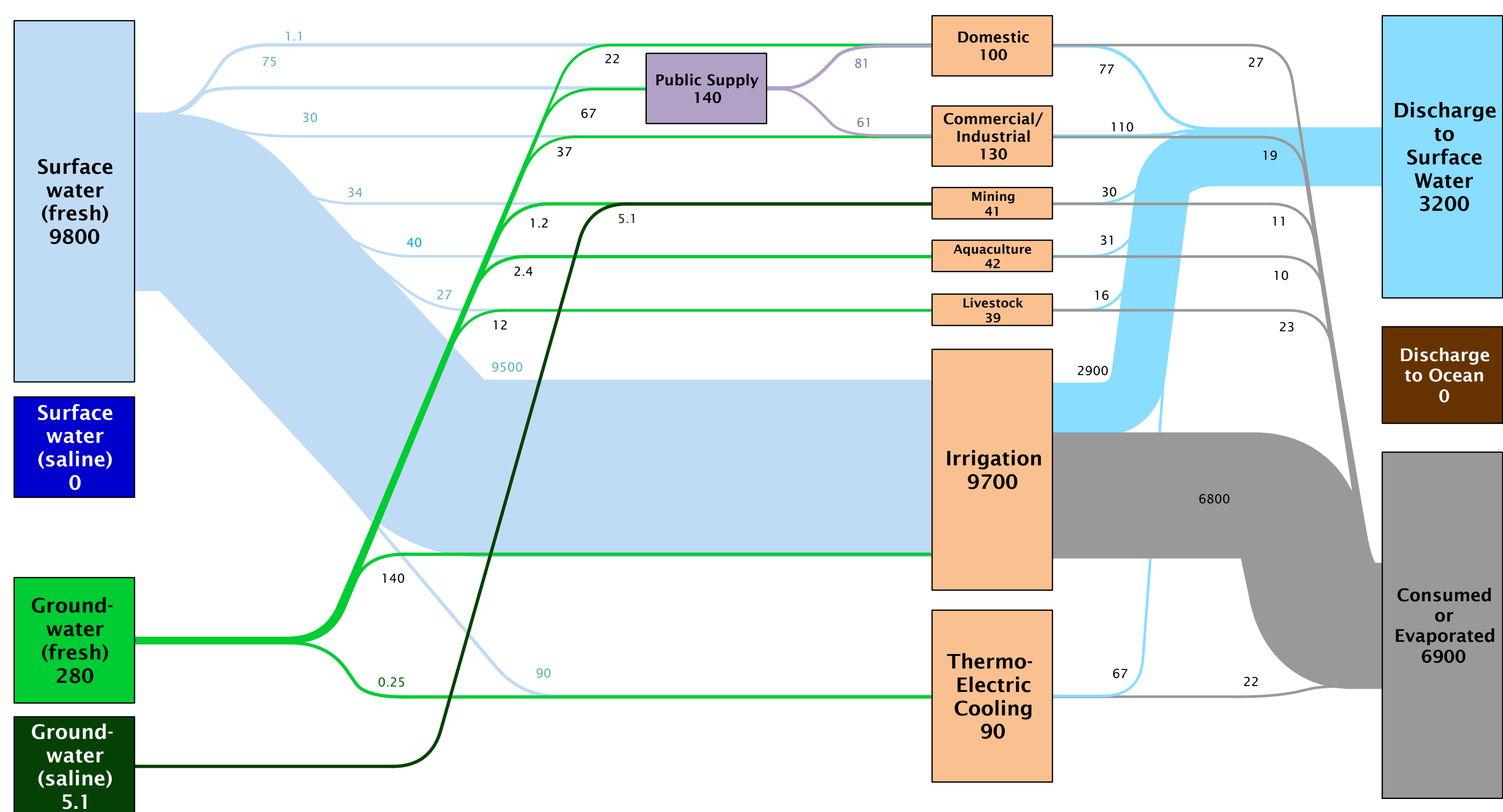

Source: LLNL 2011. Data is based on USGS Circular 1344, October 2009. If this information or a reproduction of it is used, credit must be given to the Lawrence Livermore National Laboratory and the Department of Energy, under whose auspices the work was performed. All quantities are rounded to 2 significant digits and annual flows of less than $0.05 \mathrm{MGal} / \mathrm{day}$ are not
included. Totals may not equal sum of flows due to independent rounding. Further detail on how all flows are calculated can be found at http://flowcharts.llnl.gov. LLNL-TR-475772. 


\section{Estimated Nebraska Water Flow in 2005: 13000 Million Gallons/Day}

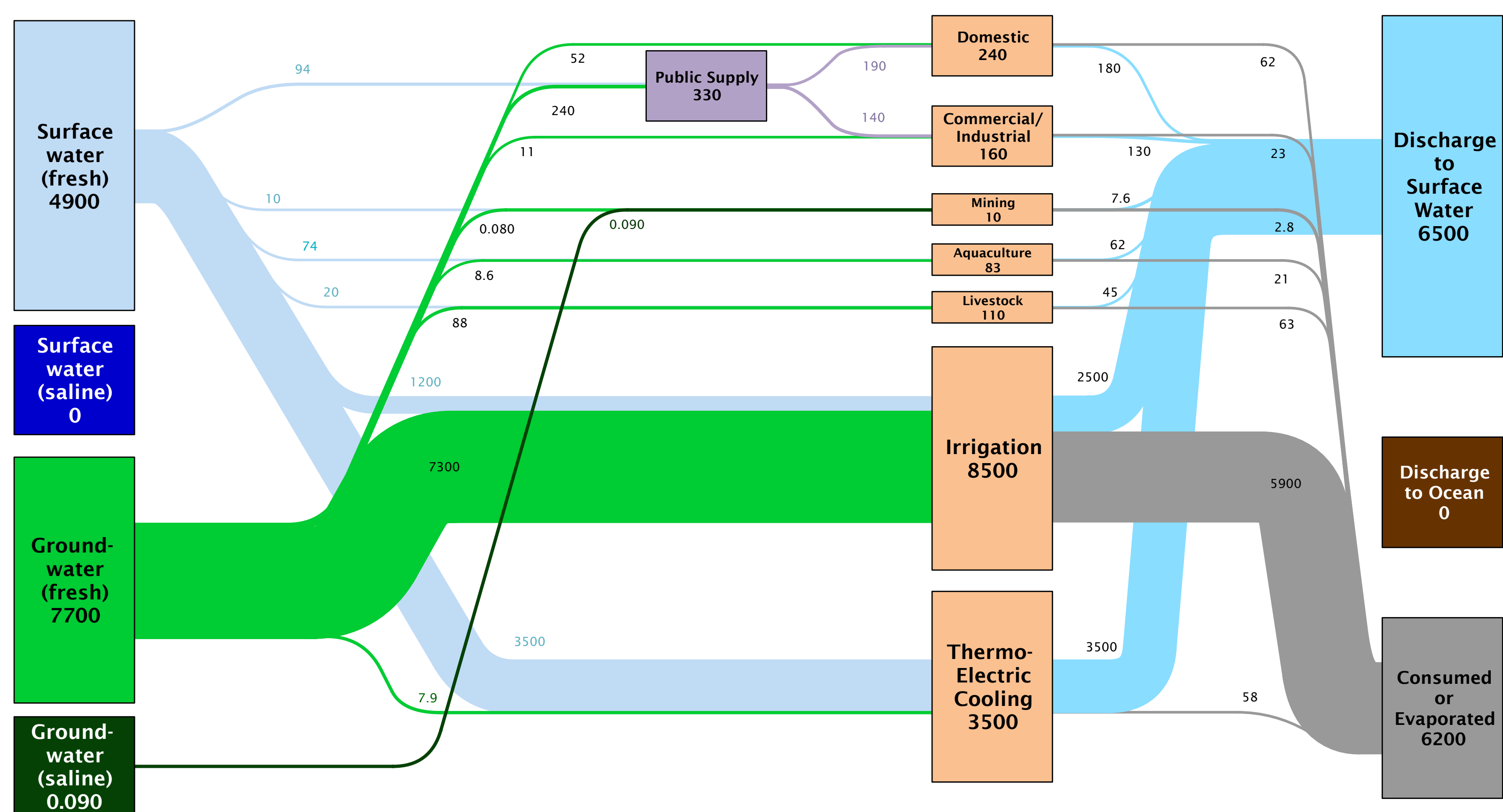

Source: LLNL 2011. Data is based on USGS Circular 1344, October 2009. If this information or a reproduction of it is used, credit must be given to the Lawrence Livermore National Laboratory and the Department of Energy, under whose auspices the work was performed. All quantities are rounded to 2 significant digits and annual flows of less than $0.05 \mathrm{MGal} / \mathrm{day}$ are not
included. Totals may not equal sum of flows due to independent rounding. Further detail on how all flows are calculated can be found at http://flowcharts.llnl.gov. LLNL-TR-475772. 


\section{Estimated Nevada Water Flow in 2005: 2400 Million Gallons/Day}

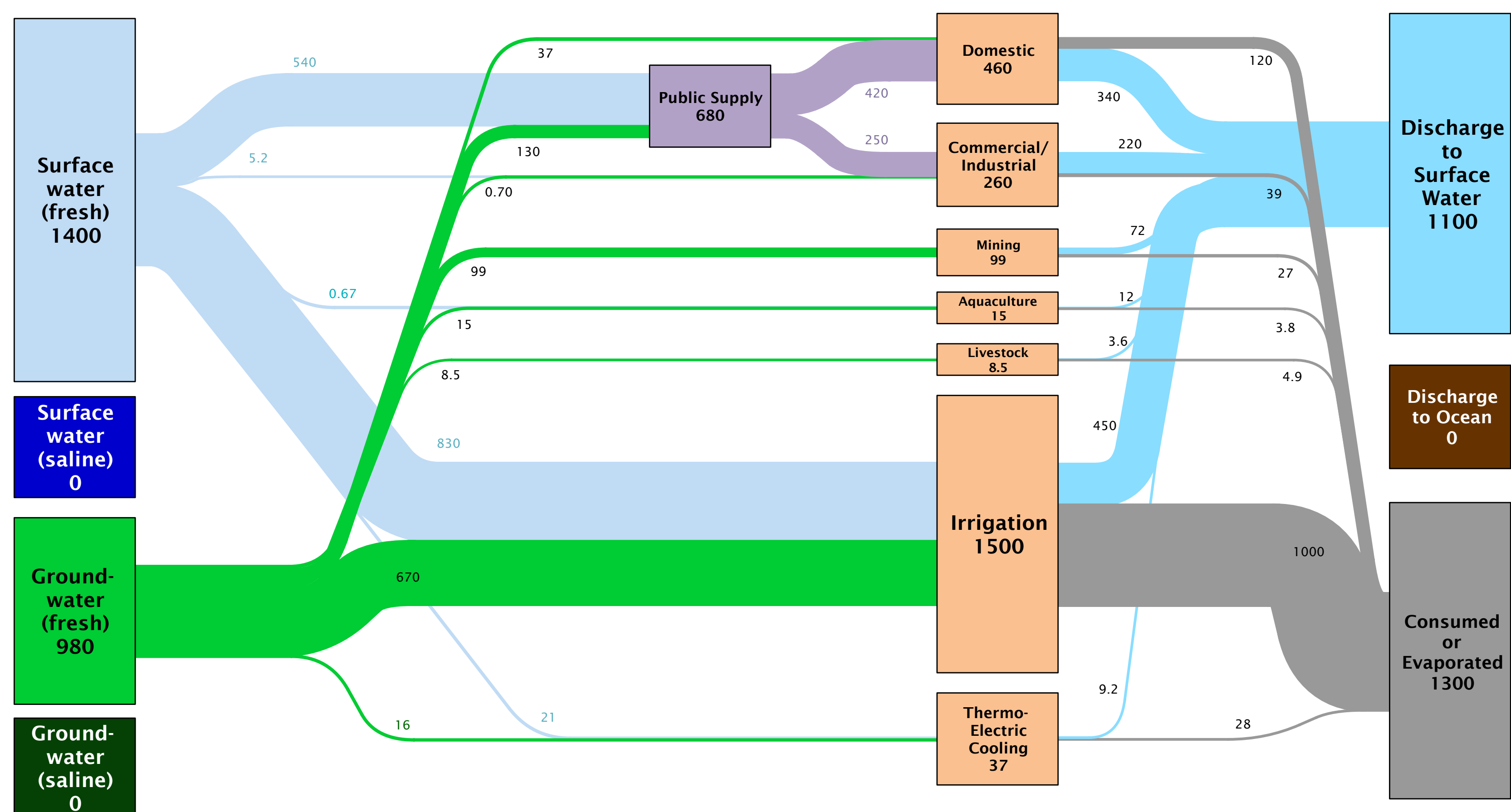

Source: LLNL 2011. Data is based on USGS Circular 1344, October 2009. If this information or a reproduction of it is used, credit must be given to the Lawrence Livermore National Laboratory and the Department of Energy, under whose auspices the work was performed. All quantities are rounded to 2 significant digits and annual flows of less than $0.05 \mathrm{MGal} / \mathrm{day}$ are not 


\section{Estimated New Hampshire Water Flow in 2005: 1300 Million Gallons/Day}

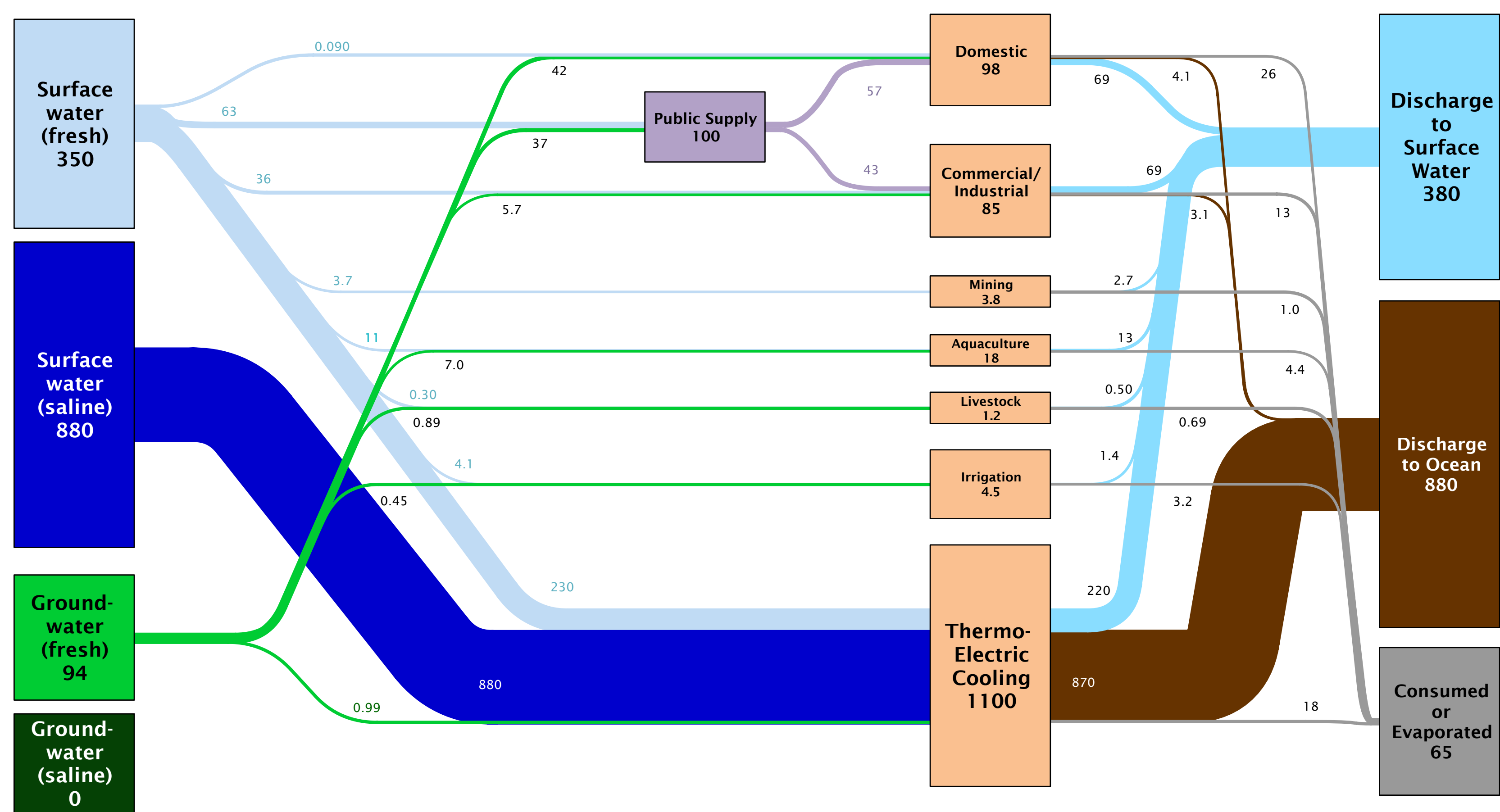

Source: LLNL 2011. Data is based on USGS Circular 1344, October 2009. If this information or a reproduction of it is used, credit must be given to the Lawrence Livermore National Laboratory and the Department of Energy, under whose auspices the work was performed. All quantities are rounded to 2 significant digits and annual flows of less than $0.05 \mathrm{MGal} / \mathrm{day}$ are not
included. Totals may not equal sum of flows due to independent rounding. Further detail on how all flows are calculated can be found at http://flowcharts.llnl.gov. LLNL-TR-475772. 


\section{Estimated New Mexico Water Flow in 2005: 3300 Million Gallons/Day}

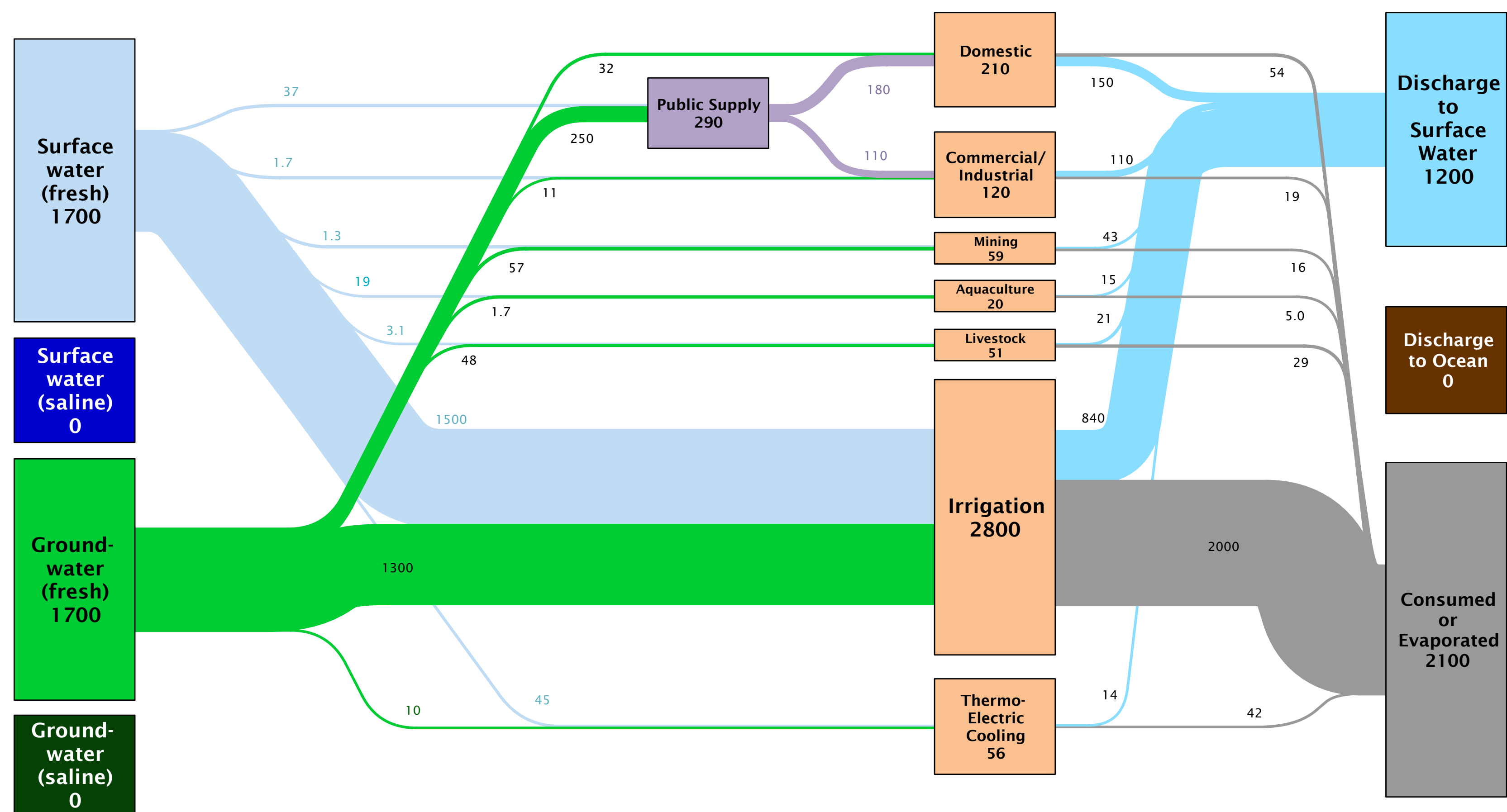

Source: LLNL 2011. Data is based on USGS Circular 1344, October 2009. If this information or a reproduction of it is used, credit must be given to the Lawrence Livermore National Laboratory and the Department of Energy, under whose auspices the work was performed. All quantities are rounded to 2 significant digits and annual flows of less than $0.05 \mathrm{MGal} / \mathrm{day}$ are not
included. Totals may not equal sum of flows due to independent rounding. Further detail on how all flows are calculated can be found at http://flowcharts.llnl.gov. LLNL-TR-475772. 


\section{Estimated New York Water Flow in 2005: 15000 Million Gallons/Day}

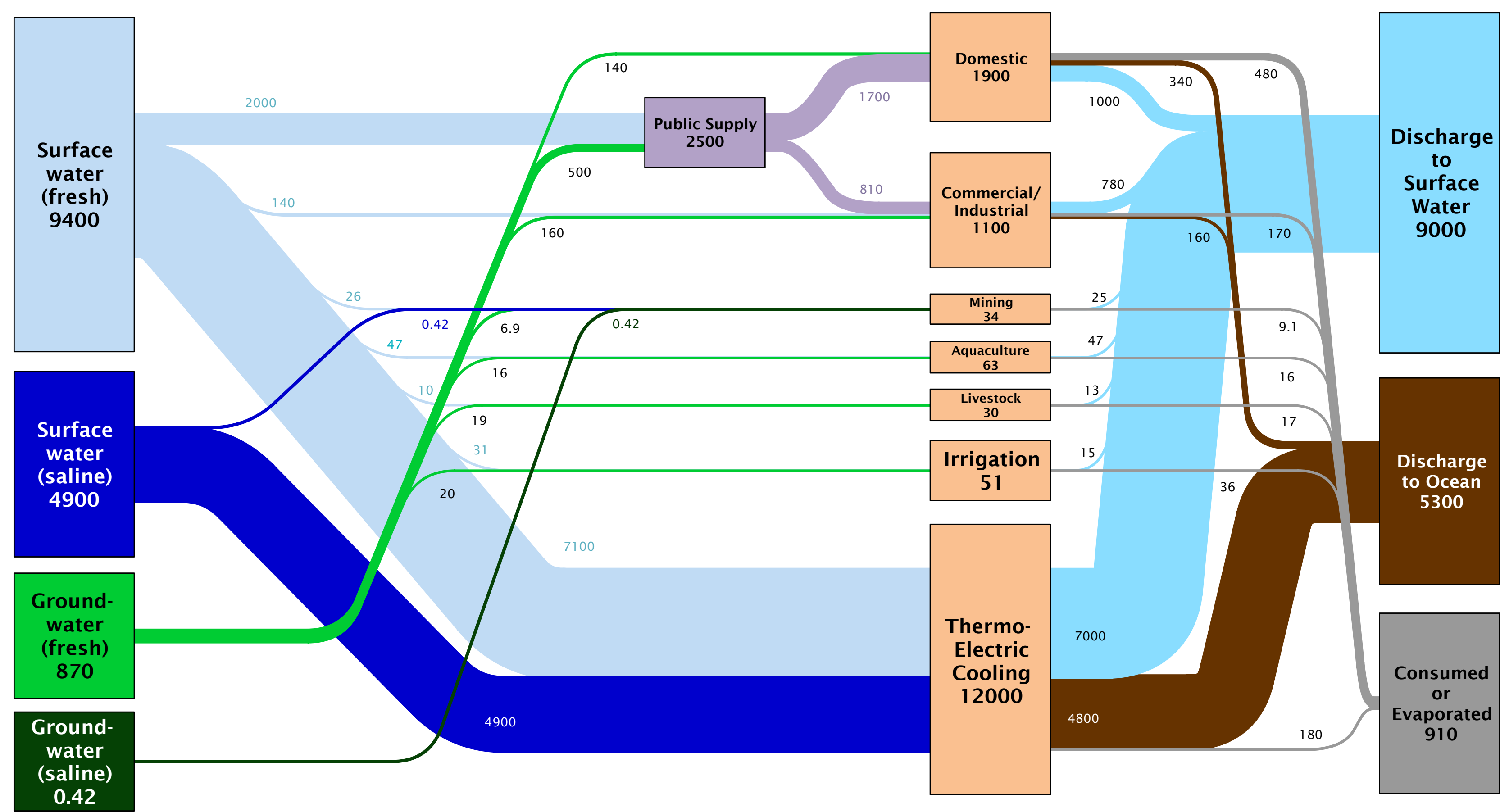

Source: LLNL 2011. Data is based on USGS Circular 1344, October 2009. If this information or a reproduction of it is used, credit must be given to the Lawrence Livermore National Laboratory and the Department of Energy, under whose auspices the work was performed. All quantities are rounded to 2 significant digits and annual flows of less than $0.05 \mathrm{MGal} / \mathrm{day}$ are not
included. Totals may not equal sum of flows due to independent rounding. Further detail on how all flows are calculated can be found at http://flowcharts.llnl.gov. LLNL-TR-475772. 


\section{Estimated North Carolina Water Flow in 2005: 13000 Million Gallons/Day}

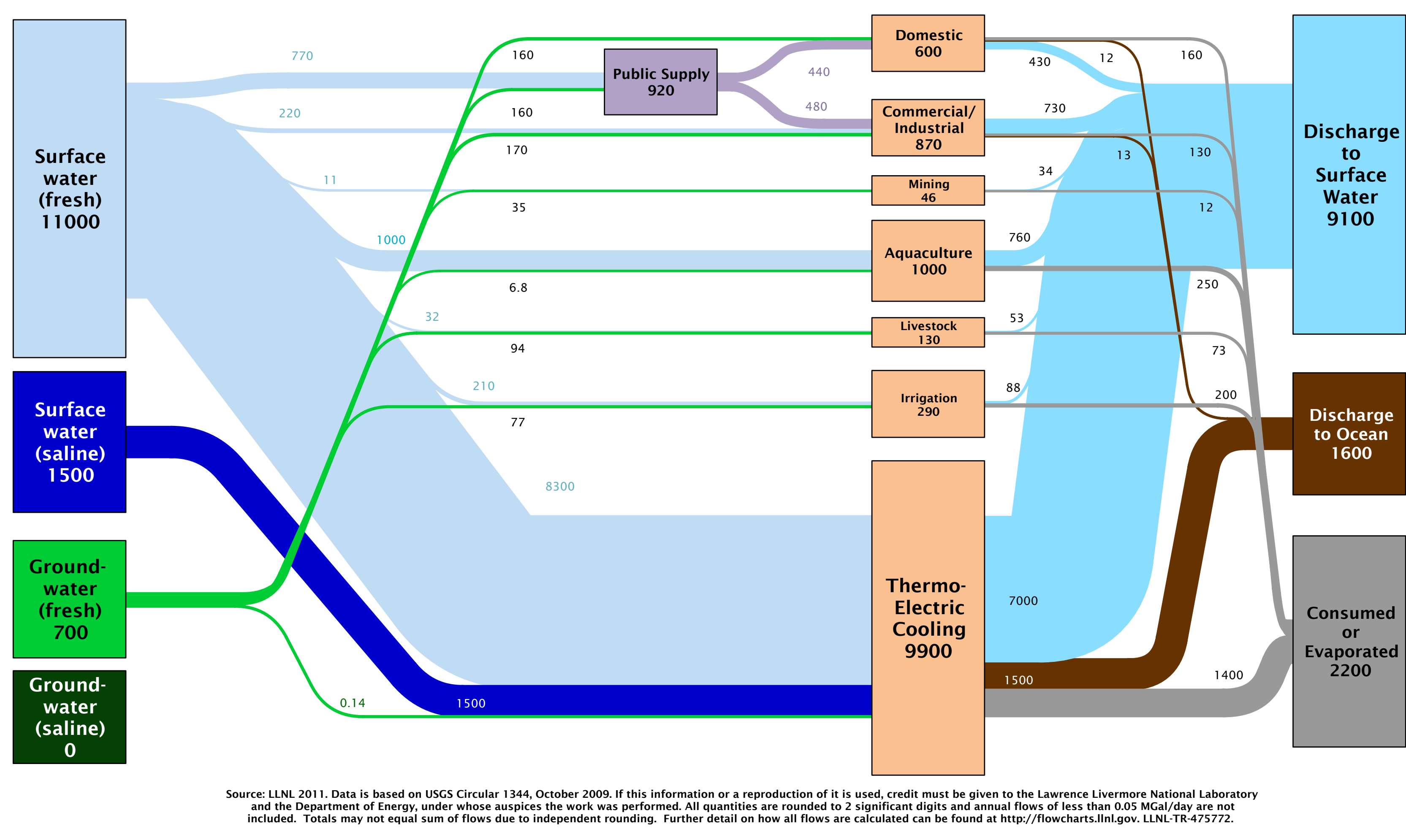




\section{Estimated North Dakota Water Flow in 2005: 1300 Million Gallons/Day}

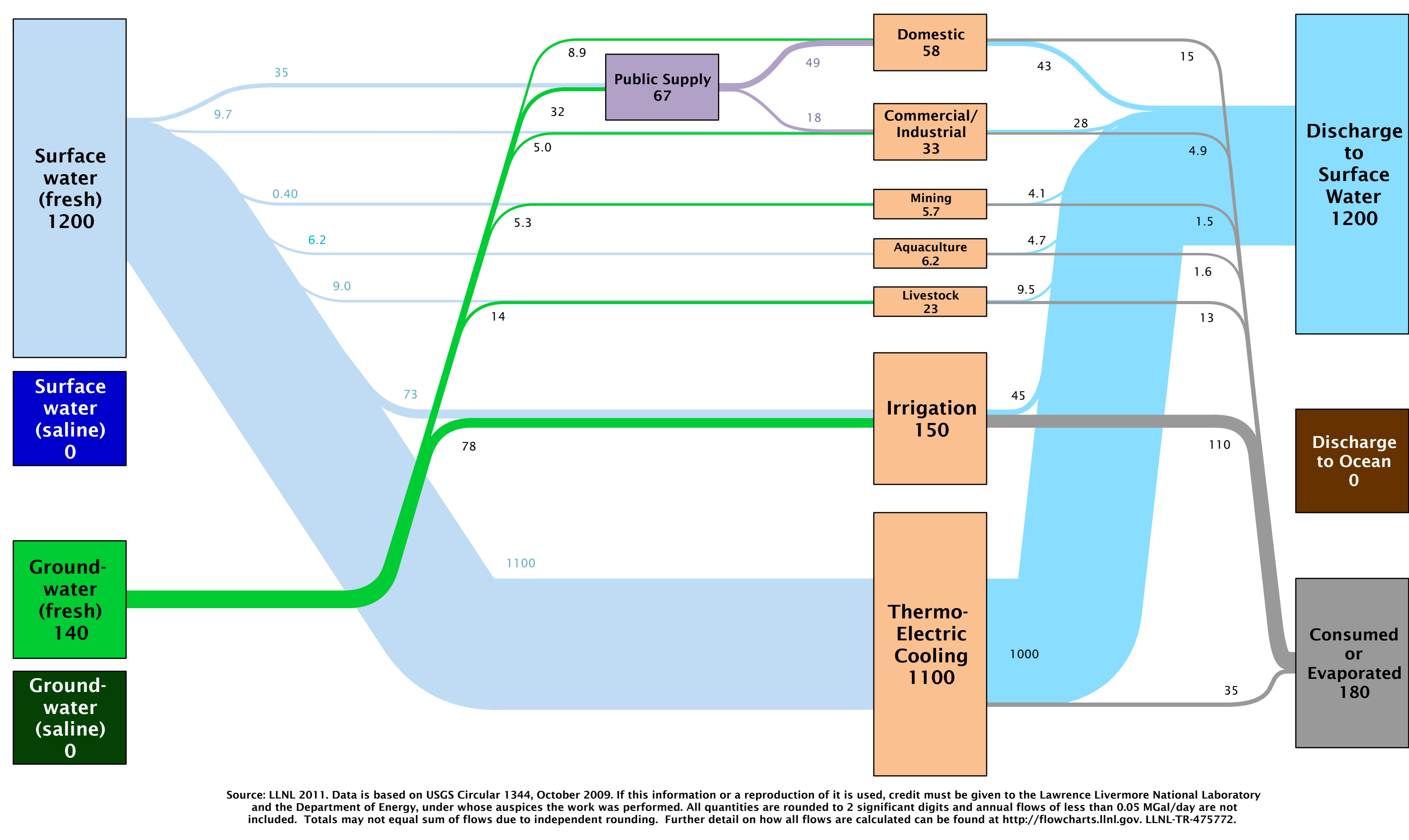




\section{Estimated Ohio Water Flow in 2005: 11000 Million Gallons/Day}

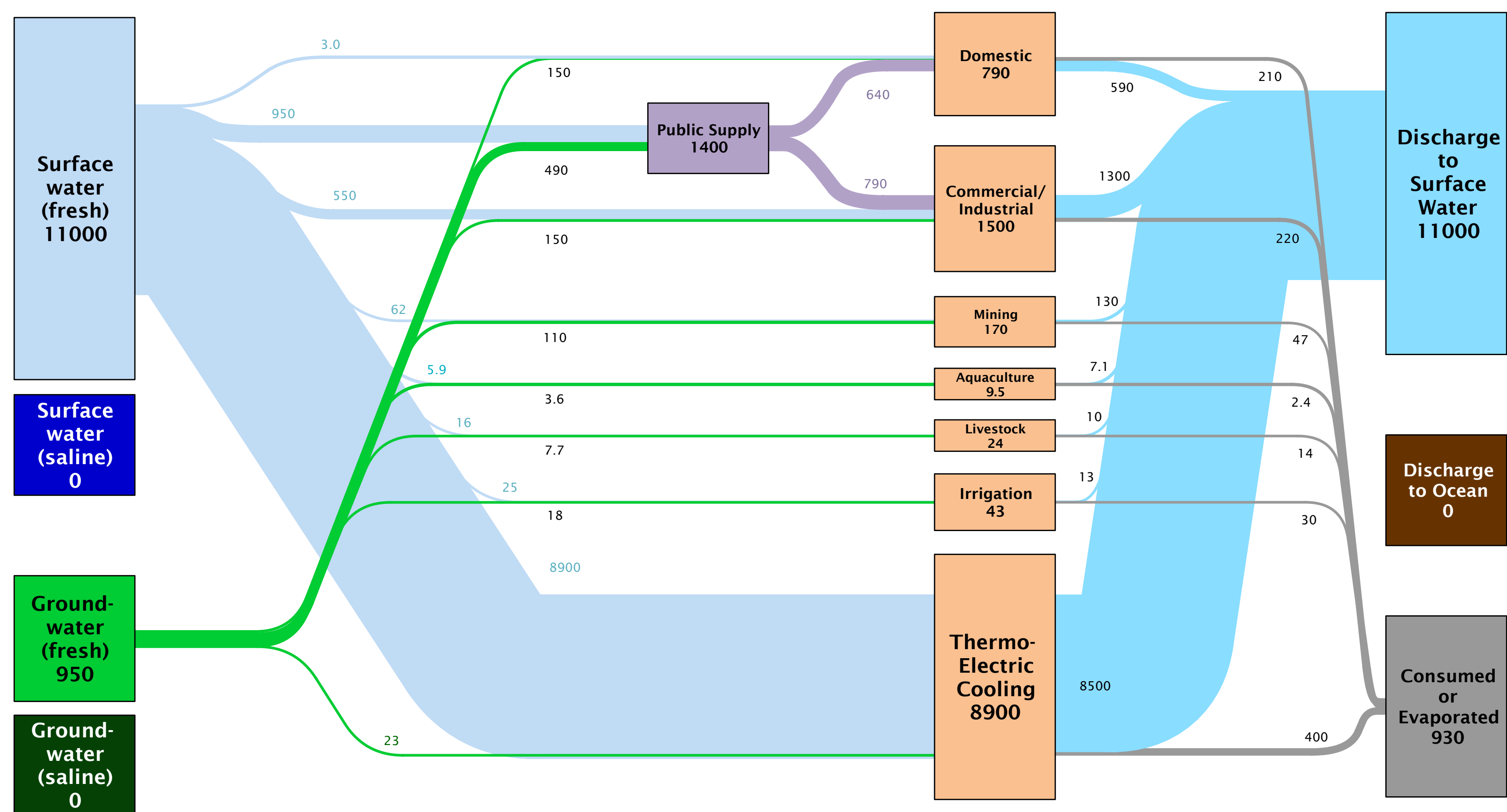

Source: LLNL 2011. Data is based on USGS Circular 1344, October 2009. If this information or a reproduction of it is used, credit must be given to the Lawrence Livermore National Laboratory and the Department of Energy, under whose auspices the work was performed. All quantities are rounded to 2 significant digits and annual flows of less than $0.05 \mathrm{MGal} /$ day are not 


\section{Estimated Oklahoma Water Flow in 2005: 1700 Million Gallons/Day}

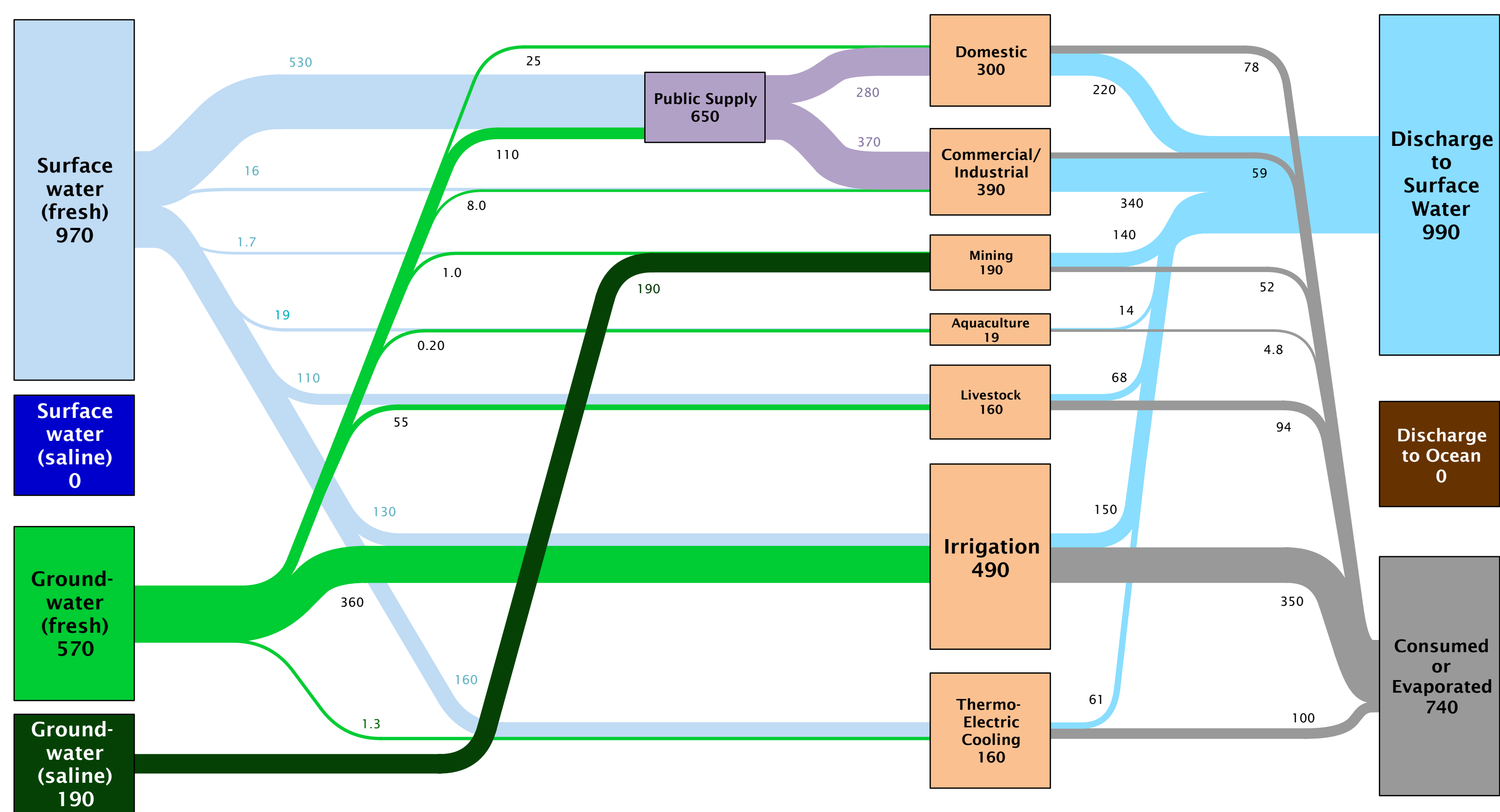

Source: LLNL 2011. Data is based on USGS Circular 1344, October 2009. If this information or a reproduction of it is used, credit must be given to the Lawrence Livermore National Laboratory and the Department of Energy, under whose auspices the work was performed. All quantities are rounded to 2 significant digits and annual flows of less than $0.05 \mathrm{MGal} /$ day are not
included. Totals may not equal sum of flows due to independent rounding. Further detail on how all flows are calculated can be found at http://flowcharts.IInl.gov. LLNL-TR-475772. 


\section{Estimated Oregon Water Flow in 2005: 7200 Million Gallons/Day}

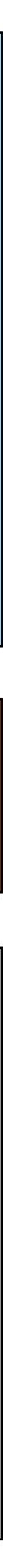

Source: LLNL 2011. Data is based on USGS Circular 1344, October 2009. If this information or a reproduction of it is used, credit must be given to the Lawrence Livermore National Laboratory and the Department of Energy, under whose auspices the work was performed. All quantities are rounded to 2 significant digits and annual flows of less than $0.05 \mathrm{MGal} / \mathrm{day}$ are not
included. Totals may not equal sum of flows due to independent rounding. Further detail on how all flows are calculated can be found at http://flowcharts.llnl.gov. LLNL-TR-475772. 


\section{Estimated Pennsylvania Water Flow in 2005: 9500 Million Gallons/Day}

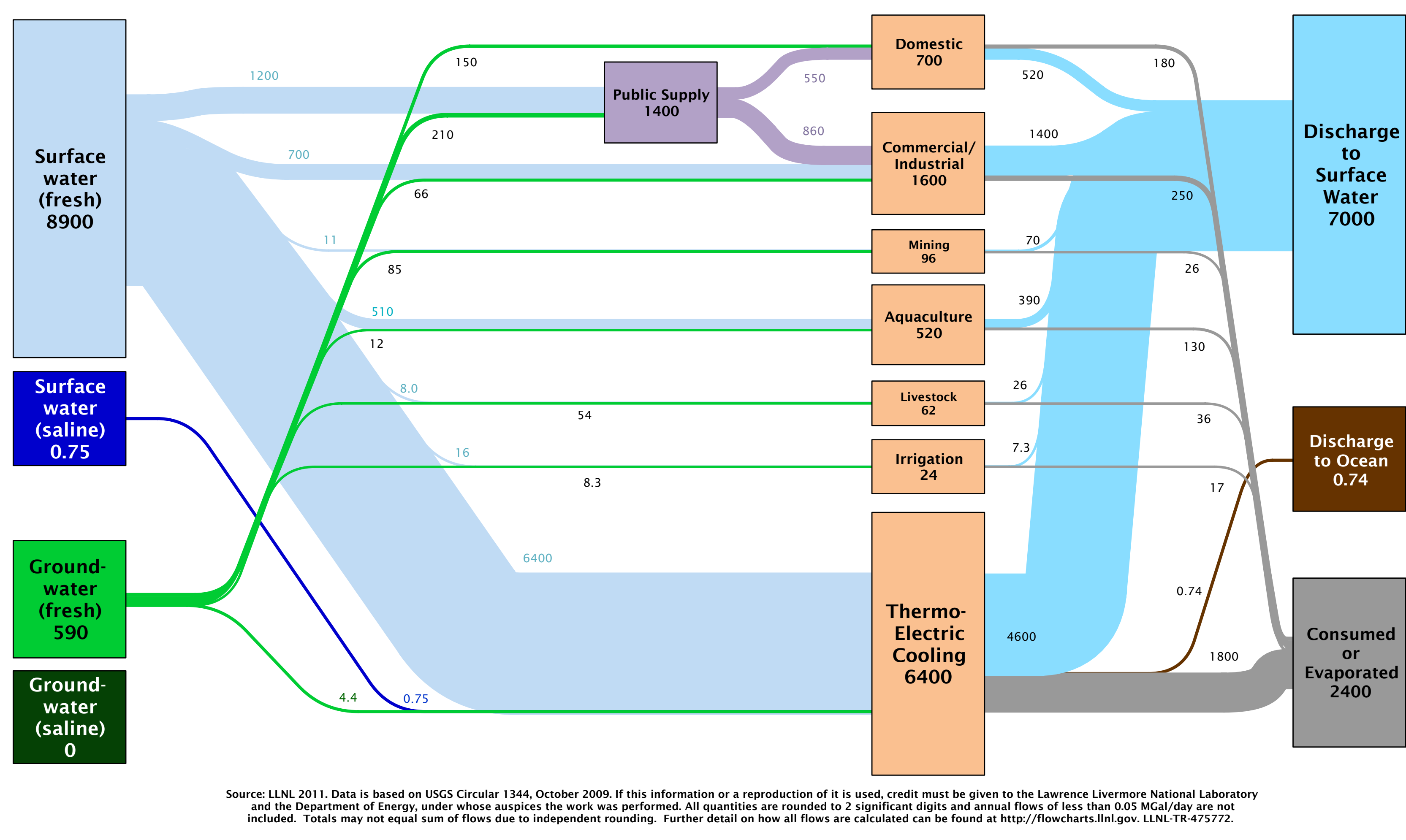




\section{Estimated Rhode Island Water Flow in 2005: 410 Million Gallons/Day}

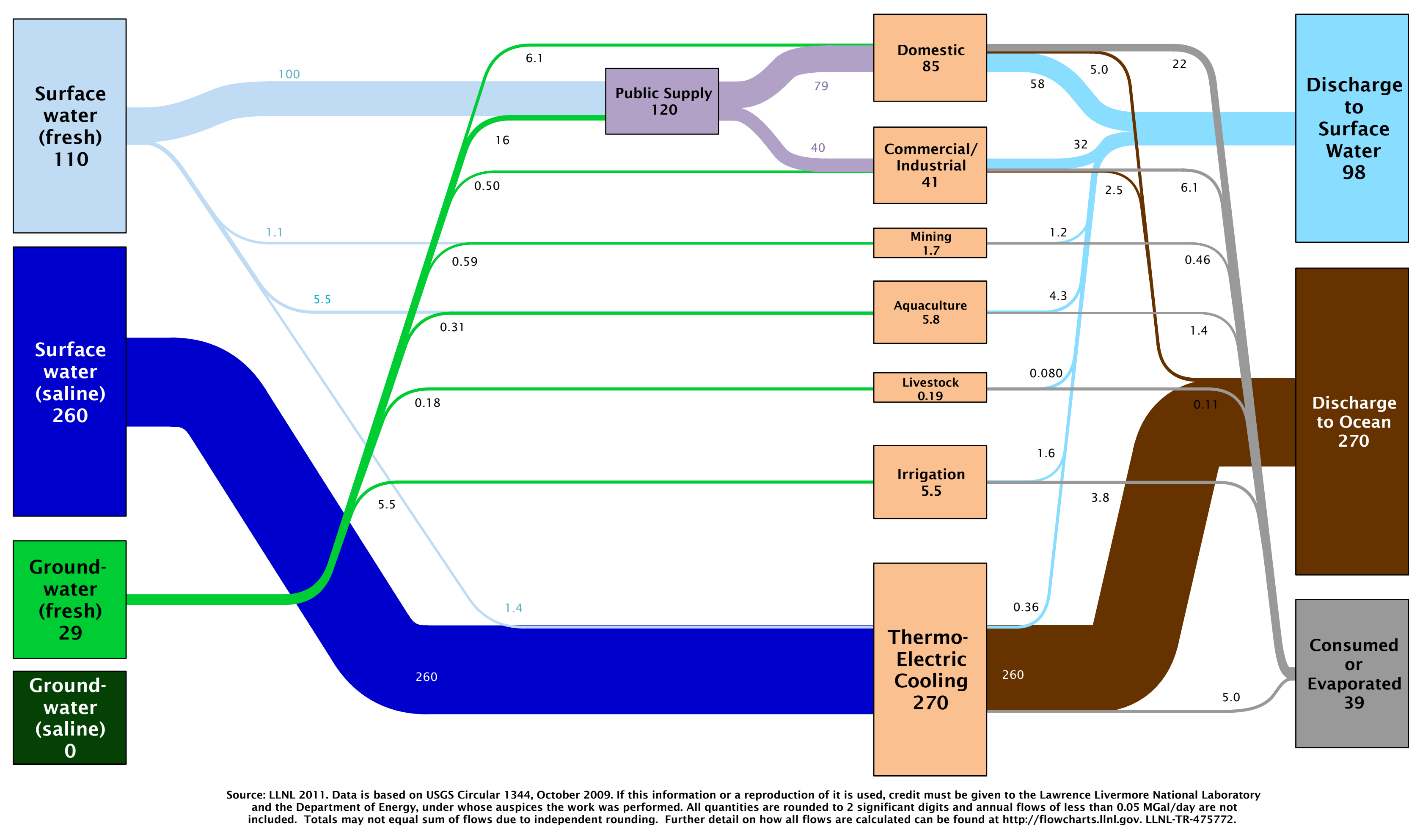




\section{Estimated South Carolina Water Flow in 2005: 7800 Million Gallons/Day}

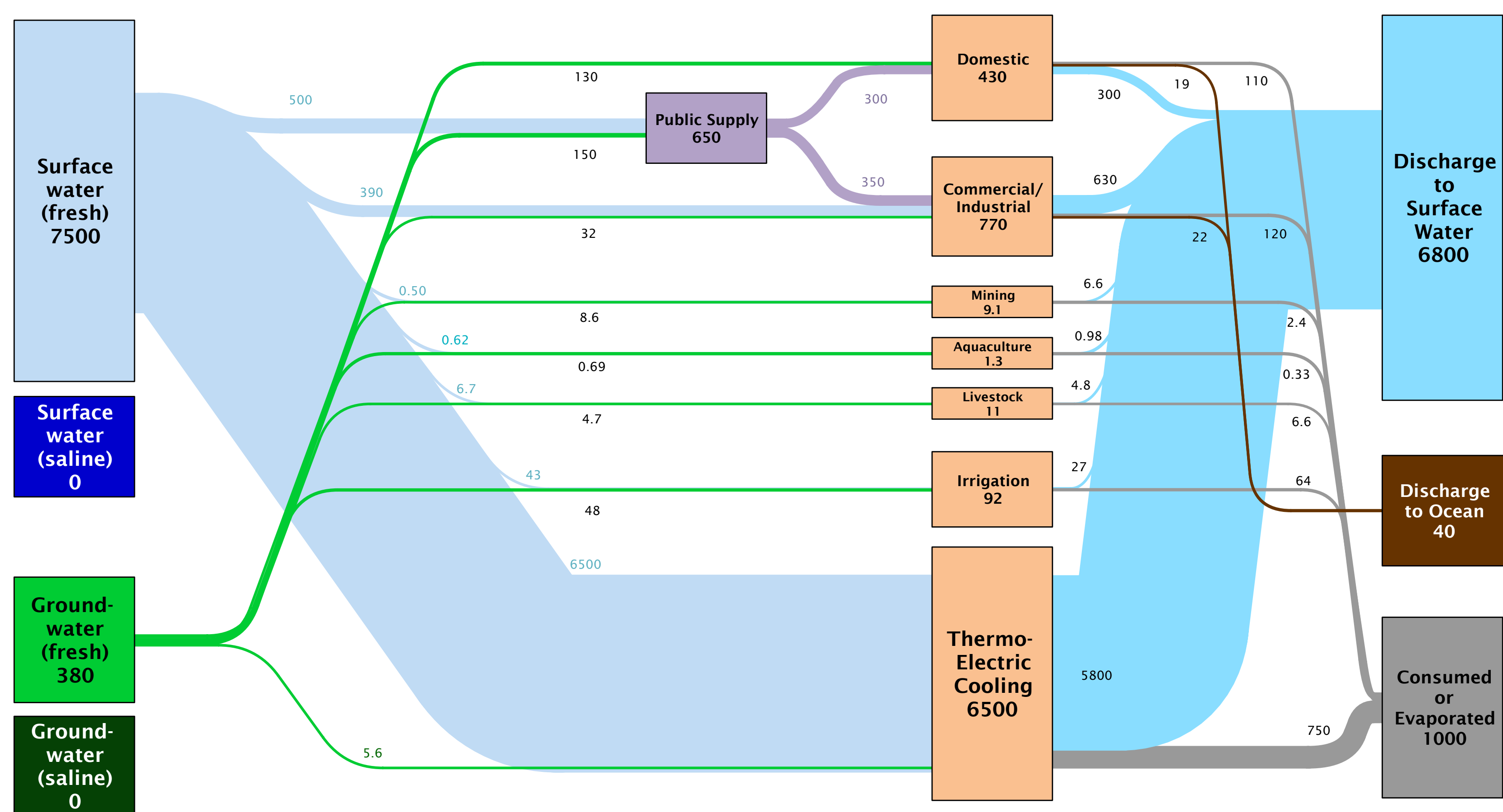

Source: LLNL 2011. Data is based on USGS Circular 1344, October 2009. If this information or a reproduction of it is used, credit must be given to the Lawrence Livermore National Laboratory and the Department of Energy, under whose auspices the work was performed. All quantities are rounded to 2 significant digits and annual flows of less than $0.05 \mathrm{MGal} / \mathrm{day}$ are not
included. Totals may not equal sum of flows due to independent rounding. Further detail on how all flows are calculated can be found at http://flowcharts.llnl.gov. LLNL-TR-475772. 


\section{Estimated South Dakota Water Flow in 2005: 500 Million Gallons/Day}

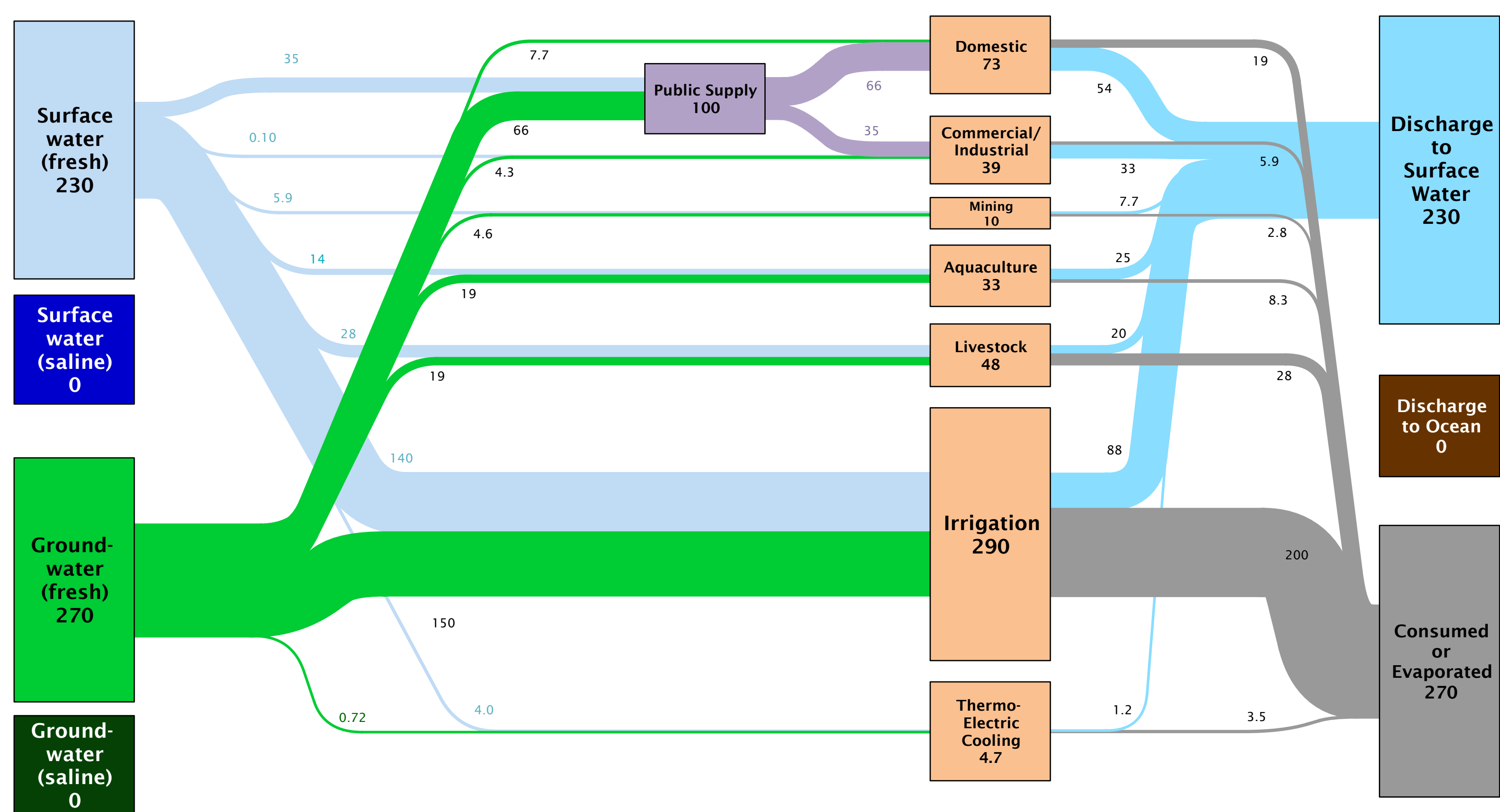

Source: LLNL 2011. Data is based on USGS Circular 1344, October 2009. If this information or a reproduction of it is used, credit must be given to the Lawrence Livermore National Laboratory and the Department of Energy, under whose auspices the work was performed. All quantities are rounded to 2 significant digits and annual flows of less than $0.05 \mathrm{MGal} /$ day are not
included. Totals may not equal sum of flows due to independent rounding. Further detail on how all flows are calculated can be found at http://flowcharts.IInl.gov. LLNL-TR-475772. 


\section{Estimated Tennessee Water Flow in 2005: 11000 Million Gallons/Day}

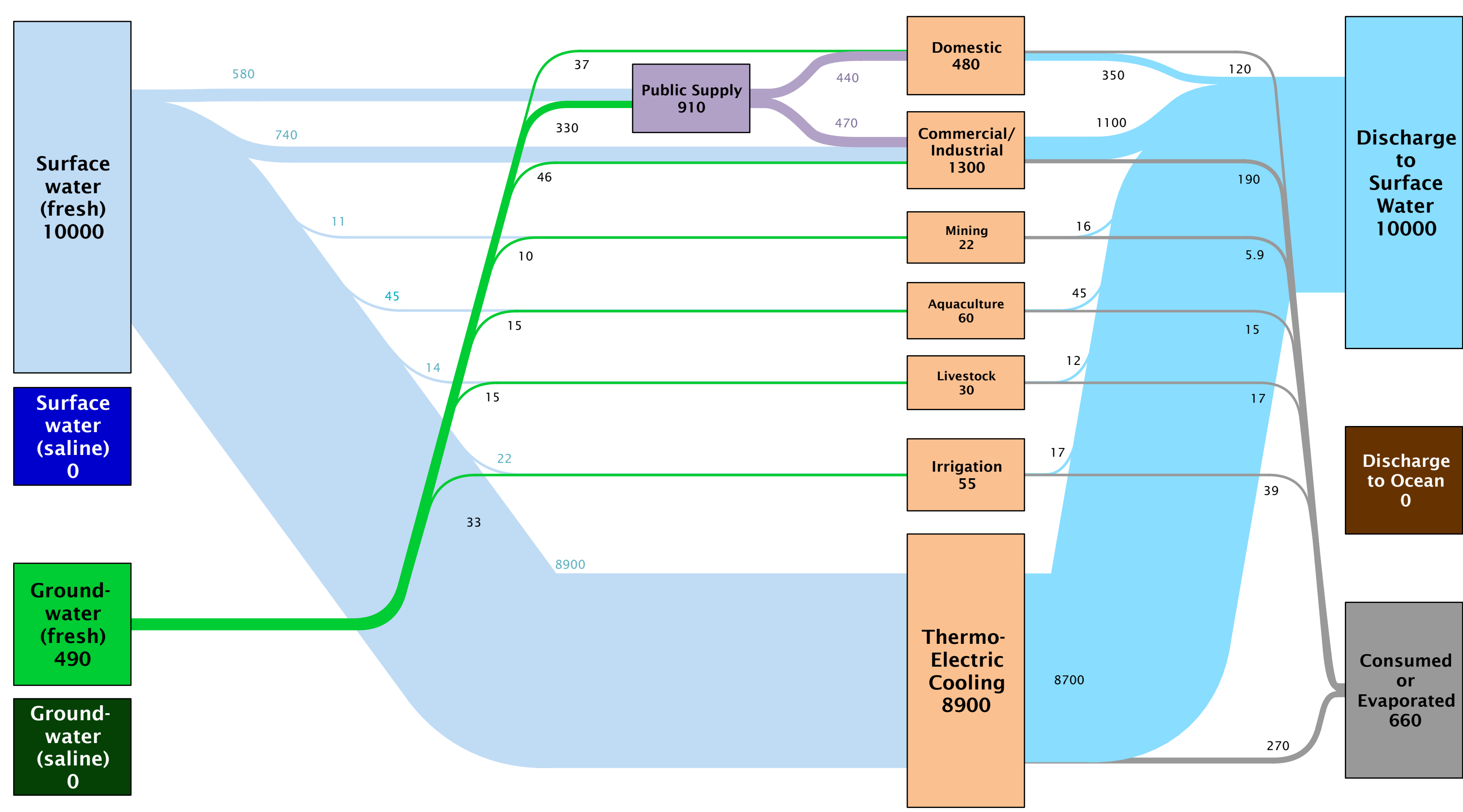

Source: LLNL 2011. Data is based on USGS Circular 1344, October 2009. If this information or a reproduction of it is used, credit must be given to the Lawrence Livermore National Laboratory and the Department of Energy, under whose auspices the work was performed. All quantities are rounded to 2 significant digits and annual flows of less than $0.05 \mathrm{MGal} / \mathrm{day}$ are not
included. Totals may not equal sum of flows due to independent rounding. Further detail on how all flows are calculated can be found at http://flowcharts.llnl.gov. LLNL-TR-475772. 


\section{Estimated Texas Water Flow in 2005: 27000 Million Gallons/Day}

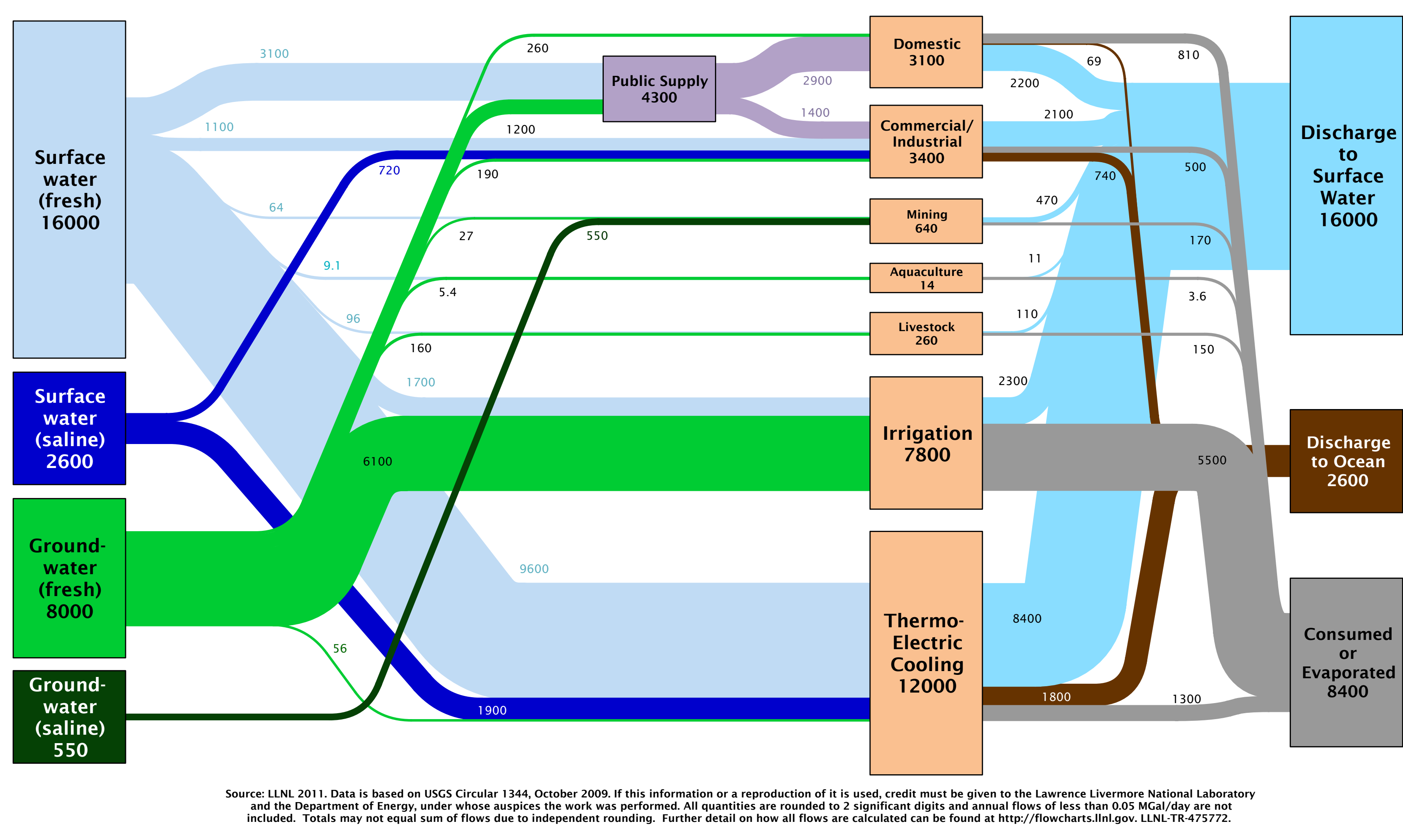




\section{Estimated Utah Water Flow in 2005: 5100 Million Gallons/Day}

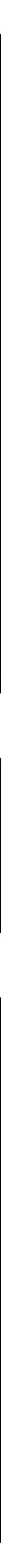

Source: LLNL 2011. Data is based on USGS Circular 1344, October 2009. If this information or a reproduction of it is used, credit must be given to the Lawrence Livermore National Laboratory and the Department of Energy, under whose auspices the work was performed. All quantities are rounded to 2 significant digits and annual flows of less than $0.05 \mathrm{MGal} / \mathrm{day}$ are not
included. Totals may not equal sum of flows due to independent rounding. Further detail on how all flows are calculated can be found at http://flowcharts.llnl.gov. LLNL-TR-475772. 


\section{Estimated Vermont Water Flow in 2005: 520 Million Gallons/Day}

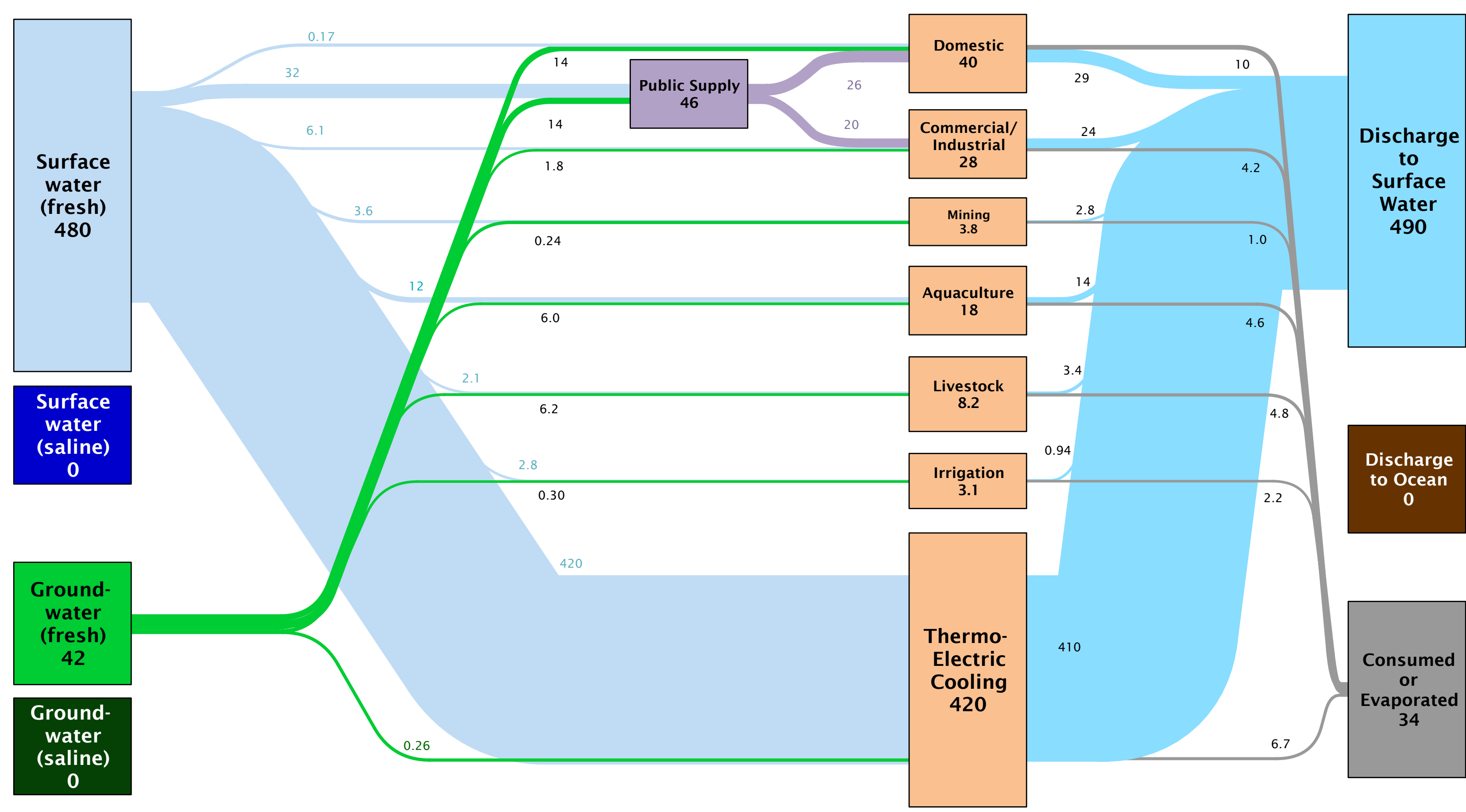

Source: LLNL 2011. Data is based on USGS Circular 1344, October 2009. If this information or a reproduction of it is used, credit must be given to the Lawrence Livermore National Laboratory and the Department of Energy, under whose auspices the work was performed. All quantities are rounded to 2 significant digits and annual flows of less than $0.05 \mathrm{MGal} / \mathrm{day}$ are not
included. Totals may not equal sum of flows due to independent rounding. Further detail on how all flows are calculated can be found at http://flowcharts.llnl.gov. LLNL-TR-475772. 


\section{Estimated Washington Water Flow in 2005: 5600 Million Gallons/Day}

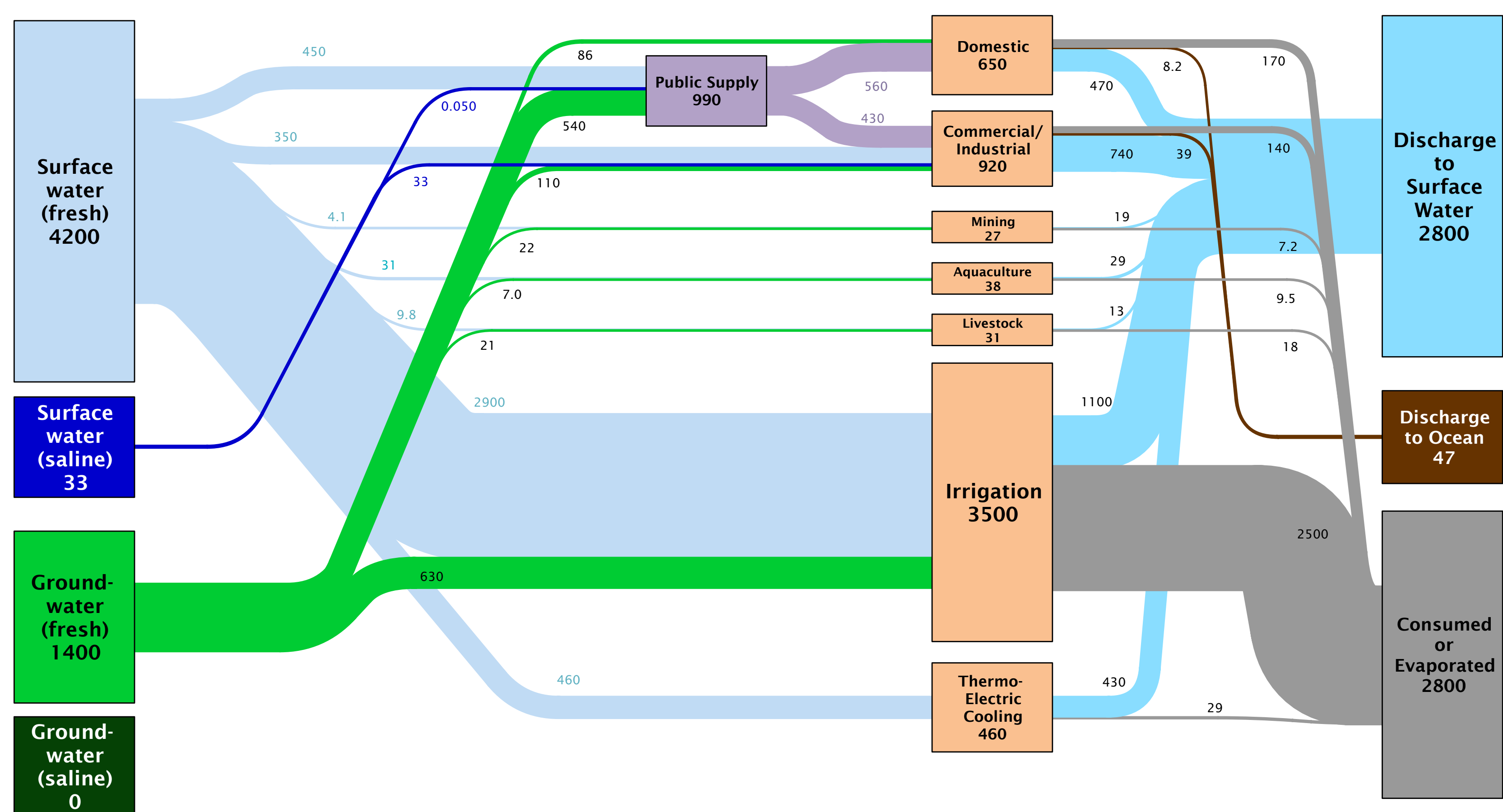

Source: LLNL 2011. Data is based on USGS Circular 1344, October 2009. If this information or a reproduction of it is used, credit must be given to the Lawrence Livermore National Laboratory and the Department of Energy, under whose auspices the work was performed. All quantities are rounded to 2 significant digits and annual flows of less than $0.05 \mathrm{MGal} / \mathrm{day}$ are not
included. Totals may not equal sum of flows due to independent rounding. Further detail on how all flows are calculated can be found at http://flowcharts.llnl.gov. LLNL-TR-475772. 


\section{Estimated West Virginia Water Flow in 2005: 4800 Million Gallons/Day}

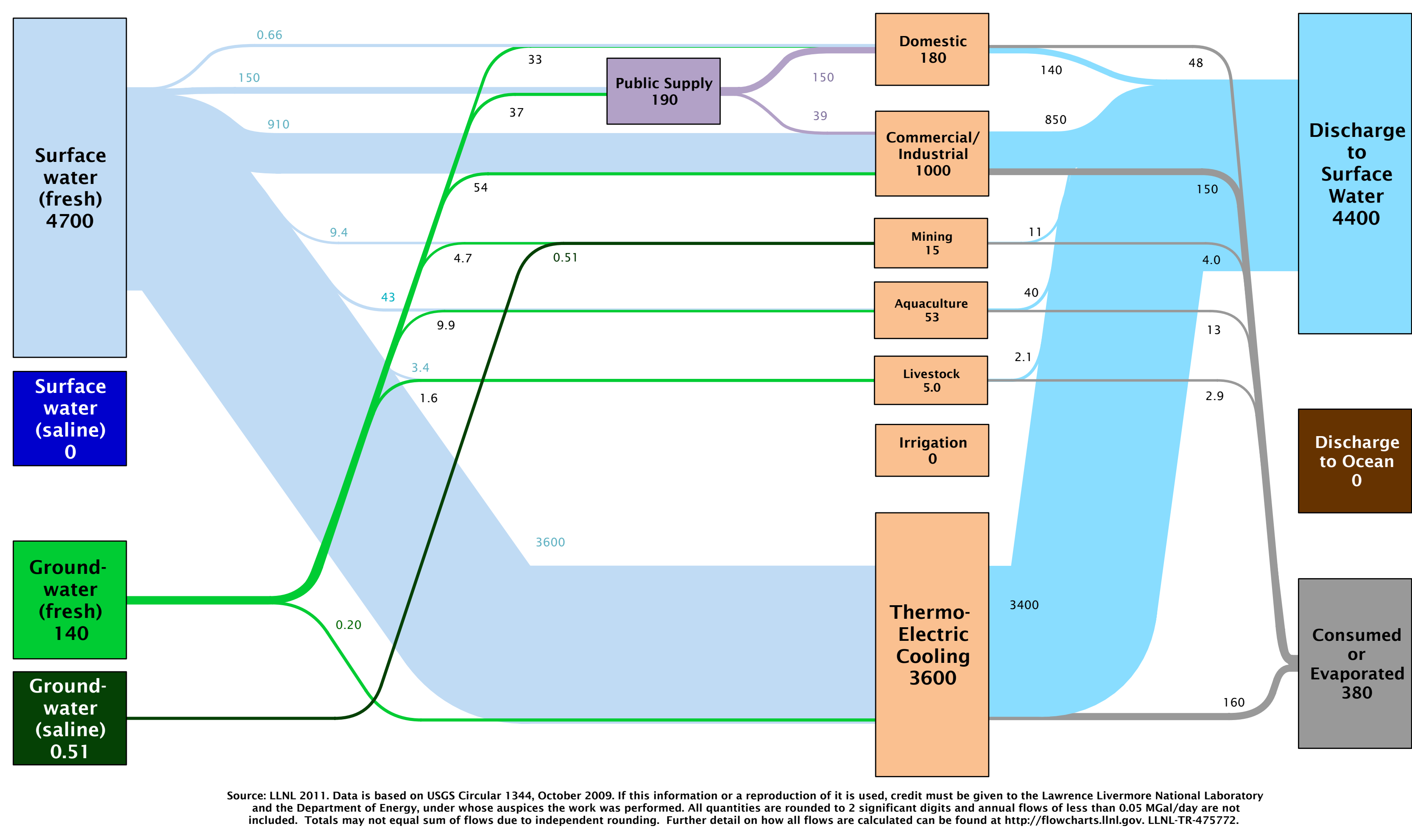




\section{Estimated Wisconsin Water Flow in 2005: 8600 Million Gallons/Day}

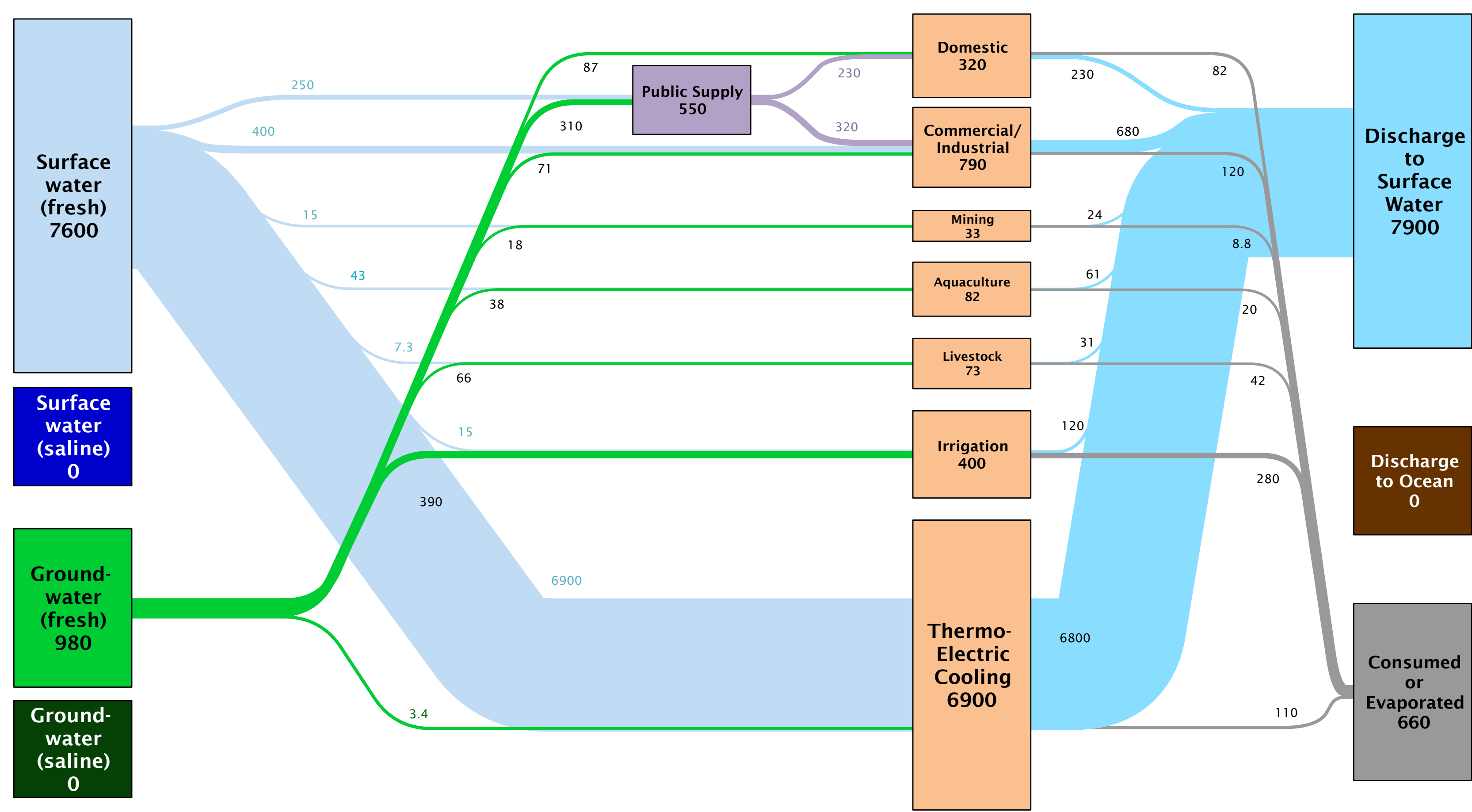

Source: LLNL 2011. Data is based on USGS Circular 1344, October 2009. If this information or a reproduction of it is used, credit must be given to the Lawrence Livermore National Laboratory and the Department of Energy, under whose auspices the work was performed. All quantities are rounded to 2 significant digits and annual flows of less than $0.05 \mathrm{MGal} /$ day are not
included. Totals may not equal sum of flows due to independent rounding. Further detail on how all flows are calculated can be found at http://flowcharts.IInl.gov. LLNL-TR-475772. 


\section{Estimated Wyoming Water Flow in 2005: 4600 Million Gallons/Day}

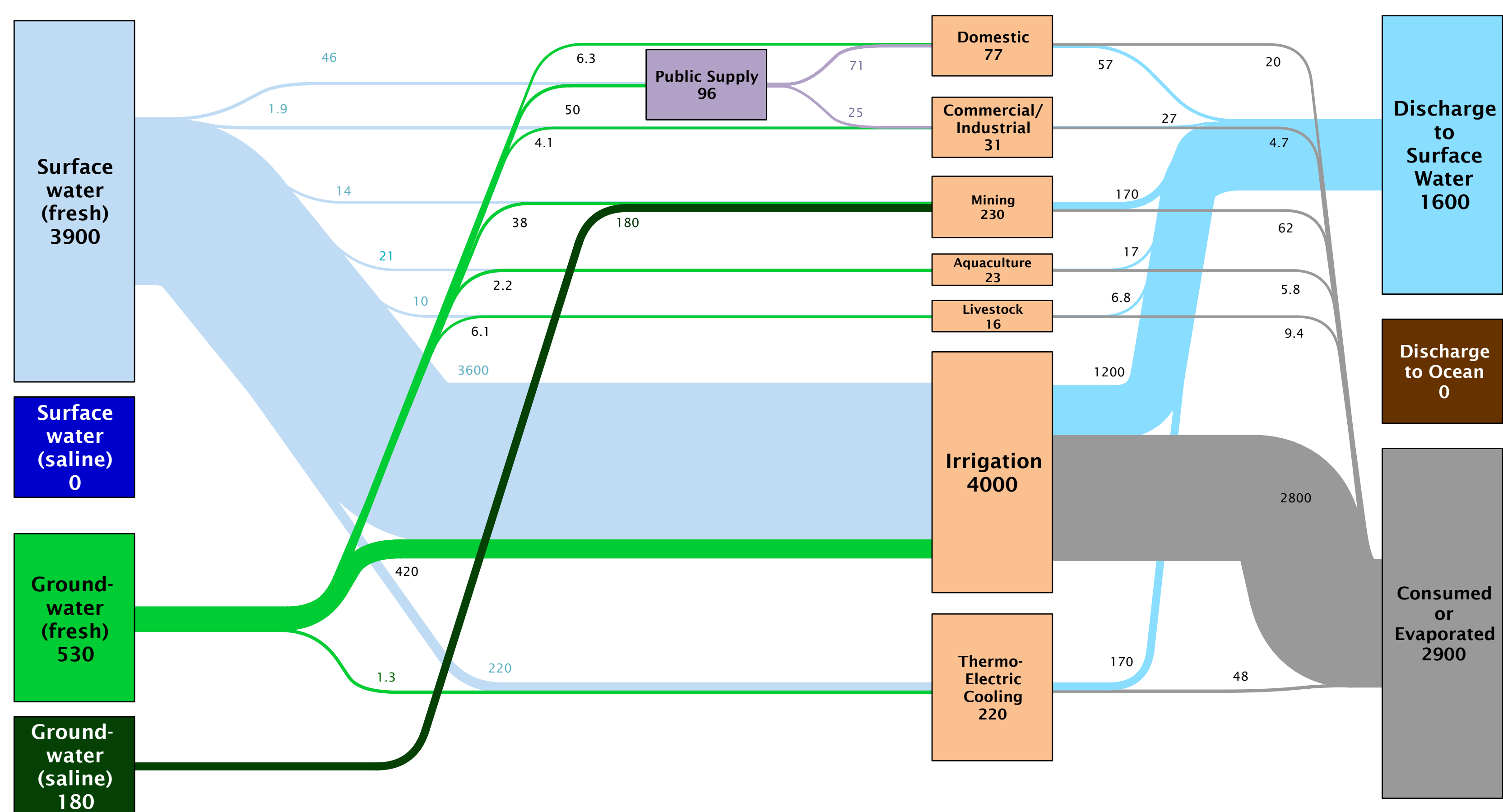

Source: LLNL 2011. Data is based on USGS Circular 1344, October 2009. If this information or a reproduction of it is used, credit must be given to the Lawrence Livermore National Laboratory and the Department of Energy, under whose auspices the work was performed. All quantities are rounded to 2 significant digits and annual flows of less than $0.05 \mathrm{MGal} / \mathrm{day}$ are not
included. Totals may not equal sum of flows due to independent rounding. Further detail on how all flows are calculated can be found at http://flowcharts.llnl.gov. LLNL-TR-475772. 


\section{Estimated Puerto Rico Water Flow in 2005: 3000 Million Gallons/Day}

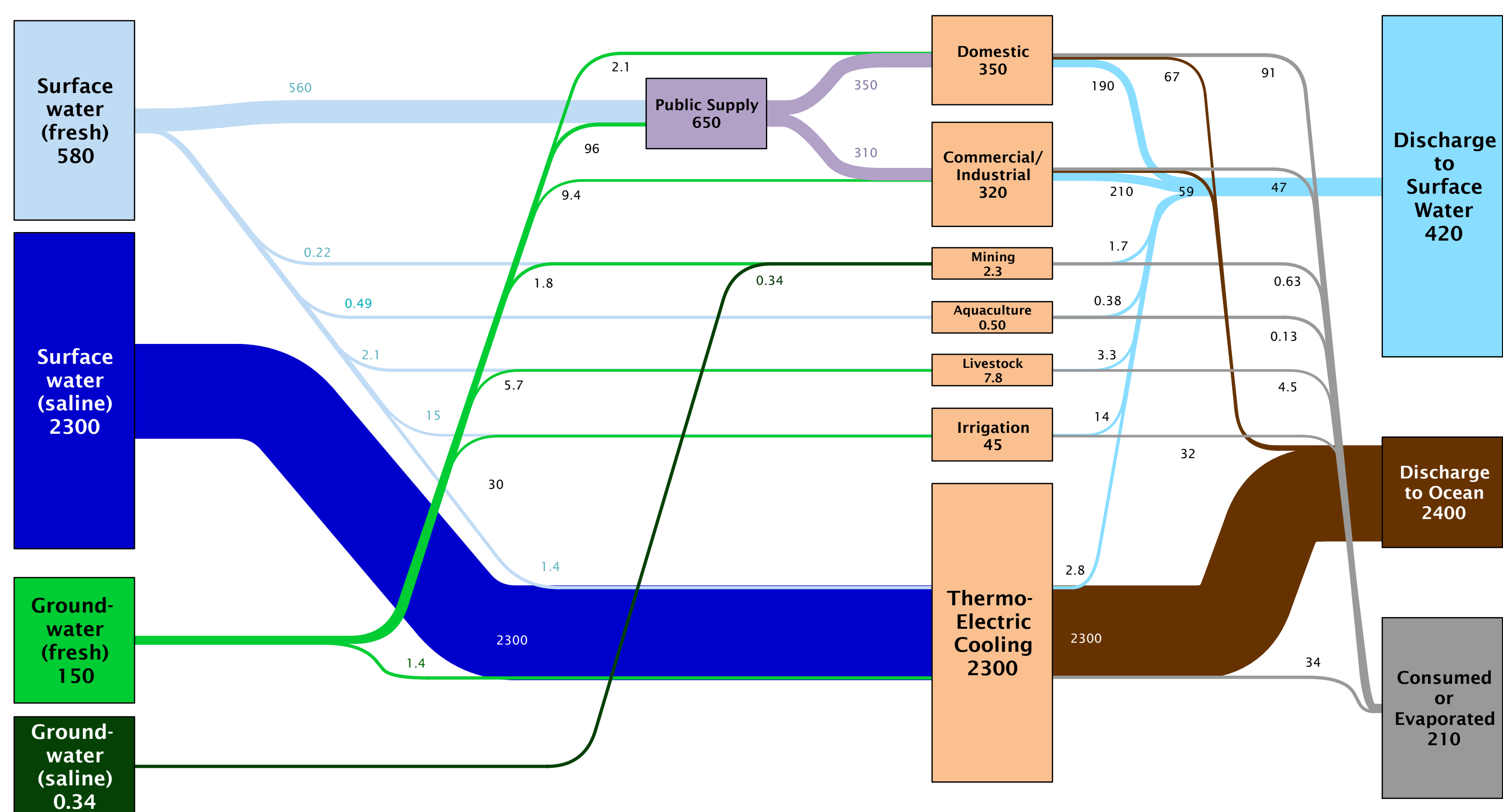

Source: LLNL 2011. Data is based on USGS Circular 1344, October 2009. If this information or a reproduction of it is used, credit must be given to the Lawrence Livermore National Laboratory and the Department of Energy, under whose auspices the work was performed. All quantities are rounded to 2 significant digits and annual flows of less than $0.05 \mathrm{MGal} / \mathrm{day}$ are not
included. Totals may not equal sum of flows due to independent rounding. Further detail on how all flows are calculated can be found at http://flowcharts.llnl.gov. LLNL-TR-475772. 


\section{Estimated Virgin Islands Water Flow in 2005: 140 Million Gallons/Day}

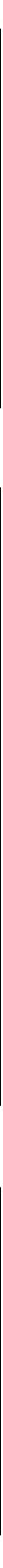

Source: LLNL 2011. Data is based on USGS Circular 1344, October 2009. If this information or a reproduction of it is used, credit must be given to the Lawrence Livermore National Laboratory and the Department of Energy, under whose auspices the work was performed. All quantities are rounded to 2 significant digits and annual flows of less than $0.05 \mathrm{MGal} /$ day are not
included. Totals may not equal sum of flows due to independent rounding. Further detail on how all flows are calculated can be found at http://flowcharts.llnl.gov. LLNL-TR-475772. 


\section{Estimated United State Water Flow in 2005: 410000 Million Gallons/Day}

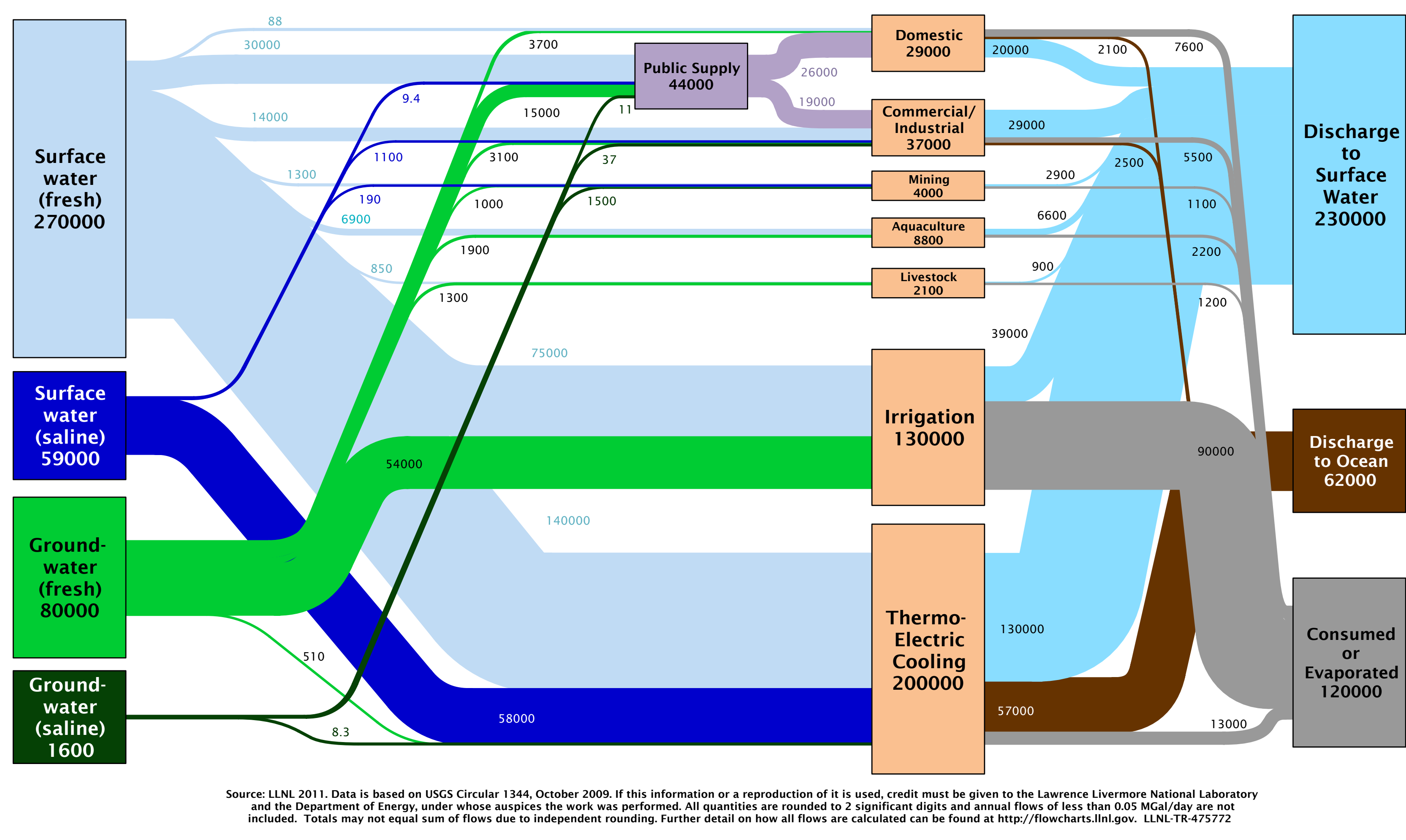




\section{Analysis}

Fundamental to this analysis is the assumption that water use can be accurately traced from resource to distribution network to use by sector to disposition. There are fairly large uncertainties with respect to the actual amount of water withdrawn, consumed, and returned; and there are many instances where water disposed as "return flow" is immediately withdrawn by another user. Such arrangements can make water accounting difficult and the USGS is to be commended for its extraordinary effort in collecting sparsely and inconsistently recorded data. Assembly of this water flow chart represents a small step in a very long chain of analysis that collapses the cyclic nature of the nation's water infrastructure into a conceptually linear series of unit operations. Unless stated otherwise, all data in this analysis comes from the USGS Water Use report for 2005 (Kenny et. al., 2009). Where water flows have been calculated, the USGS definitions are available in the Data Dictionary included in the appendix of this report.

Flows of water on the flow chart were calculated as follows:

\section{Withdrawals:}

USGS directly reports the total withdrawals from each of the four available water resources.

\section{Public Supply:}

Public Supply represents the municipally managed distribution network for water. This network obtains its water from all four water resources, but uses very little saline water (desalination of seawater and groundwater for municipal use is growing rapidly, but represents less than $0.05 \%$ of public supply). The public supply delivers water to the domestic and commercial/industrial sectors.

USGS directly reports the total water withdrawn from each resource to the public supply.

USGS directly reports the water delivered from the public supply to the domestic sector. USGS does not report how the remainder of public supply is apportioned. In this analysis, it is assumed that all water withdrawn for public supply (PS-Wtotl) that is not delivered to the domestic sector (DO-PSDel) is delivered to the commercial/industrial sector (PS-CI). For the purposes of this analysis, the commercial sector includes commercial and light industrial entities, municipalities, golf courses, and "own use" by the public supply sector.

$$
\text { PS-CI = PS-Wtotl - DO-PSDel }
$$

\section{Domestic}

USGS reports the withdrawals of fresh surface-water and groundwater by the domestic sector. These withdrawals comprise privately owned water resources (primarily individual wells), generally in areas not served by public supply. There are no reported direct uses of saline water in the domestic sector.

USGS reports directly the deliveries of public supplied water to the domestic sector. 
USGS no longer reports the disposition of domestic water. This analysis assumes that of the total amount of water withdrawn for the domestic sector (DO-TOTAL), the percentage consumed by the domestic sector (DO-Consum) has not changed substantially from 26\%, the value reported in 1995 (Solley et. al., 1999).

$$
\text { DO-Consum }=26 \% * \text { DO-TOTAL }
$$

The remainder of domestic water is returned to surface waters such as rivers, lakes, or oceans. It is difficult to find comprehensive data on domestic wastewater discharge to saline surface waters (DOSaSW). Therefore, a percentage is calculated for each state on the basis of coastal populations from the reported domestic water delivered from the public supply (\%DO-> SaSW(STATE)). For landlocked states, the amount of water supplied by and returned to the ocean is zero. For states with coastal boundaries, the estimation is based on data collected in California.

It is estimated that 1.35 billion gallons per day are discharged by municipal wastewater treatment in California (Heal the Ocean, 2010). This quantity represents approximately $20 \%$ of California's public supply (\% DO-SaSW(CA)). As reported in the 2006 census $62 \%$ of the total population of California (\%Coast(CA)) (US Places, 2010) live in coastal counties. The percentage of the population living in coastal counties in each state can similarly be calculated (\%Coast(STATE)).

It is assumed that the ratio of public supply water discharge to the ocean to percent coastal population remains consistent for every other coastal state and can be used to find the percent of a state's public water supply discharged to saline surface water. For example, Alaska has a percent coastal population of $80 \%$ and its percentage of the public supply water discharged to the ocean is found by multiplying its $80 \%$ coastal population percentage by the $20 \%$ of the public supply water discharged to the ocean in California and dividing by the $62 \%$ the California coastal population percentage.

$$
\% \mathrm{DO}-\mathrm{SaSW}(\mathrm{STATE})=\frac{\% \mathrm{DO}-\mathrm{SaSW}(\mathrm{CA}) * \% \operatorname{Coast}(\mathrm{STATE})}{\% \operatorname{Coast}(\mathrm{CA})}
$$

The flow of domestic water discharged to saline surface waters (DO-SaSW) is then calculated from the total domestic water delivered from the public supply.

$$
\text { DO-SaSW }=\% \text { DO-SaSW }(\text { STATE }) * \text { DO-PSDel }
$$

Any domestic water not consumed or discharged to the ocean is returned to fresh surface waters (DO->FrSW).

$$
\text { DO-FrSW = DO-TOTAL }-(\text { DO-Consum }+ \text { DO-SaSW })
$$




\section{Commercial/Industrial}

USGS reports directly the withdrawals of all four water resources by the industrial sector.

Because the latest edition of Circular 1344 does not describe commercial water use, this analysis combines commercial and industrial water uses. The total use by the commercial/industrial sector ( $\mathrm{Cl}-$ Totl) therefore includes the total industrial withdrawal (IN-Wtotl) plus the portion of public supply that is not delivered to domestic consumers (PS-Wtotl - DO-PSDel).

$$
\text { CI-Totl = IN-Wtotl }+ \text { PS-Wtotl }- \text { DO-PSDel }
$$

USGS no longer reports the disposition of water by the commercial and industrial sectors. In 1995, the percentages of withdrawn water consumed by the commercial and industrial sectors ( $\mathrm{Cl}$ - Consum) were reported to be $14 \%$ and $15 \%$, respectively. In this analysis, we assume that the composite commercial/industrial water consumption fraction is $15 \%$ (Solley et. al., 1999). This fraction includes the $1.5 \%$ of saline surface withdrawals by industry that are lost to consumption/evaporation (see below).

$$
\text { CI-Consum }=\text { CI-Tot } 1 * 15 \%
$$

The disposition of water returned to the ocean from the commercial and industrial sectors ( $\mathrm{Cl}-\mathrm{SaSW})$ is similar to the residential sector and calculated as follows: a percentage of public supply deliveries to the commercial/industrial sector are returned to municipalities that discharge water into the ocean based on the coastal population of the state. Additionally, it is assumed that $1.5 \%$ of the saline surface withdrawals are lost to consumption or evaporation, and the remaining $98.5 \%$ are returned to the ocean.

$$
\text { CI-SaSW }=(\text { PS-CI * \%DO-SaSW }(\text { STATE }))+(\text { IN-WSWSa } * 98.5 \%)
$$

The remainder of commercial/industrial water is returned to bodies of freshwater ( $\mathrm{Cl}$ - FrSW).

$$
\text { CI-FSW }=\text { CI-Totl }-(\text { CI-Consum }+ \text { CI-SaSW })
$$




\section{Mining}

USGS directly reports the withdrawals of all four water resources by the mining sector. The mining sector does not take water deliveries from public supplies.

In 1995, USGS estimates that of the total amount of water used in mining (MI-Totl) $27 \%$ is consumptive (MI-Consum) (Solley et. al., 1999), and the remainder is returned to surface bodies of water (MI-FrSW). This analysis assumes that no water is returned from the mining sector to the ocean. ${ }^{1}$

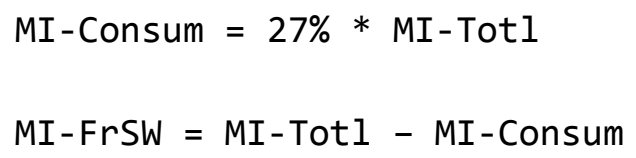

\section{Aquaculture}

USGS reports directly the withdrawals of fresh surface-water and fresh groundwater for use in aquaculture. No saline water use is reported for aquaculture.

Of the total amount of water used in aquaculture (LA-Totl), the percentage consumed (LA- Consum) varies from $20 \%$ to $55 \%$ (Boyd et. al., 2008). This analysis assumes that on average, $25 \%$ of water used in aquaculture is consumed. It is assumed that no freshwater used in aquaculture is returned directly to the ocean as the remaining water is returned to surface waters (LA- FrSW).

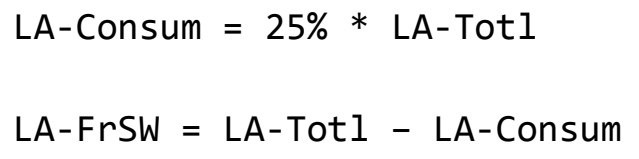

Livestock

USGS reports directly the withdrawals of fresh surface-water and fresh groundwater for use by livestock. No saline water use is reported by livestock.

Of the total amount of water used in livestock applications (LI-Totl), 58\% was estimated as consumed in 1995 (LI-Consum) (Solley et. al., 1999). This percentage is assumed to remain unchanged for this analysis of water flow in 2005. It is assumed that no water used for livestock is returned to the ocean. Therefore, the water returned to fresh surface water from livestock use (LI-FrSW) is the amount that which is not consumed by the livestock.

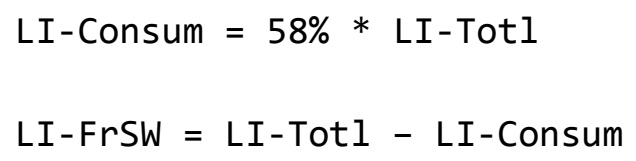

\footnotetext{
${ }^{1}$ It is likely that significant quantities of seawater are withdrawn and returned to the ocean in offshore drilling processes. These withdrawals are not included in the USGS accounting.
} 


\section{Irrigation}

USGS reports directly the withdrawals of fresh surface-water and fresh groundwater for use in irrigation. No saline water use is reported by irrigation.

In 1995 , it was estimated that $61 \%$ of irrigation water use was consumptive, $20 \%$ was returned and $19 \%$ was lost in conveyance (Solley et. al., 1999). It is unclear whether conveyance losses should be accounted for as return flow (if the "lost" water remains in the watershed or if it evaporates). For this analysis, we assume that some progress has been made in irrigation efficiency (increasing the consumptive percentage in irrigation) and that some conveyance losses can be considered to be consumptive. Of the total amount of water used in irrigation (IR-Totl), the total consumptive percentage for irrigation is assumed to be $70 \%$ (IR-Consum). It is assumed that no irrigation water is returned to the ocean. Therefore, the water returned to fresh surface water from irrigation (IR-FrSW) is the amount that is not consumed by irrigation.

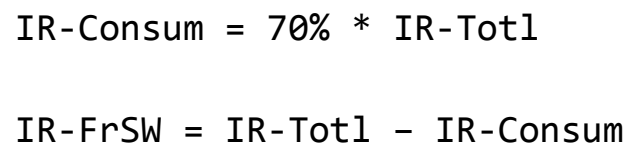

Thermoelectric Cooling ${ }^{2,3}$

USGS reports directly the withdrawals of all four water resources for use in thermoelectric cooling. The thermoelectric sector does not take deliveries from public supplies.

USGS reports separately the quantities of each water resource withdrawn for once-through and recirculating power plants, which together total the amount of water used in thermoelectric cooling (PTTotl). Power plants cooled with ocean water that have once-through cooling designs and are assumed to return $98.5 \%$ of saline surface- and groundwater used in thermoelectric cooling (PO-WSaTo) to the ocean while the remainder is consumed. Water returned to the ocean from recirculating power plants using saline surface-and groundwater (PC-WSaTo) is assumed to be $25 \%$ of that withdrawn from the ocean while the remaining $75 \%$ is consumed during the process. These two calculated values are summed to represent the total amount of water returned to the ocean from thermoelectric cooling processes (PT->SaSW).

$$
\text { PT-SaSW }=98.5 \% * \text { PO-WSaTo }+25 \% * \text { PC-WSaTo }
$$

\footnotetext{
${ }^{2}$ There are two discrepancies between the data as reported by the USGS and the flow charts depicted in this report. The first is that water use in Kentucky has been over-reported for power plants using recirculating cooling loops. An example of the data modification is for the thermoelectric water usage for McCracken County, Kentucky, where the water use was reported for a recirculating power plant. However, the major power plant in McCracken County is the TVA Shawnee Power Plant, a power plant that utilizes once-through cooling (Dziegielewski, 2006). Therefore, the power plant water usage for this county has been altered to indicate once-through cooling.

${ }^{3}$ The second discrepancy occurs in Hawaii where the thermoelectric water withdrawals for Hawaii were reported as originating from saline groundwater. From geographic examination of the location of the major power plants, the likely source of thermoelectric cooling water is saline surface-water and the water flows are represented in these flowcharts as such.
} 
The total flow of water consumed through thermoelectric processes (PT- Consum) is the sum of the remainders from power plants with once-through cooling designs (PO-WTotl) and power plant with recirculating cooling designs (PC-WTotl).

$$
\text { PT-Consum }=1.5 \% * \text { PO-WTot } 1+75 \% * \text { PC-WTot } 1
$$

The remainder of all water withdrawn by the thermoelectric sector is returned to the surface (PT- FrSW).

$$
\text { PT-FrSW }=\text { PT-Totl }-(\text { PT-SaSW }+ \text { PT-Consum })
$$




\section{Conclusion}

The flow charts described in this report are compact depictions of the national water use data contained in the USGS report on water use in the United States in 2005. These diagrams are available at: http://flowcharts.IInl.gov

\section{References}

Boyd, C.E., Lim, C., Queiroz, J., Salie, K., de Wet, L., and McNevin, A., 2008, Best Management Practices for Responsible Aquaculture. USAID (Boyd et. al, 2008)

Crossett, K.M., Culliton, T.J., Wiley, P.C., and Goodspeed, T.R., 2004, Population Trends Along the Coastal Unites States: 1980 - 2008: National Oceanic and Atmospheric Administration (Crossett et. al., 2004)

Dziegielewski, B. et al. Water Use Benchmarks for Thermoelectric Power Generation. United States Geological Survey, Grant No. 04HQGR0148. 2006.Available at:

http://www.circleofblue.org/waternews/wp-content/uploads/2010/08/ThermoReport.pdf.pdf (Dziegielewski, 2006).

Heal the Ocean, 2010, California Ocean Wastewater Discharge Report and Inventory. Available at: http://www.healtheocean.org/images/ pages/research/HTO COWDI.pdf (Heal The Ocean, 2010)

Kenny, J.F., Barber, N.L., Hutson, S.S., Linsey, K.S., Lovelace, J.K., and Maupin, M.A., 2009, Estimated use of water in the United States in 2005: U.S. Geological Survey Circular 1344 (Kenny et. al, 2009)

Lawrence Livermore National Laboratory, 2009, Energy Flow Chart. Available at:

http://flowcharts.IInl.gov (Livermore, 2009)

Solley, W.B., Pierce, R.R., Perlman, H.A., 1999, Estimated use of water in the United States in 1995:

Reston, Va., U.S. Geological Survey Circular 1200 (Solley et. al, 1999)

US-Places.com, Online Searches LLC. The United States reference guide by state and county. http://www.us-places.com/ (US Places, 2010) 


\section{Appendix: Selections from Data Dictionary}

(reproduced from the excel file available at http://water.usgs.gov/watuse/data/2005/ )

\section{USGS defined terms}

PS-WGWFr

PS-WGWSa

PS-WGWTo

PS-WSWFr

PS-WSWSa

PS-WSWTo

PS-WFrTo

PS-WSaTo

PS-Wtotl

DO-WGWFr

DO-WSWFr

DO-WFrTo

DO-PSDel

DO-TOTAL

IN-WGWFr

IN-WGWSa

IN-WGWTo

IN-WSWFr

IN-WSWSa

IN-WSWTo

IN-WFrTo

IN-WSaTo

IN-Wtotl

IR-WGWFr

IR-WSWFr

IR-WFrTo

IC-WGWFr

IC-WSWFr

IC-WFrTo

IC-IrSpr

IC-IrMic

IC-IrSur

IC-IrTot

LS-WGWFr

LS-WSWFr

LS-WFrTo

LA-WGWFr

LA-WSWFr

LA-WFrTo

MI-WGWFr

MI-WGWSa

MI-WGWTo

MI-WSWFr

MI-WSWSa

MI-WSWTo

MI-WFrTo

MI-WSaTo

MI-Wtotl

PT-WGWFr

PT-WGWSa

PT-WGWTo

PT-WSWFr

PT-WSWSa

PT-WSWTo
Public Supply, groundwater withdrawals, fresh, in Mgal/d

Public Supply, groundwater withdrawals, saline, in Mgal/d

Public Supply, groundwater withdrawals, total, in Mgal/d

Public Supply, surface-water withdrawals, fresh, in Mgal/d

Public Supply, surface-water withdrawals, saline, in Mgal/d

Public Supply, surface-water withdrawals, total, in Mgal/d

Public Supply, total withdrawals, fresh, in Mgal/d

Public Supply, total withdrawals, saline, in Mgal/d

Public Supply, total withdrawals, total (fresh+saline), in Mgal/d

Domestic, self-supplied groundwater withdrawals, fresh, in Mgal/d

Domestic, self-supplied surface-water withdrawals, fresh, in Mgal/d

Domestic, total self-supplied withdrawals, fresh, in Mgal/d

Domestic, deliveries from Public Supply, in Mgal/d

Domestic, total use (withdrawals + deliveries)

Industrial, self-supplied groundwater withdrawals, fresh, in Mgal/d

Industrial, self-supplied groundwater withdrawals, saline, in Mgal/d

Industrial, self-supplied groundwater withdrawals, total, in Mgal/d

Industrial, self-supplied surface-water withdrawals, fresh, in Mgal/d

Industrial, self-supplied surface-water withdrawals, saline, in Mgal/d

Industrial, self-supplied surface-water withdrawals, total, in Mgal/d

Industrial, self-supplied total withdrawals, fresh, in Mgal/d

Industrial, self-supplied total withdrawals, saline, in Mgal/d

Industrial, self-supplied total withdrawals, total (fresh+saline), in Mgal/d

Irrigation, groundwater withdrawals, fresh, in Mgal/d

Irrigation, surface-water withdrawals, fresh, in $\mathrm{Mgal} / \mathrm{d}$

Irrigation, total withdrawals, fresh, in Mgal/d

Irrigation-Crop, groundwater withdrawals, fresh, in Mgal/d

Irrigation-Crop, surface-water withdrawals, fresh, in Mgal/d

Irrigation-Crop, total withdrawals, fresh, in Mgal/d

Irrigation-Crop, acres irrigated, sprinkler, in thousands

Irrigation-Crop, acres irrigated, microirrigation, in thousands

Irrigation-Crop, acres irrigated, surface (flood), in thousands

Irrigation-Crop, acres irrigated, total, in thousands

Livestock, groundwater withdrawals, fresh, in Mgal/d

Livestock, surface-water withdrawals, fresh, in Mgal/d

Livestock, total withdrawals, fresh, in Mgal/d

Aquaculture, groundwater withdrawals, fresh, in Mgal/d

Aquaculture, surface-water withdrawals, fresh, in Mgal/d

Aquaculture, total withdrawals, fresh, in Mgal/d

Mining, groundwater withdrawals, fresh, in Mgal/d

Mining, groundwater withdrawals, saline, in Mgal/d

Mining, groundwater withdrawals, total, in Mgal/d

Mining, surface-water withdrawals, fresh, in Mgal/d

Mining, surface-water withdrawals, saline, in Mgal/d

Mining, surface-water withdrawals, total, in Mgal/d

Mining, total withdrawals, fresh, in Mgal/d

Mining, total withdrawals, saline, in Mgal/d

Mining, total withdrawals, total (fresh+saline), in Mgal/d

Thermoelectric, groundwater withdrawals, fresh, in Mgal/d

Thermoelectric, groundwater withdrawals, saline, in Mgal/d

Thermoelectric, groundwater withdrawals, total, in Mgal/d

Thermoelectric, surface-water withdrawals, fresh, in Mgal/d

Thermoelectric, surface-water withdrawals, saline, in Mgal/d

Thermoelectric, surface-water withdrawals, total, in Mgal/d 


\begin{tabular}{|c|c|}
\hline PT-WFrTo & Thermoelectric, total withdrawals, fresh, in Mgal/d \\
\hline PT-WSaTo & Thermoelectric, total withdrawals, saline, in Mgal/d \\
\hline PT-Wtotl & Thermoelectric, total withdrawals, total (fresh+saline), in Mgal/d \\
\hline PT-Power & Thermoelectric, power generated, in gigawatt-hours \\
\hline PO-WGWFr & Thermoelectric once-through, groundwater withdrawals, fresh, in Mgal/d \\
\hline PO-WGWSa & Thermoelectric once-through, groundwater withdrawals, saline, in Mgal/d \\
\hline PO-WGWTo & Thermoelectric once-through, groundwater withdrawals, total, in Mgal/d \\
\hline PO-WSWFr & Thermoelectric once-through, surface-water withdrawals, fresh, in Mgal/d \\
\hline PO-WSWSa & Thermoelectric once-through, surface-water withdrawals, saline, in Mgal/d \\
\hline PO-WSWTo & Thermoelectric once-through, surface-water withdrawals, total, in Mgal/d \\
\hline PO-WFrTo & Thermoelectric once-through, total withdrawals, fresh, in Mgal/d \\
\hline PO-WSaTo & Thermoelectric once-through, total withdrawals, saline, in Mgal/d \\
\hline PO-WTotl & Thermoelectric once-through, total withdrawals, total, in Mgal/d \\
\hline PO-Power & Thermoelectric once-through, power generated, in gigawatt-hours \\
\hline PC-WGWFr & Thermoelectric recirculation, groundwater withdrawals, fresh, in Mgal/d \\
\hline PC-WGWSa & Thermoelectric recirculation, groundwater withdrawals, saline, in Mgal/d \\
\hline PC-WGWTo & Thermoelectric recirculation, groundwater withdrawals, total, in Mgal/d \\
\hline PC-WSWFr & Thermoelectric recirculation, surface-water withdrawals, fresh, in Mgal/d \\
\hline PC-WSWSa & Thermoelectric recirculation, surface-water withdrawals, saline, in Mgal/d \\
\hline PC-WSWTo & Thermoelectric recirculation, surface-water withdrawals, total, in Mgal/d \\
\hline PC-WFrTo & Thermoelectric recirculation, total withdrawals, fresh, in Mgal/d \\
\hline PC-WSaTo & Thermoelectric recirculation, total withdrawals, saline, in Mgal/d \\
\hline PC-WTotl & Thermoelectric recirculation, total withdrawals, total (fresh+saline), in Mgal/d \\
\hline TO-WGWFr & Total groundwater withdrawals, fresh, in Mgal/d \\
\hline TO-WGWSa & Total groundwater withdrawals, saline, in Mgal/d \\
\hline TO-WGWTo & Total groundwater withdrawals, total (fresh+saline), in Mgal/d \\
\hline TO-WSWFr & Total surface-water withdrawals, fresh, in Mgal/d \\
\hline TO-WSWSa & Total surface-water withdrawals, saline, in Mgal/d \\
\hline TO-WSWTo & Total surface-water withdrawals, total (fresh+saline), in Mgal/d \\
\hline TO-WFrTo & Total withdrawals, fresh, in Mgal/d \\
\hline TO-WSaTo & Total withdrawals, saline, in Mgal/d \\
\hline TO-WTotl & Total withdrawals, total (fresh+saline), in Mgal/d \\
\hline
\end{tabular}




\section{LLNL defined terms}

PS-Cl

DO-Consum

DO-SaSW

DO-FrSW

\%DO-SaSW(STATE)

$\%$ DO-SaSW(CA)

$\%$ Coast(CA)

$\%$ Coast(STATE)

Cl-Totl

Cl-Consum

Cl-SaSW

Cl-FrSW

MI-TotI

MI-Consum

MI-FrSW

LA-Totl

LA-Consum

LA-FrSW

LS-Totl

LS-Consum

LS-FrSW

IR-TotI

IR-Consum

IR-FrSW

PT-Totl

PT-Consum

PT-SaSW

PT-FrSW

Water withdrawn from the public supply delivered to the commercial/industrial sector, in Mgal/d

Water consumed or evaporated during activities in the domestic sector, in $\mathrm{Mgal} / \mathrm{d}$

Water used in the domestic sector and discharged to saline surface-water, in Mgal/d

Water used in the domestic sector and discharged to fresh surface-water, in Mgal/d

Percentage of water used in the domestic sector discharged to saline surface-water in a given state

Percentage of water used in the domestic water discharged to saline surface-water in California

Percentage of the population living in coastal counties in California

Percentage of the population living in coastal counties in a given state

The total amount of water used in commercial/industrial sectors, in Mgal/d

Water consumed or evaporated during activities in commercial/industrial sectors, in Mgal/d

Water used in commercial/industrial sectors and discharged to saline surface-water, in Mgal/d

Water used in commercial/industrial sectors and discharged to fresh surface-water, in Mgal/d

The total amount of water used in the mining sector, in Mgal/d

Water consumed or evaporated during activities in the mining sector, in Mgal/d

Water used in the mining sector and discharged to fresh surface-water, in Mgal/d

The total amount of water used in the aquaculture sector, in Mgal/d

Water consumed or evaporated during activities in the aquaculture sector, in Mgal/d

Water used in the aquaculture sector and discharged to fresh surface-water, in Mgal/d

The total amount of water used in the livestock sector, in Mgal/d

Water consumed or evaporated during activities in the livestock sector, in Mgal/d

Water used in the livestock sector and discharged to fresh surface-water, in Mgal/d

Water consumed or evaporated during activities in the commercial/industrial sectors, in $\mathrm{Mgal} / \mathrm{d}$

Water consumed or evaporated during activities in the commercial/industrial sectors, in Mgal/d

Water consumed or evaporated during activities in the commercial/industrial sectors, in $\mathrm{Mgal} / \mathrm{d}$

Water consumed or evaporated during activities in the commercial/industrial sectors, in Mgal/d

Water consumed or evaporated during activities in the commercial/industrial sectors, in Mgal/d

Water consumed or evaporated during activities in the commercial/industrial sectors, in Mgal/d

Water consumed or evaporated during activities in the commercial/industrial sectors, in $\mathrm{Mgal} / \mathrm{d}$ 